\title{
Agriculture
}

$\begin{array}{ll}\begin{array}{l}\text { Research Direction générale } \\ \text { Branch }\end{array} & \text { de la recherche }\end{array}$

Contribution 1983-20F

La méthode d'évaluation des aliments par le calcul de l'énergie métabolisable vraie (E.M.V.) 


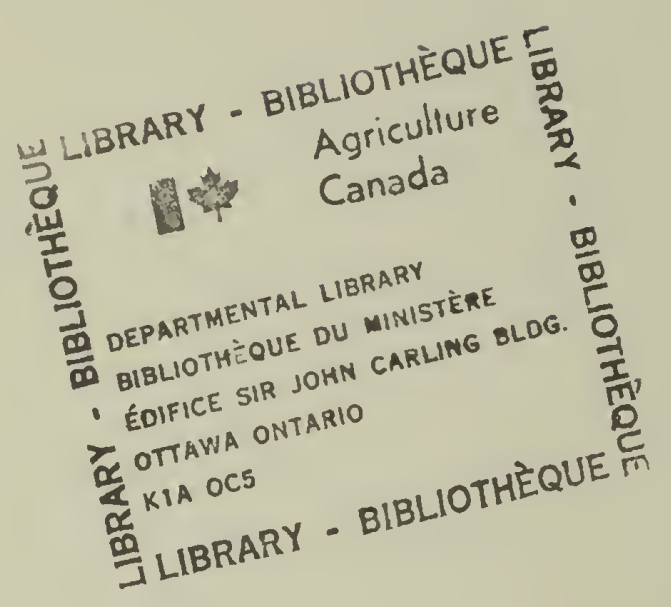




\section{La méthode d'évaluation des aliments par le calcul de l'énergie métabolisable vraie (É.M.V.)}

\section{I.R. SIBBALD}

Centre de recherches zootechniques

Ottawa (Ontario)

Contribution 83-1 du Centre de recherches zootechniques

Direction générale de la recherche Agriculture Canada 1983 
On peut se procurer des exemplaires de ce bulletin en s'adressant au:

\section{Directeur}

Centre de recherches zootechniques

Direction générale de la recherche

Agriculture Canada

Ottawa (Ontario), Canada

K1A 0C6

Production du Service aux programmes de recherche

(c) Ministre des Approvisionnements et Services Canada 1983

Also available in English under the title

The T.M.E. system of feed evaluation. 
RÉSUMÉ

Le méthode d'évaluation des aliments par le calcul de l'énergie métabolisable vraie (ÉMV) attire actuellement l'intérêt des gens. Le gavage, méthode qui consiste à introduire une quantité déterminée d'aliments dans le jabot d'un oiseau, est un élément essentiel de l'ensemble des épreuves biologiques qui constituent la méthode. Dans 1 'introduction nous expliquons la méthode et présentons un diagramme de la répartition de l'énergie chez l'oiseau. Nous passons ensuite à la description des épreuves et traitons, dans les sous-sections, des précautions à prendre ainsi que la méthode d'alimentation contrôlée, d'une méthode de collecte des déjections récenment mise au point et des cages destinées aux coquelets adultes. La partie traitant de la composition des aliments comprend essentiellement un tableau indiquant la composition chimique des éléments nutritifs ainsi que les valeurs en énergie brute, en ÉMV, et. en ÉMV d'échantillons de plusieurs types d'aliments. La bibliographie constitue l'essentiel de ce bulletin; elle donne les titres de toutes les publications connues traitant directement ou indirectement des épreuves basées sur l'alimentation contrôlée.

SUMMARY

The true metabolizable energy (TME) system of feed evaluation is attracting attention throughout the world. Precision feeding, a procedure for placing a known quantity of a feedingstuff in the crop of a bird, is fundamental to the group of bioassays which form this system of feed 
evaluation. In this Bulletin the 'Introduction' explains the principles of the system and includes a diagram showing the partition of energy within the bird. The section entitled 'Bioassay Procedures' describes the basic methodology. Sub-sections contain a list of precautions together with detailed descriptions of the precision feeding technique, a recently developed method for excreta collection, and the design and construction of cages for adult cockerels. The section on 'Feed Composition' consists primarily of a table listing the proximate compositions, gross energy, TME and TME ${ }_{n}$ values of samples of many feedingstuffs. The primary purpose of the Bulletin is the 'Bibliography' which contains references to all known publications concerned directly, or indirectly, with assays based on precision feeding. 


\section{PRÉEACE}

Le présent bulletin est une mise à jour d'une publication antérieure (bulletin technique $n^{\circ} 3$ du Centre de recherches zootechniques, 1981) qui a fait I'objet d'une forte demande. Le besoin d'une réimpression a permis d'élargir et de modifier le contenu pour ainsi répondre aux nombreuses demandes de renseignements au sujet de la méthode d'évaluation des aliments par le calcul de $I^{\prime}$ énergie métabolisable vraie (ÉMV).

La disposition du bulletin a été quelque peu modifiée pour faire place à des informations additionnelles sur la collecte des déjections, sur les précautions à prendre dans les dosages biologiques faisant appel à 1 'ÉMV, et sur une description de la conception et de la construction de cages destinécs à des coquelets adultes. Le bulletin comporte maintenant une addition importante, soit un tableau sur la composition des alinents. La bibliographie a été mise à jour par l'addition de plus de 140 références.

Cette méthode de dosage biologique basée sur l'alimentation contrôlée continue de susciter beaucoup d'intérêt parmi les collectivités industrielle et scientifique. A 1 'heure actuelle, quelque 104 laboratoires répartis dans 39 pays y ont déjà recours ou sont en train de l'évaluer. Plusieurs fabricants d'aliments utilisent les données sur l'ÉMV ou l'ÉMV pour préparer leurs aliments pour volailles.

Le Centre de recherches zootechniques prévoit tenir une liste à jour de toutes les publications scientifiques pertinentes et des suppléments au 
présent bulletin seront préparés au besoin. Pour aider à tenir la bibliographie à jour. les lecteurs sont invités à faire parvenir des références et des tirés à part à l'auteur. Le bulletin devrait s'avérer utile pour ceux qui travaillent avec la méthode de dosage des aliments par l'ÉMV, qu'ils soient enseignants, étudiants, chercheurs ou fabricants d'aliments. 
TABI.F DFS MATIËRE'S

Résuné/Sunumary

Page

Préface

Table des matières

Remerciements

Introduction

Méthodes de dosage biologique

-précautions

-alimentation contrôlée

-collecte des déjections

-conception et construction des cages 


\section{RISMERCIEMENT'S}

L'auteur tient à remercier D. Balrave de l'Universilé de Sydney en Australie; N. Dale de l'Université de la Géorgie aux F.tats-Unis; I.C. Edmundson du Centre de recherches avicoles de I'Université Massey en Nouvelle-Zélande; C. Fisher du Centre de recherches avicoles du Royaume Uni et J.J. du Preez de 1'Université de Stellenbosch en Afrique du Sud pour leur précieuse collaboration à la constitution de la bibliographie. L'utilisation de sacs de colostomie pour recueillir les déjections est une idéc originale de J.K. Rayton de Rangkok en Thailiande, et J.W. Scace de 3M Canada Inc. d'OLtawa (Canada) a formulé des suggestions utiles sur 1'application d'adhésifs. Les croquis préparatoires aux figures illustrant la conception et la construction des cages ont été préparés par F. Nachbaur, alors que les dessins définitifs et toutes les photos proviennent du Service aux programmes de recherche d'Agriculture Canada à Ottawa. La compilation du tableau sur la composition des aliments aurait élé impossible n'eût été de l'aide technique fournie par S. Tobin; les analyses de la composition chimique des éléments nutritifs onl été effectuées par l'Instilut de recherches chiniques ol biologiques du ministère fédéral de l'Agriculture à otlawa. Finalement, je m’en voudrais d'oublier D. Leger qui a obtenu 1 'information nécessaire sur la conception des cages et qui a aidé à la rédaction du présent bulletin.

DÉNI DE RESPONSARIL,LTÉ

Toute mention de raison sociale, de produil breveté ou de matériel particulier ne signifie pas automatiquemonl son approbation à l'exclusion d'autres produits qui pourraient loul aussi bien faire l'affaire. 


\section{INTRODUCTION}

Cette méthode d'évaluation des aliments comprend le dosage biologique de l'énergie métabolisable vraie (ÉMV), des acides aminés disponibles vrais (AADV), des lipides disponibles vrais (LDV) et des minéraux disponibles vrais (MDV). Chaque dosage comporte certaines corrections pour tenir compte des pertes métaboliques et endogènes qui représentent les dépenses d'entretien corporel. L'hypothèse voulant que ces pertes soient directement attribuables à l'alimentation est erronée. L'importance de faire des corrections pour tenir compte des pertes d'azote fécal métabolique et urinaire endogène $\left(\mathrm{NF}_{\mathrm{m}}+\mathrm{NU} \mathrm{e}_{\mathrm{e}}\right.$ ) pendant le processus d'évaluation des protéines alimentaires est reconnue depuis de nombreuses années (Mitchell, 1924, J. Biol. Chem. 58:873); il n'en reste pas moins que $1^{\prime}$ utilisation de facteurs de correction analogues dans les dosages biologiques de l'énergie est comparativement récente.

L'expression "énergie métabolisable vraie" a été définie par Harris (1). L'effet des pertes d'énergie fécale métabolique et urinaire endogène (ÉF ${ }_{\mathrm{m}}+$ ÉU ${ }_{e}$ ' sur les valeurs de $I$ 'énergie métabolisable apparente (ÉMA) a été décrit

à I'aide de données théoriques par Guillaume et summers (2). L'apparition plutôt tardive de la méthode de dosage biologique de l'ÉMV traduit peut-être un manque de confiance dans la capacité d'évaluer ÉF ${ }_{m}+E_{e} \cdot$ La correction des valeurs de l'énergie contenue dans les déjections (ÉF + Éu) de façon à ramener le bilan azoté à zéro $\left(E_{n} F+E_{n} U\right)$ tient compte de la majeure partie de la variation qui caractérise les évaluations de ÉF ${ }_{m}+$ ÉU (plus correctement appelé $E_{n} F_{m}+E_{n} U_{e}$ ). 
La mise au point de la méthode du dosage biologique de l'ÉMV a été accidentelle. En effet, une étude des variations des valeurs de l'ÉmA parmi les sujets et au fil des jours a révélé une courbe en "dents de scie". Pour un sujet en particulier, ces valeurs ont eu tendance au fil des jours à être tour à tour plus élevées et plus faibles que la moyenne (8). L'étude de la cause de cette variation a révélé l'effet fondamental de l'ingestion d'aliments sur les valeurs de $1^{\prime}$ ǴMA (3). C'est ce phénomène qui a abouti à la création de la méthode du dosage biologique (9). La méthode a subi plusieurs modifications depuis et a été élargie à d'autres éléments nutritifs.

Le dosage biologique consiste généralement à alimenter un sujet à jeun d'une quantité connue de $l^{\prime}$ aliment à $l^{\prime}$ étude et à recueillir quantitativement les déjections qui en résultent. Chaque aliment est servi à deux ou plusieurs niveaux d'ingestion pour établir le rapport entre l'apport et l'excrétion de substances nutritives. Pour simplifier les choses, on établit généralement un niveau d'apport nul. Les récents travaux à ce sujet, dont une bonne partie est encore sous presse, révèlent que les sujets à jeun ont tendance à cataboliser davantage leurs protéines corporelles que les sujets normalement nourris. Ce phénomène modifie l'excrétion d'énergie et introduit une erreur dans le dosage biologique de l'ÉMV. De même, la perte de protéines corporelles sous forme de produits d'excrétion énergétiques est tributaire de la quantité et de la qualité de la protéine dont se compose l'aliment à l'étude, ce qui introduit une autre cause d'erreur, quoique d'importance secondaire. On résout le problème en corrigeant l'excrétion d'énergie contenue dans les déjections des sujets nourris et à jeun pour ramener le bilan azoté à zéro. Cetle correction qui est fortement recommandée sera 
décrite un peu plus loin. Il ne semble pas que de telles corrections soient nécessaires dans le dosage biologique des AADV, LDV et MDV.

La figure 1 donne une représentation schématique de la répartition de l'énergie des aliments ingérés par le sujet. La terminologie et les abréviations suivent celles publiées par le Conseil national de la recherche des Etats-Unis (248), mais 1 a répartition diffère dans la mesure où É ${ }_{m}^{+}$ ÉU sont inclus comme partie intégrante de l'énergie nette nécessaire aux besoins d'entretien corporel. La figure aide à expliquer les différences entre 1 'ÉMA et 1 'ÉMV et montre que les matières fécales et 1 'urine contiennent des composants énergétiques provenant de l'organisme plutôt que des aliments. 


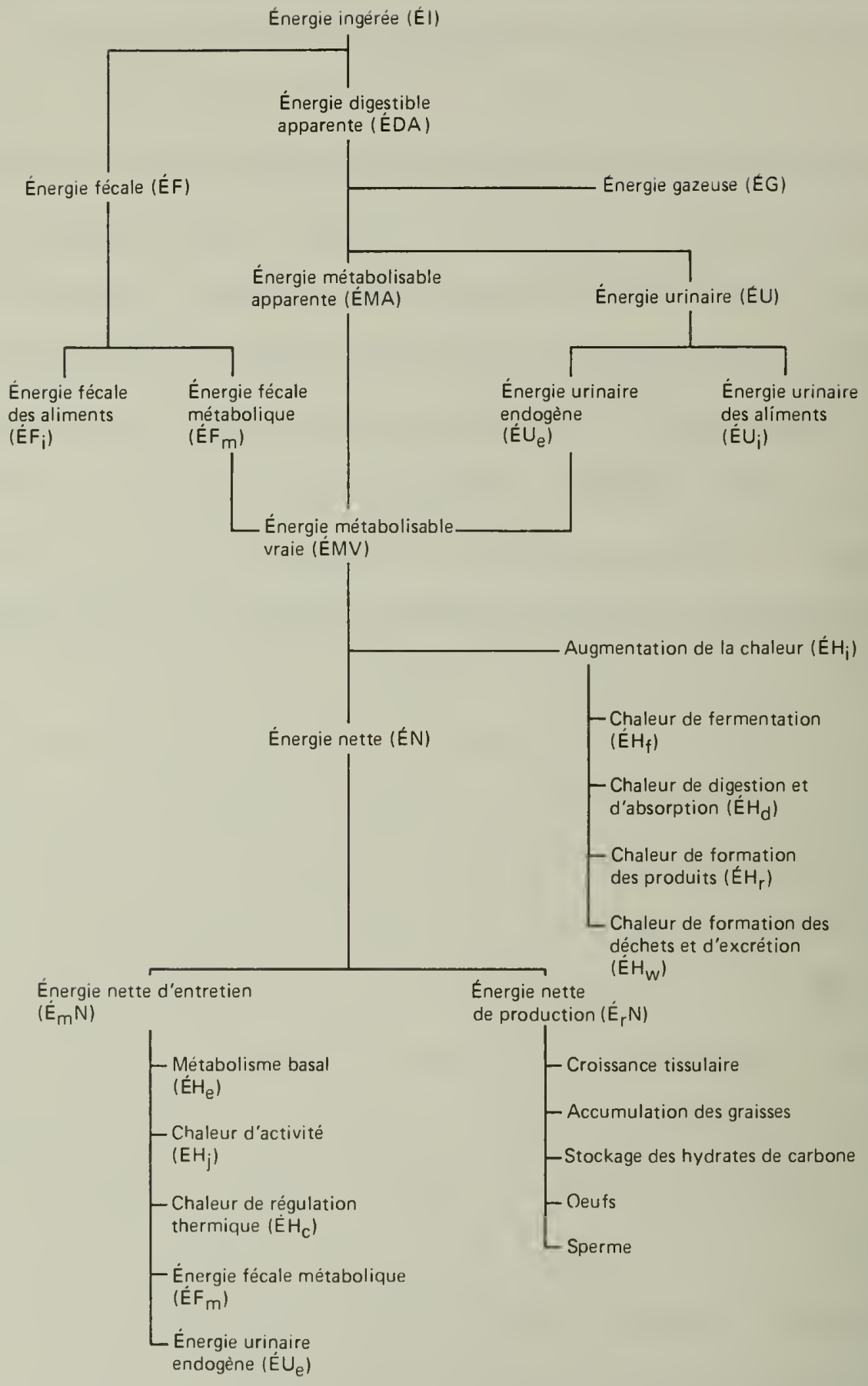

Figure 1. La répartition de 1 'énergie des aliments ingérés par le sujet (tirée de la référence 296). 


\section{MÉTHODES DE DOSAGE BIOLOGIQUE}

\section{Généralités}

Les dosages biologiques par le calcul de l'ÉMV ont plusieurs points en commun et peuvent être exécutés simultanément pourvu qu'il y ait suffisamment de déjections pour effectuer les analyses physiques et chimiques. On garde les sujets à jeun pour débarrasser leur tube digestif de résidus alimentaires, puis on leur donne une quantité déterminée du produit que l'on veut doser. Le sujet est placé dans une cage métallique où l'eau est disponible à volonté.

Le temps est enregistré et les déjections sont recueillies quantitativement pendant un laps de temps prédéterminé. Un sujet par paire restera à jeun et servira de témoin pour mesurer les déperditions métaboliques et endogènes. Les déjections et les échantillons des produits à l'étude sont ensuite analysés pour doser l'énergie brute, les acides aminés, les lipides ou les éléments minéraux selon le cas. La méthode de calcul est la suivante:

$$
X T=X I-(X F+X U)+\left(X F_{m}+X U_{e}\right)
$$

où: $\quad X T$ sont les substances nutritives $X$ disponibles vraies;

XI est la quantité de $X$ introduite dans le jabot du sujet nourri:

$(X F+X U)$ est la quantité de $X$ excrétée par le sujet nourri; et

$$
\left(X F+X U_{e}\right) \text { est la quantité de } X \text { excrétée par le sujet à jeun. }
$$

On choisira de préférence un coquelet adulte écrêté d'une lignéc de ponte. qui n'a jamais eu accès au grit. On peut également utiliser d'autres oiseaux, mais les poussins ne peuvent recevoir qu'une quantité limitée d'aliments et les pondeuses gardées à jeun produisent souvent des oeufs à coquille fragile 
qui ont tendance à se briser et à contaminer les déjections. Les pondeuses peuvent s'avérer utiles pour le dosage des MDV où les besoins de minéraux sont souvent élevés (298), mais c'est plutôt rare. On évite également d'utiliser des sujets qui ont avalé du grit car il peut être retenu dans le gésier et éliminé de façon irrégulière. La présence de grit dans les déjections abîme le matériel de broyage et introduit des erreurs importantes dans les bilans minéraux à court terme.

Tous les sujets utilisés dans le dosage doivent avoir reçu la même ration alimentaire. La composition de cette ration n'est pas déterminante, pourvu qu'elle permette aux sujets de satisfaire leurs besoins nutritifs. De nombreux laboratoires utilisent une ration pour pondeuses à $15 \%$ de protéines au cours de la période d'entretien séparant les dosages. En règle générale, un jeûne de 24 heures donne des résultats satisfaisants, mais il se peut que cette période soit trop courte si le régime d'entretien contient une forte quantité de substances indigestes. En cas d'incertitude, mieux vaut mesurer le temps de passage des aliments d'entretien avant d'amorcer une série de dosages.

Au fur et à mesure qu'on augmente l'apport d'aliments à l'étude, le pourcentage d'erreurs expérimentales diminue, mais la possibilité de régurgitation augmente; à cet égard, 30 à $40 \mathrm{~g}$ d'aliments donnent généralement des résultats satisfaisants. Les apports trop considérables, en particulier d'aliments de lest cellulosique, peuvent entraîner la surcharge du jabot. Les sujets dont le jabot est surchargé affichent des temps de rétention prolongés 
de résidus alimentaires, ce qui peut introduire des données trompeuses. II existe toutefois une exception, soit le dosage des MDV dans lequel les apports de minéraux à l'étude ne devraient pas dépasser les besoins du sujet.

Contrairement aux acides aminées, aux lipides et à d'autres sources d'énergie, les minéraux excédentaires sont tout. simplemenl évacués dans les déjections.

Au début, on recommandait de faire de petites boulettes avec les alinenls, mais cette pratique n'est plus nécessaire si le tube de l'entonnoir a un diamètre interne d'environ $1,0 \mathrm{~cm}$. On veillera touterois à ne pas perdre l'aliment qui pourrait adhérer à l'entonnoir. Si le produit est hygroscopique ou pulvérulent, mieux vaut le mélanger à un support, par exemple $90 \%$ de maìs moulu avec $10 \%$ d'huile végétale; en pareil cas, il sera nécessaire de doser le support.

Les aliments à $l$ 'étude sont d'abord pesés avanl le dosage et gardés dans des contenants jusqu'à leur utilisation. Tes contenants de polypropylène transparents ( $130 \mathrm{ml}$ ) à couvercle hermétique comme ceux ut.ilisés pour les échantillons d'urine s'avèrent sati:iraisants. On recommande de peser des sous-échantillons des aliments à l'étude pour en déterminer la teneur en matière sèche en même temps qu'on prépare les contenants. Le facteur temps est important puisqu'il permet d'éviter les erreurs liées à l'absorption ou à la perte d'humidilé par les aliments. Il faudra ensuite exprinier les données analytiques subséquentes sur une base de mat.ière sèche.

Les sujets snnt logés dans les cages métalliques de l'étage inférieur d'un 
système d'élevage en batterie. La conception et la construction des cages sont décrites plus loin (page 29). L'eau est fournie par un système d'abreuvoir à tétine et l'aliment est servi dans une mangeoire qui fait toute la longueur de chaque bloc de cages. Au début d'un dosage, on amorce le jeûne des oiseaux par le retrait de 1a mangeoire. Dans d'autres régimes de conduite (p. ex. lorsque $l^{\prime}$ eau est fournie dans des abreuvoirs ordinaires), on veillera à ne pas perdre les aliments qui se retrouvent dans le système d'abreuvement ou qui adhèrent à la cage.

Les sujets gardés à jeun sont prélevés de l'étage inférieur de la batterie, reçoivent le traitement approprié et sont ensuite logés dans les cages de l'étage supérieur en prenant soin de les séparer par une cage vide. La technique d'alimentation contrôlée sera décrite plus loin. Les cages supérieures ne servent que durant les périodes de collecte des déjections et sont méticuleusement nettoyées avant chaque dosage. Des plateaux de collecte des déjections sont installés dans les cages sous chaque sujet. Ces plateaux, de préférence en plastique 1 isse, sont plus larges que le fond de chaque cage, ce qui permet de réduire les risques de perte de déjections. Une innovation en matière de technique de collecte des déjections est décrite un peu plus loin (page 24).

La manipulation des oiseaux entraîne des pertes d'écailles et de plumes, ce qui nuit à la mesure des déjections. Pour atténuer le problème, il suffit de souffler les écailles du plateau une heure après la mise en cage des sujets. Recueillir les déjections environ 24 heures, puis exactement 48 
heures plus tard. Une seule collecte au bout de 48 heures peut être satisfaisante, mais la double collecte est préférable puisqu'elle permet de réduire la détérioration et la contamination des déjections. Lorsque les dosages onl été décrits pour la première fois, on reconmandait une période de collecte de 24 heures, mais les travaux subséquents ont révélé qu'elle était insuffisante pour assurer le passage des résidus de certains aliments à 1'étude dans 1 'intestin des sujets. Enlever et recueillir les détections qui ont collé à la cage, ainsi que ceux qui souillent les plumes tombées dans le plateau. Veiller à ce qu'il n'y ait aucun aliment régurgilé sur le plateau, faute de quoi 1 'oiseau ne pourrait être utilisé pour le dosage. Les deux échantillons de déjections prélevés de chaque sujel sont congelés, séchés, ramenés au degré d’humidité atmosphérique, pesés, mélangés, hachés et dosés.

Il est préférahle de lyophyliser les échantillons, ce qui confère aux déjections une texture semblable à une éponge, facilitant par le fait même le broyage. Pour doser l'kMV (mais probablement pas pour le dosage des AADV ni des LDV), les déjections peuvenl être séchées au four sans modirier les valeurs finales (92). Certains laboratoires regroupent les déjections de plusieurs sujets pour réduire la durée des analyses. Cette méthode ne devrail pas modifier les valeurs estimatives de l'ÉMV, des AADV, des LDV ni des MUV, mais elle limile la capacité d'évaluer la variation et de faire des comparaisons entre les échantillons (303).

De récents travaux ont révélé la pertinence de corriger les valeurs de 1'ÉMV pour ramener le bilan azoté à zéro (ÉMV ${ }_{n}$ ). Comne première étape du calcul, les excrétions d'énergie contenue dans les déjections (ÉF + ÉU) sont 
corrigés pour ramener le bilan azoté à zéro $\left(\dot{E}_{n} F+\dot{E}_{n} U\right)$ de la façon suivante:

$$
\left(E_{n} \mathbf{H}^{0}+\dot{E}_{n}^{\prime} U\right)=(E F+E \cdot U)+k(N I-N F-N U)
$$

où: $\quad k$ est une constante qui sert à évaluer la teneur en énergie brute des produits d'excrétion résultant du catabolisme d'une unité de poids d'azote corporel;

Nl est I'apport d'azote sous forme d'aliment à l'étude; et NF et NU sont les excrétions d'azote fécal el urinaire.

Pour les sujets à jeun, NI est nul. Dans la plupart des dosages, le terme $k\left(N I\right.$ - NF - NU) est négatif; par conséquent $\left(E_{n} F+E_{n} U\right)$ est généralement inférieur à (ÉF + ÉU). Le terme $\left(E_{n} F_{m}+E_{n} U_{e}\right)$ décrit $I^{\prime e x c r e ́ t i o n ~}$ corrigée d'énergie sous forme d'azote d'un sujet à jeun. La méthode de calcul des valeurs de l'ÉMv ${ }_{n}$ est la suivante:

$$
\text { EMV }{ }_{n}=E I-\left(E_{n} F+E E_{n} U\right)+\left(E_{n} F+E_{n} E_{e}\right)
$$

où: Él est la quantité d'énergie apportée sous forme d'aliment à l'étude et introduite dans le sujet.

Il ne semble pas que des corrections analogues soient nécessaires pour les autres dosages biologiques de I'ÉMV.

\section{Précaut.ions}

Voici une liste des précautions à prendre si l'on veut obtenir des données fidèles des dosages biologiques. La liste se termine par une énumération des causes les plus courantes de valeurs anormalement élevées et faibles. 
1. Les sujets testés doivent être en bonne santé.

2. Tous les sujets testés doivent recevoir la même ration d'entretien entre les dosages.

3. Les sujets testés ne doivent pas avoir avalé de grit.

4. Les aliments à l'étude doivent être dosés pour la matière sèche au moment du pesage en contenant avant de les servir aux sujets.

5. Les aliments pulvérulents et hygroscopiques devraient être mélangés à un support, lequel doit être également dosé.

6. Les sujets testés doivent être mis à jeun le temps qu'il faut pour permettre 1 'évacuation de tous les résidus d'aliments.

7. Le retrait des aliments pour le jeûne doit être total. Il faut donc nettoyer les cages soigneusement, car les aliments qui y adhèrent et qui sont généralement ignorés par le sujet seront consommés durant le jê̂ne.

8. Les sujets doivent avoir libre accès à de l'eau fraîche.

9. Les plateaux de déjections doivent être vérifiés pour la présence d'aliments régurgités: si $1^{\prime}$ on y trouve de ces aliments, le sujet ne peut être utilisé pour le dosage.

10. La période de collecte des déjections doit être exactement la même pour tous les sujets soumis au dosage.

11. Pour des coquelets adultes et des apports alimentaires de 30 à $40 \mathrm{~g}$, une période de collecte des déjections de 48 heures devrait suffire. Pour d'autres oiseaux et apports, une première expérience peut se révéler nécessaire pour établir la durée de la période de collecte. 
12. La collecte des déjections doit être quantitative. Les plumes sont définitivement à rejeter et les écailles sont à éviter le plus possible.

13. Les déjections séchées devraient être ramenées au degré d'humidité atmosphérique ou conservées de façon à maintenir constante leur teneur en eau entre le pesage et $I^{\prime}$ analyse.

L'obtention de valeurs anormalement élevées peut résulter:

a. d'un passage incomplet de résidus de l'aliment à l'étude dans 1 'intestin; éviter alors de surcharger le jabot;

b. d'une collecte incomplète des déjections; des déjections peuvent être tombées en dehors du plateau de collecte:

c. d'une régurgitation passée inaperçue dont le produit serait tombé par terre, ce qui réduirait d'autant le volume de déjections:

d. d'erreurs dans le pesage, la préparation, ou 1'introduction de 1 'aliment à 1 'étude; et

e. d'erreurs analytiques.

On obtient des valeurs anormalement faibles lorsque:

a. le jeûne est insuffisant et que des résidus de la ration d'entretien sont présumés provenir de $l^{\prime}$ aliment à $l^{\prime}$ étude;

b. le sujet a accès à des aliments pendant le jeûne;

c. des matières régurgités sont mélangées aux déjections;

d. les écailles ou les plumes sont incluses dans les déjections; et e. des erreurs de préparation et d'analyse sont commises. 
Les dosages sont simples et relativement rapides. Mais comme tous les dosages, il faut procéder avec soin et minutie si l'on veut obtenir des données fidèles.

\section{Alimentation contrôlée}

L'alimentation contrôlée a pour objet d'assurer que les sujets reçoivent une quantité déterminée d'aliments à un moment donné. Cette façon de procéder élimine le besoin de récupérer les résidus, prévient la sélection dans 1'alimentation et élimine la variation dans 1 'ingestion entre les divers sujets. On rencontre généralement tous ces problèmes lorsque les sujets s'alimentent à volonté.

L'alimentation contrôlée consiste à introduire un tube dans le bec de 1'oiseau, puis dans $1^{\prime}$ oesophage jusqu'au jabot, d'y verser $1^{\prime}$ aliment désiré et de retirer ensuite le tube. La première technique mise au point au Centre de recherches zootechniques consistait à introduire l'aliment aggloméré dans un simple tube de verre et de le faire ensuite descendre dans le jabot à l'aide d'une tige de verre. Par la suite, on a mis au point un entonnoir de verre et une tige métallique. L'expérience aidant, on est parvenu à utiliser des tubes d'un diamètre supérieur et on a réussi à mettre au point un appareil efficace en fixant un entonnoir de verre à un bout de tuyau de cuivre d'un diamètre de $1,2 \mathrm{~cm}$. On utilisait une tige métallique pour faire descendre des aliments. Aujourd'hui, on se sert d'un entonnoir en acier inoxydable muni d'un tube de $40 \mathrm{~cm}$ de longueur, d'un diamètre externe de $1,2 \mathrm{~cm}$ et d'un diamètre interne de $1,1 \mathrm{~cm}$. La baguette est devenue une tige en aluminium d'un diamètre de $1,0 \mathrm{~cm}$ 
avec, pour extrémité, un bouton sphérique de $3,0 \mathrm{~cm}$ de diamètre. Enfin, un petit morceau de plastique a été fixé à la tige pour éviter que cette dernière ne dépasse l'extrémité du tube de plus de $0,5 \mathrm{~cm}$. Pour faciliter l'opération, on choisira un entonnoir léger et bien proportionné; en effet, les entonnoirs lourds, particulièrement ceux dont le poids n'est pas réparti de façon égale. sont difficiles à manipuler une fois introduit.s dans le gosier de l'oiseau. Les entonnoirs en plastique ont l'avantage d'être légers, mais beaucoup ont des propriétés électrostatiques qui empêche l'introduction d'une quantité précise d'aliments. T.es figures 2 et 3 illustrent certains des appareils ut.ilisés dans ce laboratoire pour l'alimentalion contrôtée.

Le succès de la méthode dépend de la façon dont on maîtrise lo sujet. Voici une technique simple et rapide mise au point au Centre de recherches zootechniques: il s'agit de s'asseoir sur un banc ou une chaise sans bras et de croisser la jambe gauche sur la droite. Prendre le sujet avec les deux mains et le placer de façon à ce que le bréchet se trouve dans le creux formé par la cuisse gauche et l'abdomen; le corps du sujet formera alors un angle de $45^{\circ}$. les pattes étendues vers la gauche, sans point d'appui. Tenir le sujet fermement avec le coude gauche et saisir le bec entre le pouce et l'index gauches. Étirer légèrement le cou du sujet, ouvrir le bec et introduire le tube de l'entonnoir. L'entonnoir devrait glisser dans l'oesophage jusqu'au jabot sans trop de difficultés. En cas de résistance, attendre quelques secondes pour permettre au sujet de déglutir ou de se détendre. Si cela ne réussit pas, retirer l'entonnoir et. recommencer. Verser l'aliment dans 1'entonnoir en tenant 1 e contenant dans la main droite et demander à une autre 


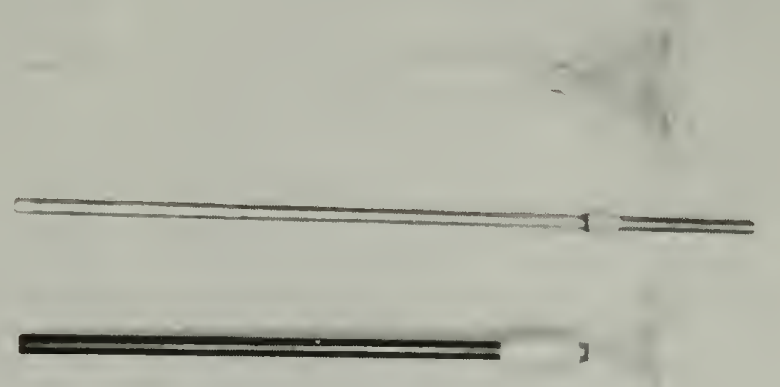

Figure 2. Quelques dispositifs d'alimentation précurseurs:

(A) entonnoir et tige de verre, (B) entonnoir de verre fixé à un tuyau de cuivre et tige en aluminium, (C) tube et tige de verre.

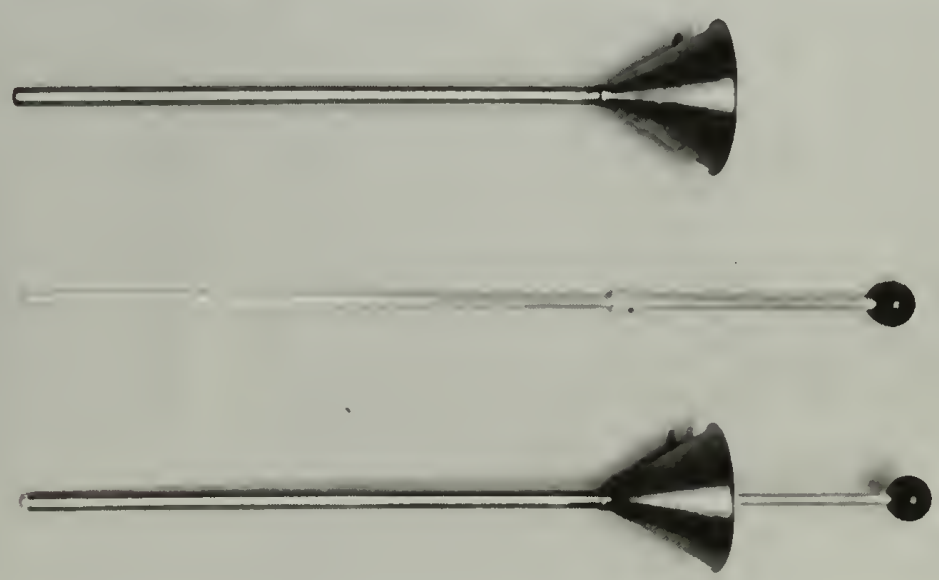

Figure 3. Entonnoirs en acier inoxydable et tiges en aluminium. A noter le petit morceau de plastique fixé sur la tige pour éviter que cette dernière ne dépasse l'extrémité de l'entonnoir. 


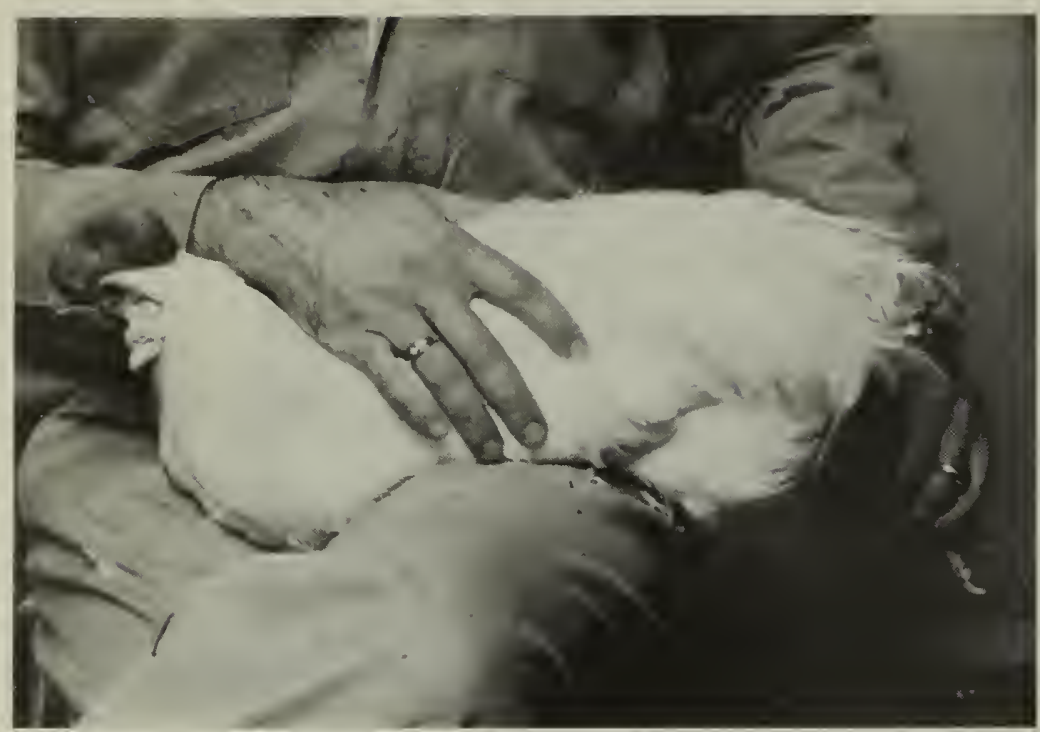

Figure 4. Le sujet est placé à un angle de $45^{\circ}$, le bréchet se trouvant dans le creux formé entre la cuisse et $1^{\prime}$ abdomen du manipulateur.

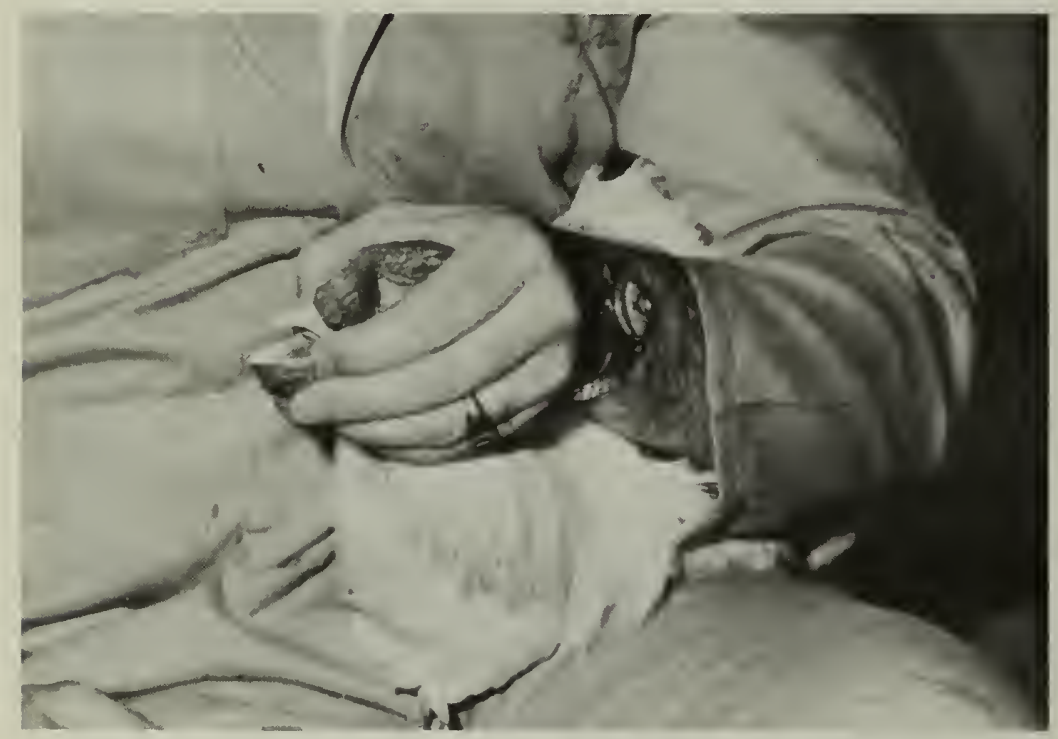

Figure 6. Le bec est ouvert par la mandibule supérieure en utilisant le pouce et $1^{\text {'index }}$ gauches.

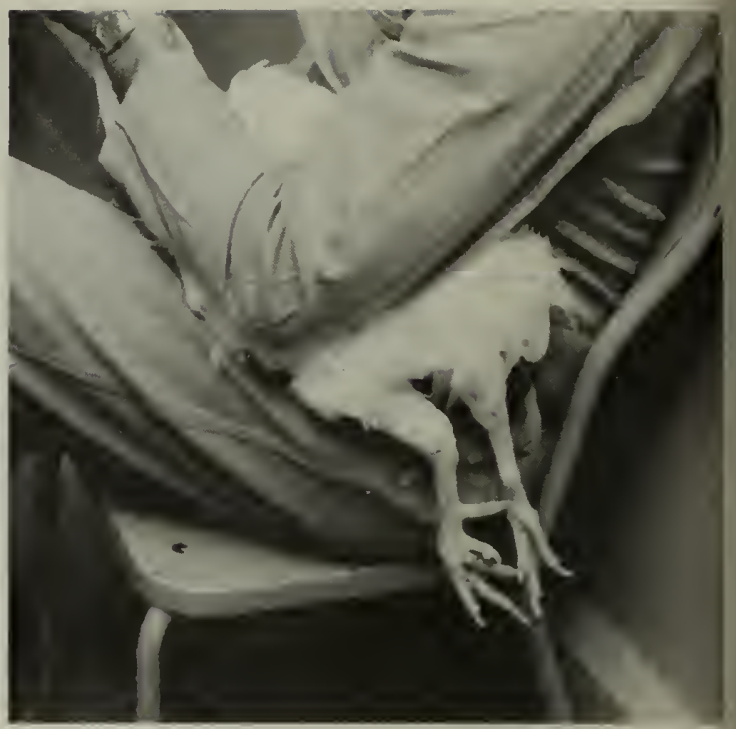

Figure 5. Les pattes sont étendues et ne peuvent prendre appui. Le sujet est maintenu en place par le coude gauche.

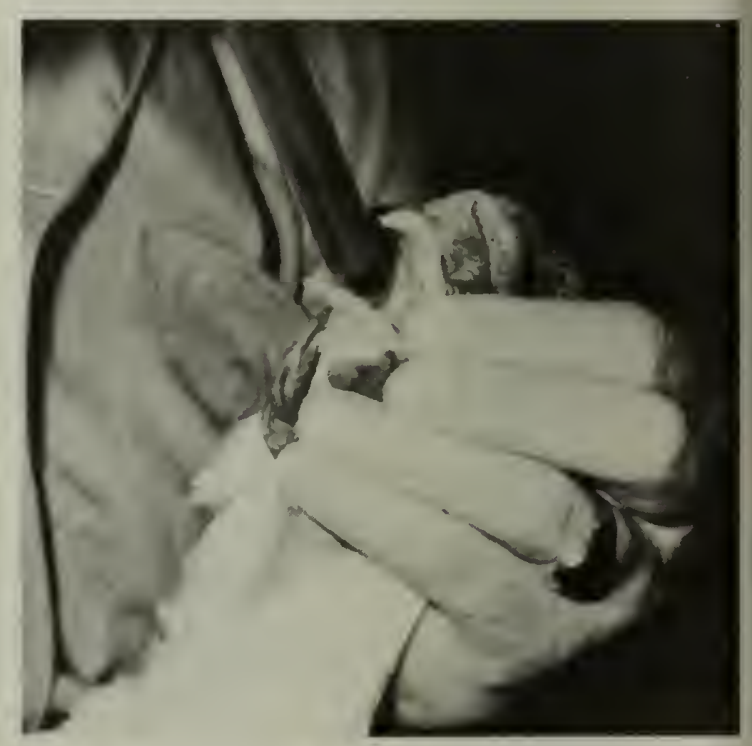

Figure 7. Le cou est

légèrement étendu et le tube de l'entonnoir est introduit. 


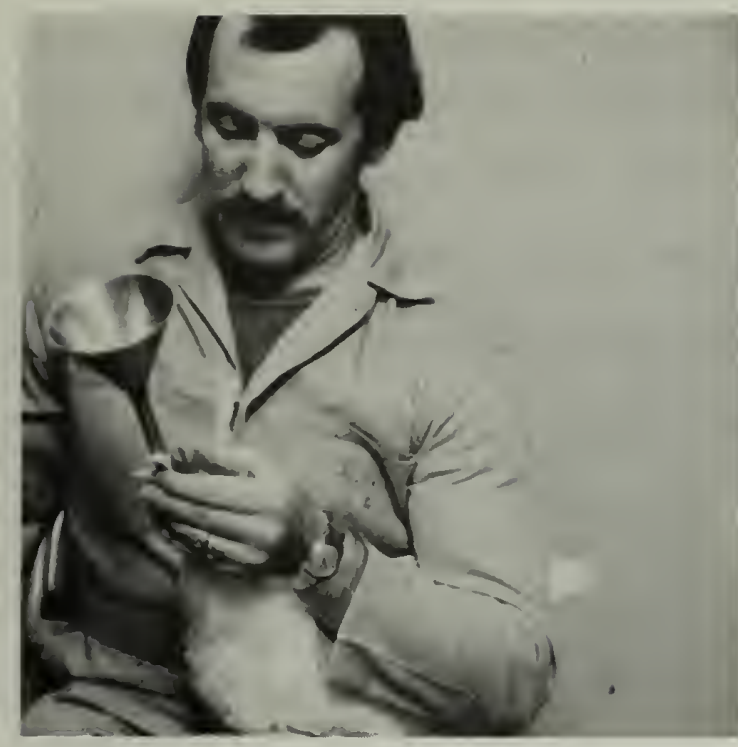

Figure 8. L'entonnoir est maintenu en place entre le pouce et $1^{\text {'index. }}$.

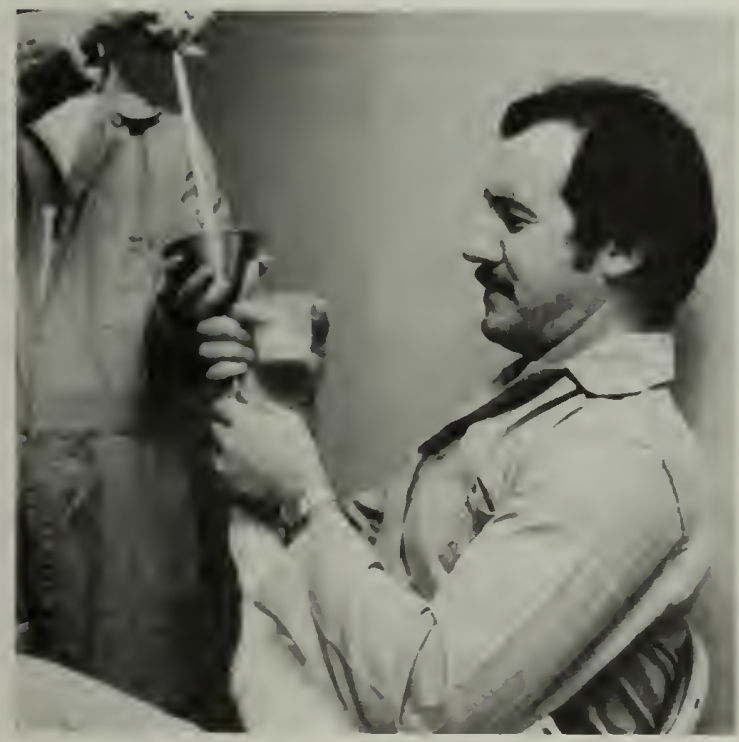

Figure 10. Une autre personne refoule les aliments dans l'entonnoir. Les deux personnes tiennent l'entonnoir pour le tenir en place.

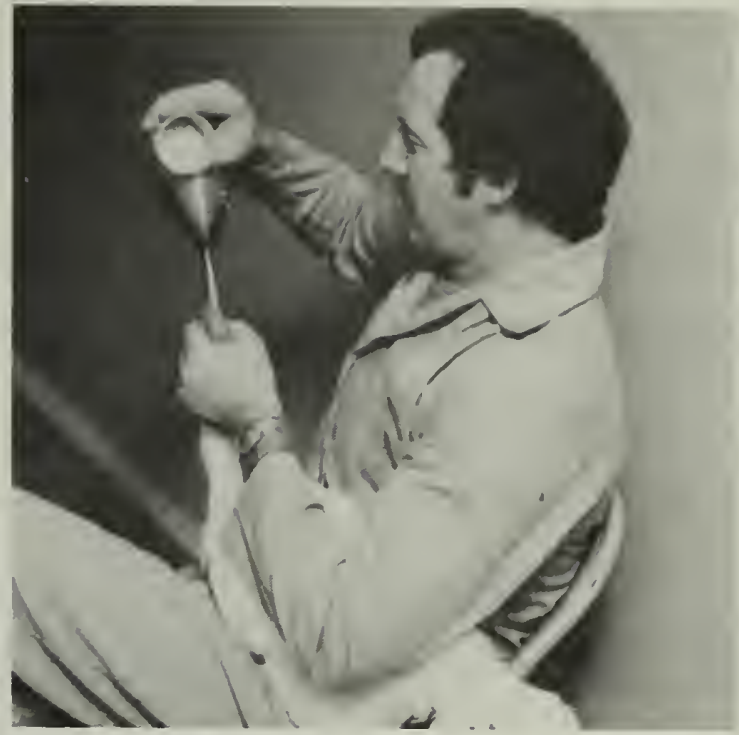

Figure 9. L'aliment est versé dans l'entonnoir; remarquer la position du sujet, pattes étendues vers la gauche.

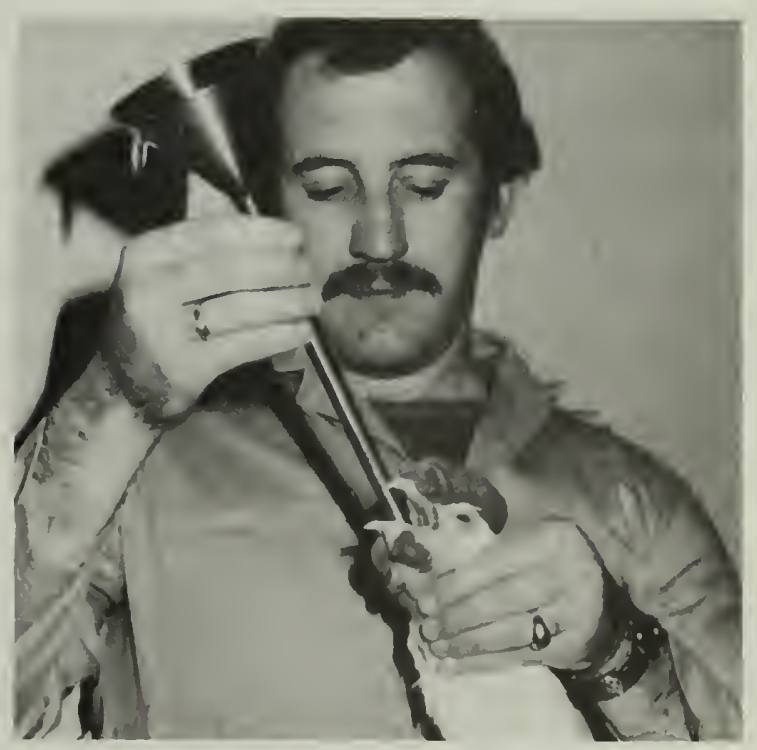

Figure 11. On retire l'entonnoir par un mouvement rotatoire en exerçant une légère pression sur l'oesophage avec la main gauche de façon à enlever toute particule d'aliment qui pourrait adhérer au tube. 
personne de pousser la nourriture dans le jabot. On veillera à ne pas déplacer l'entonnoir dont $l^{\prime}$ extrémité doit être dans le jabot, et non dans 1'oesophage, si l'on veut éviter que le sujet régurgite les aliments. Retirer l'entonnoir de la main droite en un mouvement rotatoire et, de la main gauche, appliquer une légère pression sur 1'oesophage au niveau du cou pour enlever les particules alimentaires qui pourraient adhérer à la surface externe du tube de $1^{\prime}$ entonnoir. En règle générale, 1'opération demande moins d'une minute par sujet.

Les figures 4 à 11 illustrent la technique d'alimentation contrôlée. On peut se procurer un film sonore, $16 \mathrm{~mm}$, en couleur, de $6 \mathrm{~min}$ intitulé "Gavage des volailles - Une technique expérimentale" en s'adressant à la: Direction générale des communications, Agriculture Canada, Ottawa (Ontario), Canada. K1A OC7.

\section{Collecte des déjections}

Une récente innovation qui s'inspire fortement d'une idée de J.K. Rayton simplifie et améliore la collecte des déjections. En bref, on attache un sac de colostomie au cloaque de 1 'oiseau au début de la période de collecte et on le retire avec les déjections 48 heures plus tard. La technique qu'on peut qualifier d'extension non chirurgicale de la méthode de R.M. Blakely (Can. J. Anim. Sci. 43:386, 1963) est décrite ci-dessous.

Les sujets sont préparés par le rasage de la peau entourant le cloaque. On peut utiliser une tondeuse électrique pour moutons, mais une paire de 
ciseaux fait tout aussi bien l'affaire. La zone ainsi tondue est à peu près rectangulaire $(8 \times 10 \mathrm{~cm})$ et s'étend de $1 \mathrm{a}$ base de la queue à un point situé à environ $8 \mathrm{~cm}$ du cloaque sur le ventre. Les sujets sont généralement préparés plusieurs jours avant l'exécution d'un dosage. S'il s'agit de coquelets adultes, il peut s'avérer nécessaire de rogner les ergots pour les empêcher d'abîmer les sacs.

Juste avant la collecte des déjections, préparer un sac de colostomie en plastique autocollant. Un sac de $14 \times 20 \mathrm{~cm}$ muni d'une ouverture de 3 à $5 \mathrm{~cm}$ fera l'affaire. Enlever le support de papier qui protège la surface adhésive entourant l'ouverture. Appliquer un adhésif à $1 \mathrm{~cm}$ de la marge extérieure de la surface collante. Aligner l'ouverture du sac et le cloaque et poser le sac sur le sujet en pressant légèrement la surface collante sur la peau pendant environ $10 \mathrm{~s}$. Prendre soin d'assurer une bonne étanchéité et d'éviter que 1'adhésif ne touche au cloaque. Séparer les cloisons du sac pour permettre aux déjections de tomber au fond. Placer ensuite le sujet dans une cage exempte d'aspérités qui pourraient perforer le sac. Dans la mise en cage, veillez à ne pas exercer de pression inutile sur le sac pour ne pas le décoller.

A la fin de la période de collecte, retirer soigneusement le sac et traiter la peau entourant le cloaque à l'aide d'un émollient. Plier l'extrémité supérieure du sac de façon à ce que l'adhésif qui entoure 1'ouverture assure sa propre fermeture étanche. Congeler et conserver ensuite les sacs et leur contenu. Plus tard, il suffit d'ouvrir les sacs congelés et d'en lyophyliser les déjections. Toutefois, si celles-ci sont très liquides, 


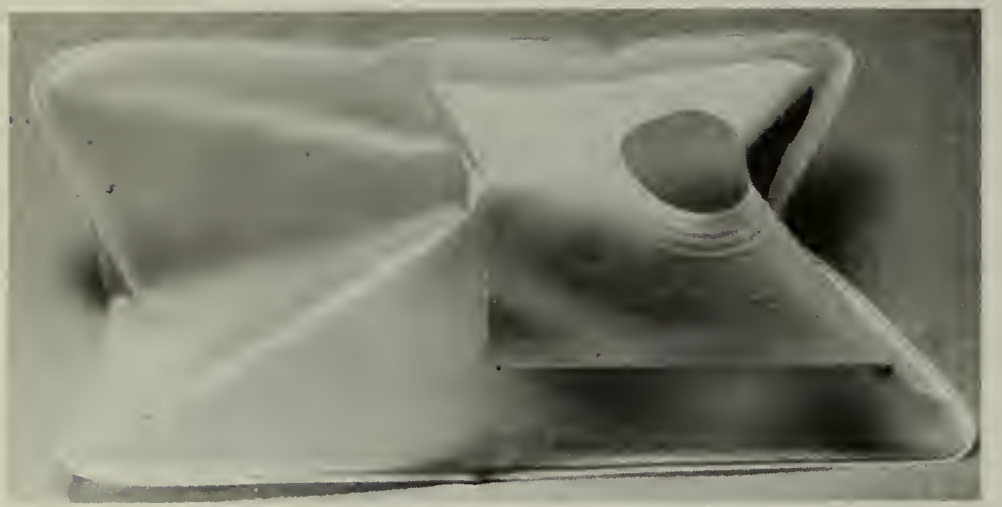

Figure 12. Sac de colostomie à surface adhésive et aux cloisons séparées.

Figure 13. Sac de colostomie avec trousse d'adhésif supplémentaire.

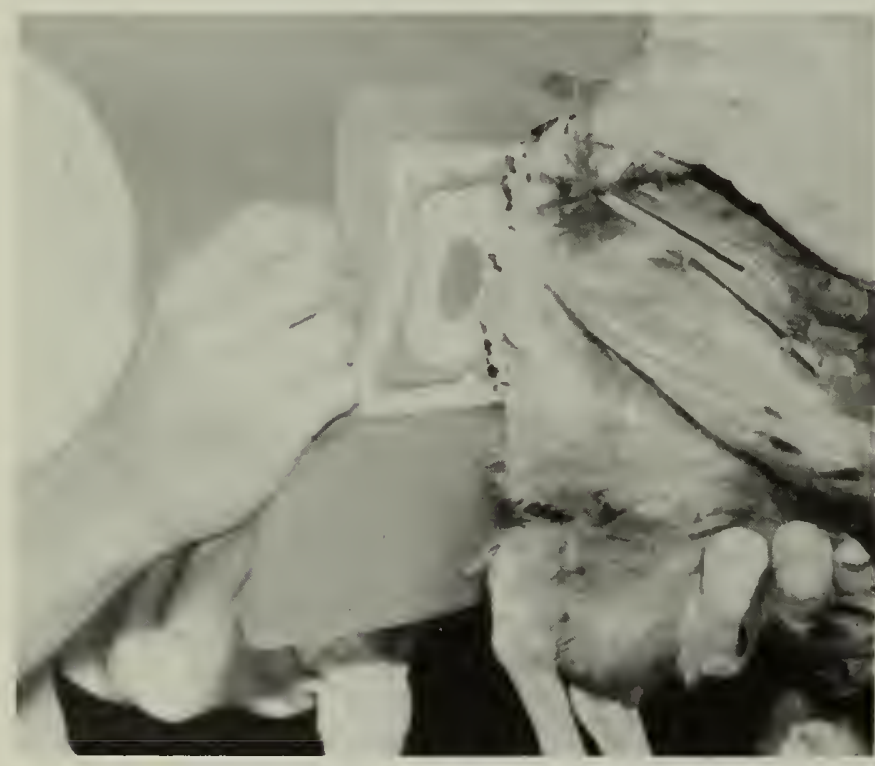

Figure 14. Centrage du sac sur le cloaque.

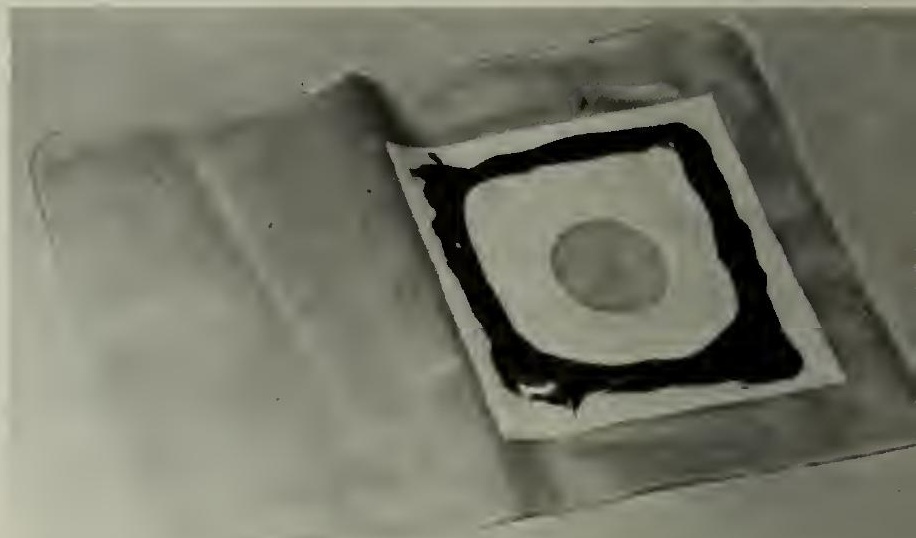

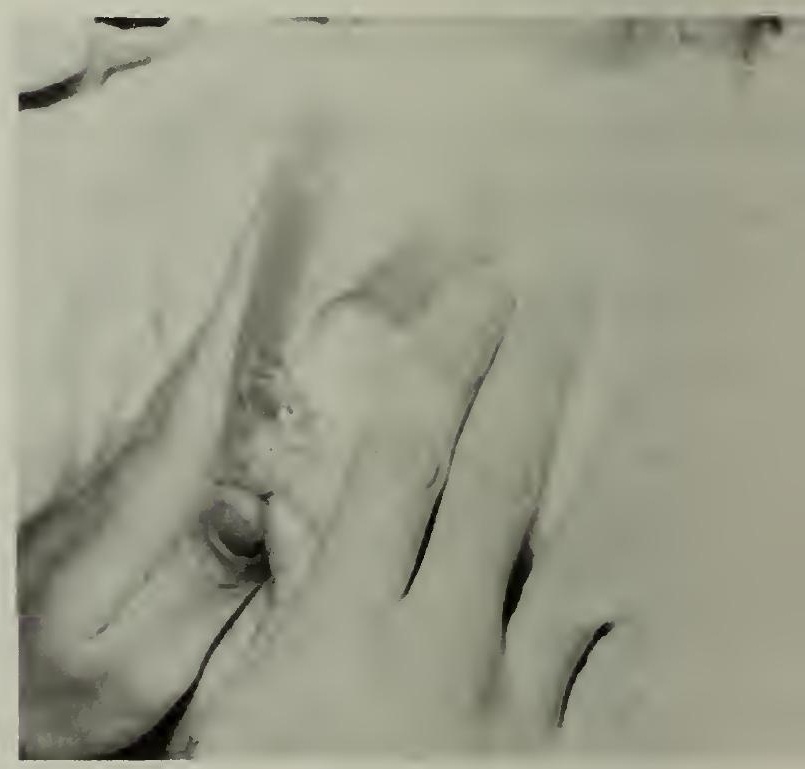

Figure 15. Pression sur 12 surface collante du sac pour la mise en place. 


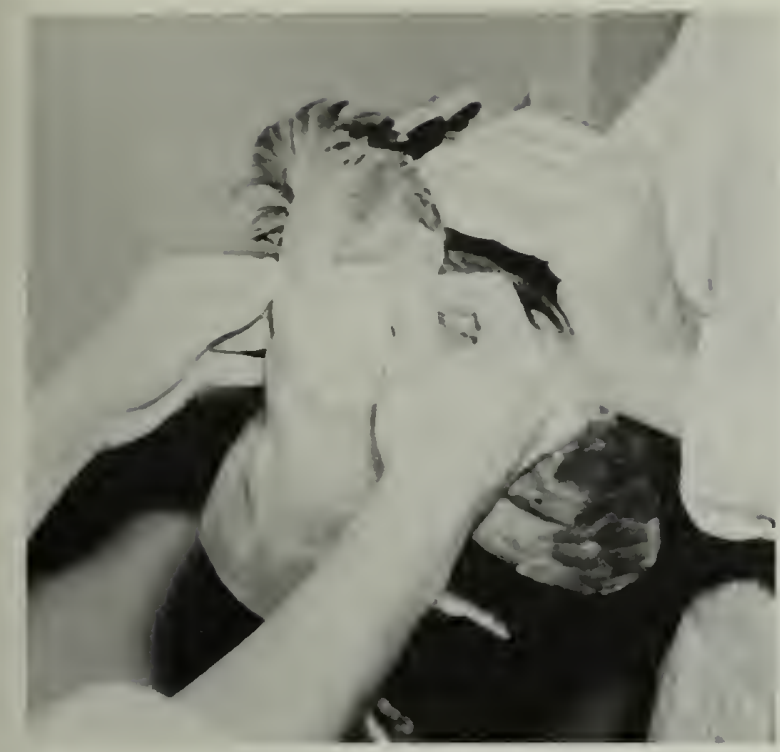

Figure 16. S'assurer d'un bon

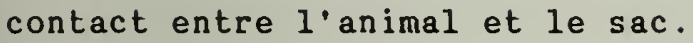

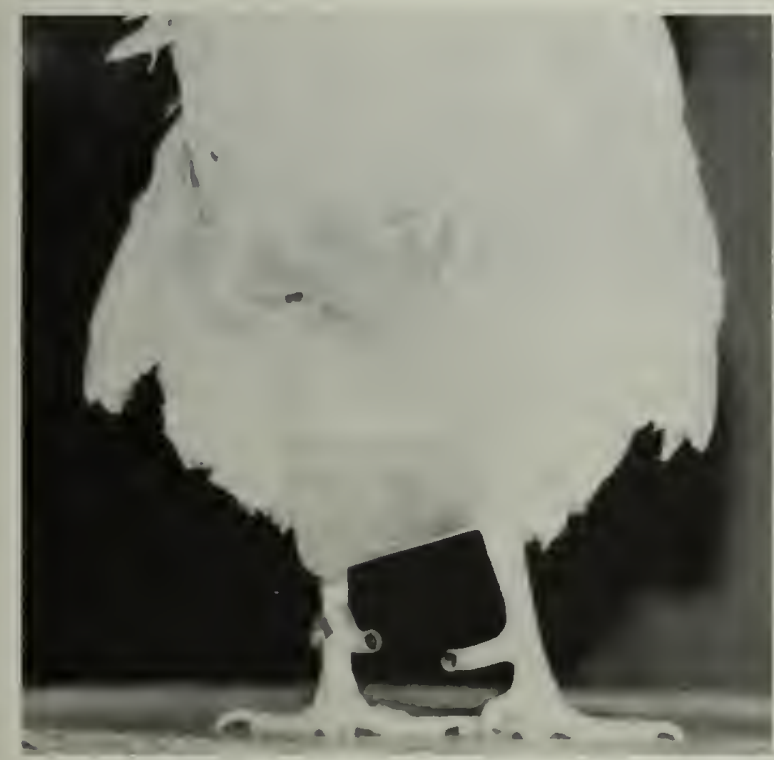

Figure 18. Vue postérieure du sujet muni d'un sac (noter les ergots rognés).

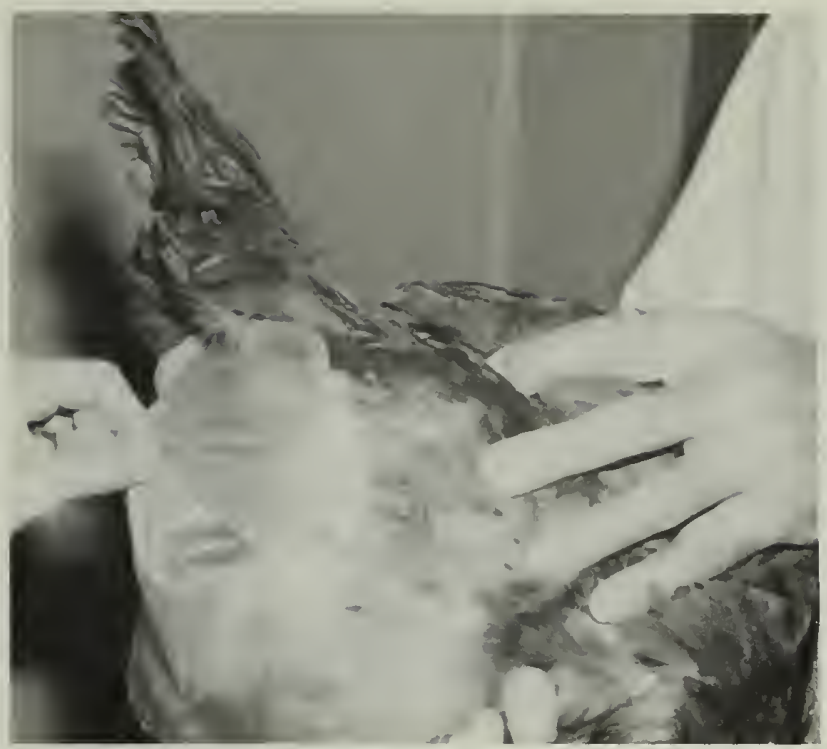

Figure 17. Séparer les cloisons du sac de colostomie (remarquer 1a surface adhésive collée sur le sujet).

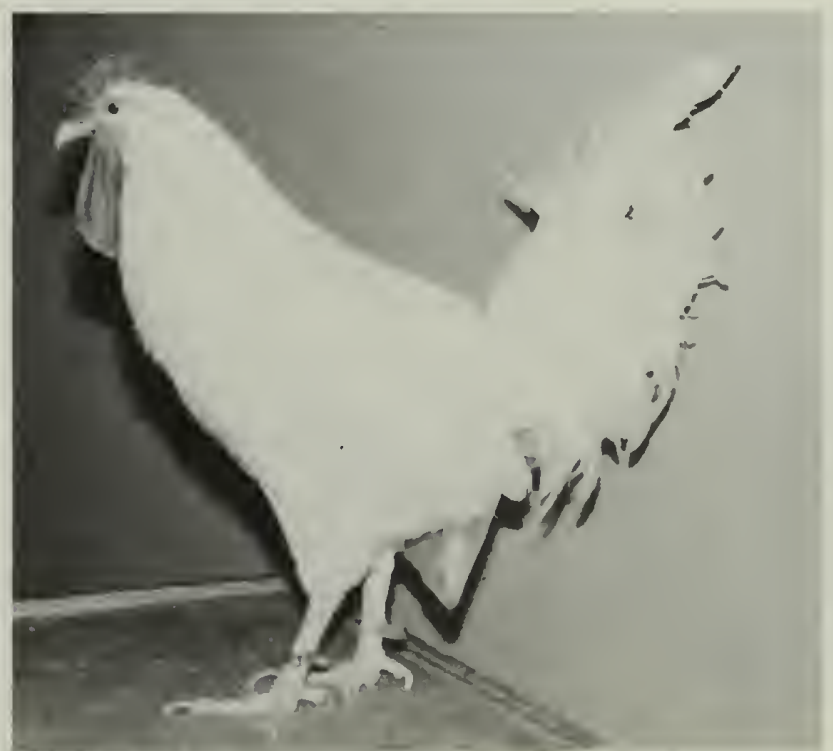

Figure 19. Le sujet muni d'un sac prêt à la mise en cage . 


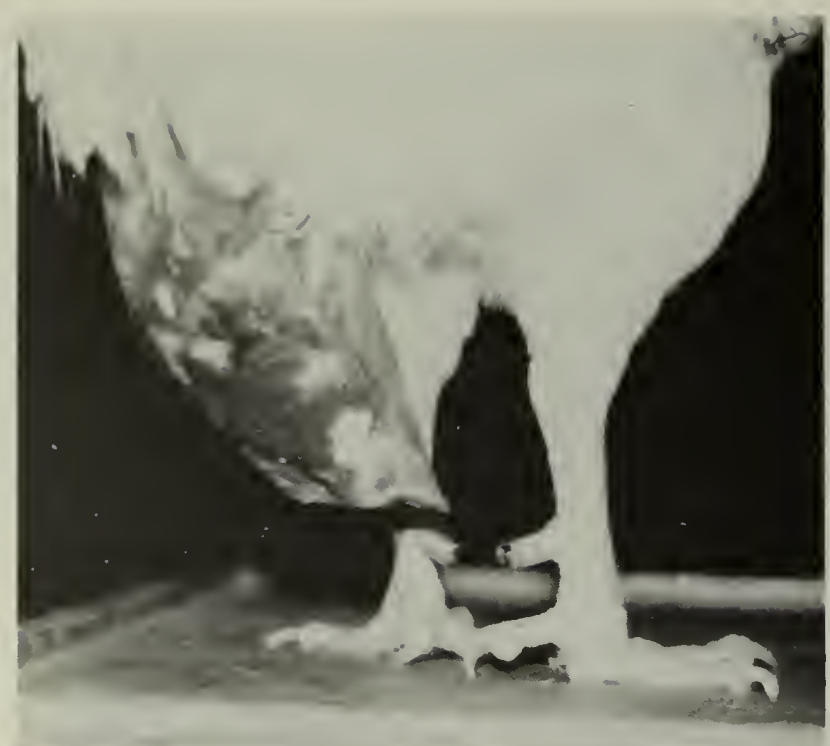

Figure 20. Vue postérieure d'un

oiseau montrant 1 'accumulation de

déjections au bout de 48 heures.

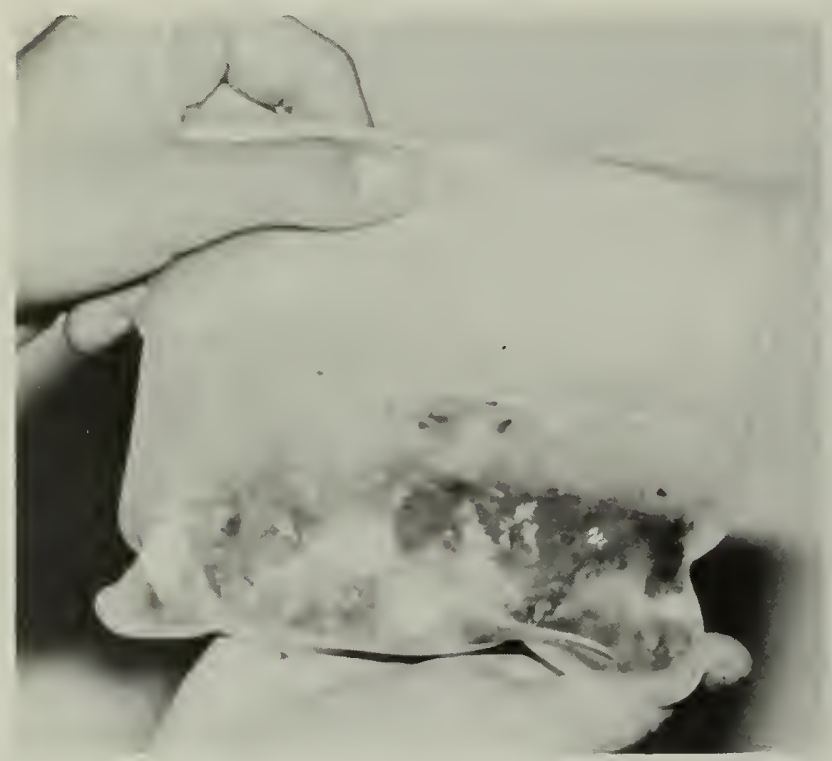

Figure 22. Scellage d'un sac par repli de son extrémité supérieure.

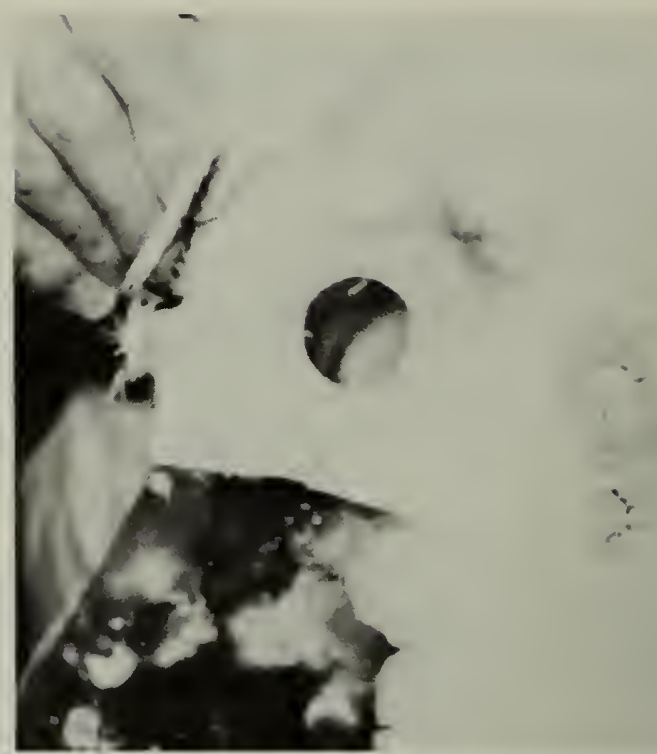

Figure 21. Enlèvement d'un sac de déjections.

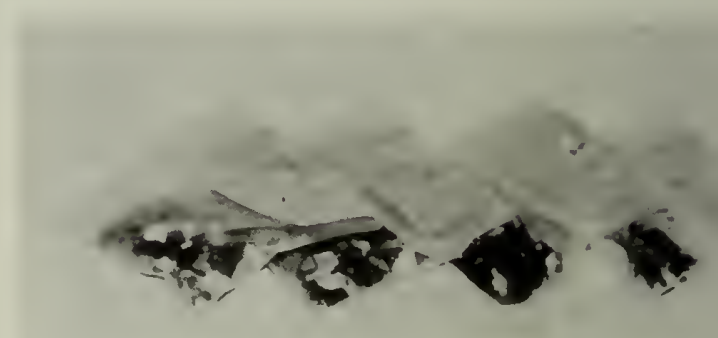

Figure 23. Groupe de sacs prêts pour la conservation et le traitement subséquent. 
mieux vaut les verser dans un autre contenant pour les conserver et les traiter. Les figures 12 à 23 illustrent la méthode à suivre.

Il existe plusieurs marques de sacs de colostomie sur le marché qui semblent posséder une résistance variable. Parmi les sacs testés, celui qui porte le nom de "Coloset (z.O.)", distribué par la Canadian Howmedica Ltd., 90 Woodlawn Road West, Guelph (Ontario) Canada, s'est avéré satisfaisant. Parmi les nombreux adhésifs testés, seuls deux donnent de bons résultats, à savoir Kamar Adhesive, de Kamar Inc., Box 26, Steamboat Springs, Colorado (U.S.A.), 80477, et 3M Scotch Brand Adhesive EC847, de 3M Canada Inc., London (Ontario) Canada, N5V $2 Z 6$.

La méthode est encore à l'étude, mais le présent article la décrit quand même pour stimuler les idées et les suggestions destinées à l'améliorer. Les déjections recueillies dans les sacs de colostomie sont exemptes d'écailles et de plumes, et ne sont pas diluées d'eau au cours de la collecte. Ces sacs permettent de réduire le temps de séchage et d'accroître efficacement la capacité du séchage. Il faut un certain temps pour préparer les sujets et pour fixer et enlever les sacs, mais cet inconvénient est largement compensé par le temps économisé à faire une seule collecte rapide.

\section{Conception et construction des cages}

Les cages utilisées pour loger les coquelets adultes ont les dimensions suivantes: $40,6 \mathrm{~cm}$ de profondeur (de $1^{\prime}$ avant à $1^{\prime}$ arrière), $50,8 \mathrm{~cm}$ de hauteur et $30,5 \mathrm{~cm}$ de largeur. Les figures 24 à 32 décrivent la cage et son assemblage; toutes les dimensions sont en centimètres. L'arrière, le dessus 
et le plancher d'une rangée de 10 cages sont faits d'un seul morceau de treillis métallique d'environ $1,3 \mathrm{~m}$ de largeur $\times 3,05 \mathrm{~m}$ de longueur (fig. 24). Le fil métallique a $2,03 \mathrm{~mm}$ de diamètre (calibre 14). Le treillis est une grille de $5,1 \times 2,5 \mathrm{~cm}$ soudée à chaque coin. Les cloisons internes et les extrémités sont faites du même matériau (fig. 25). L'avant de la cage, également de $3,05 \mathrm{~m}$ de longueur, est fait de fil métallique de $4,11 \mathrm{~mm}$ de diamètre (calibre 8) et est illustré à la figure 26. La porte de la cage est illustrée en détail à la figure 27 qui montre également l'assemblage de la porte et du devant. L'ouverture de la porte de $23 \times 28 \mathrm{~cm}$ permet d'accéder facilement aux cages pour en retirer les sujets.

La figure 28 illustre les devants et les portes fixées au corps de la cage et aux cloisons. La figure 29 illustre l'assemblage des cages. Les cages sont montées en batterie à double étage (fig. 30) et le support de déjections est fixé horizontalement pour tenir les plateaux des collectes des déjections. Le système d'abreuvoir à tétine est monté sur le dessus des cages. Les figures 31 et 32 illustrent les cages prêtes à utiliser. 


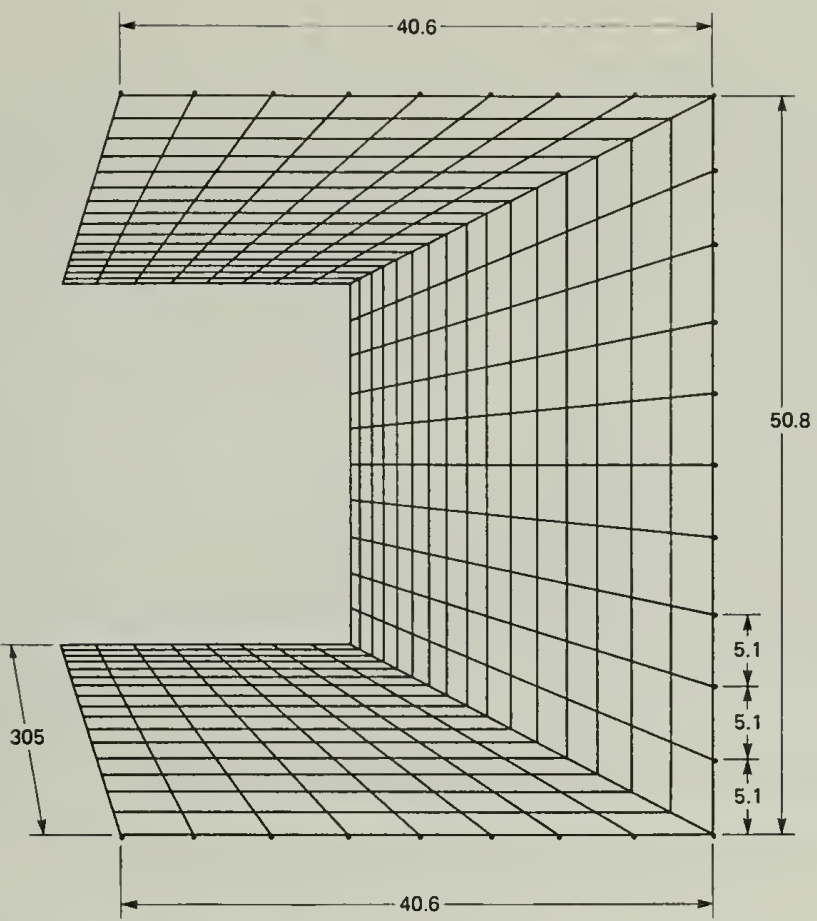

Figure 24. Vue en bout du seul morceau de treillis métallique, plié pour créer le corps (dessus, derrière et fond) d'une rangée de 10 cages.

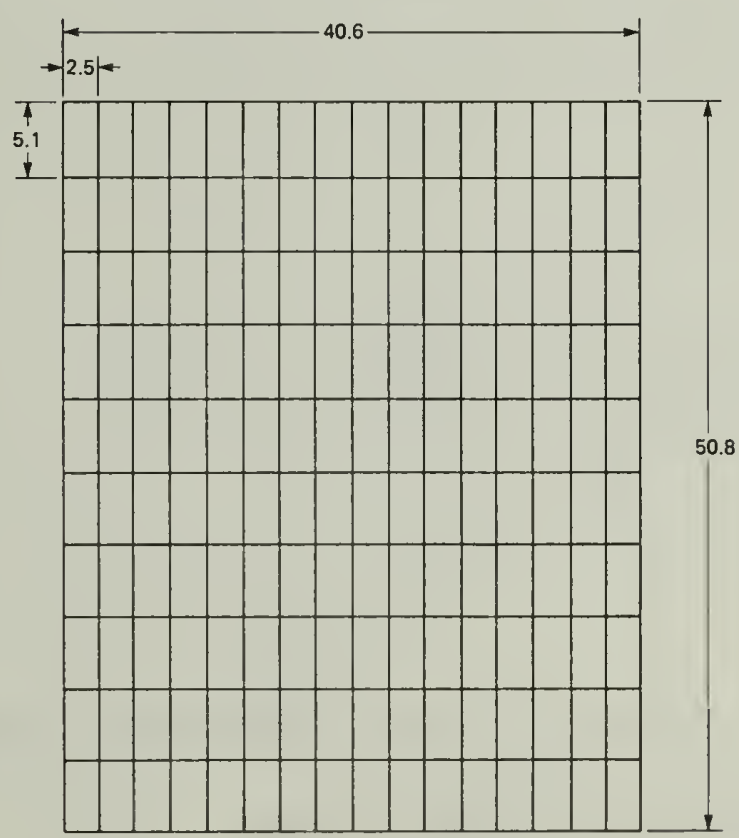

Figure 25. Cloisons ou extrémités d'une cage typique.

Les cloisons sont situées à intervalle de $30,5 \mathrm{~cm}$

et sont soudées en place. 

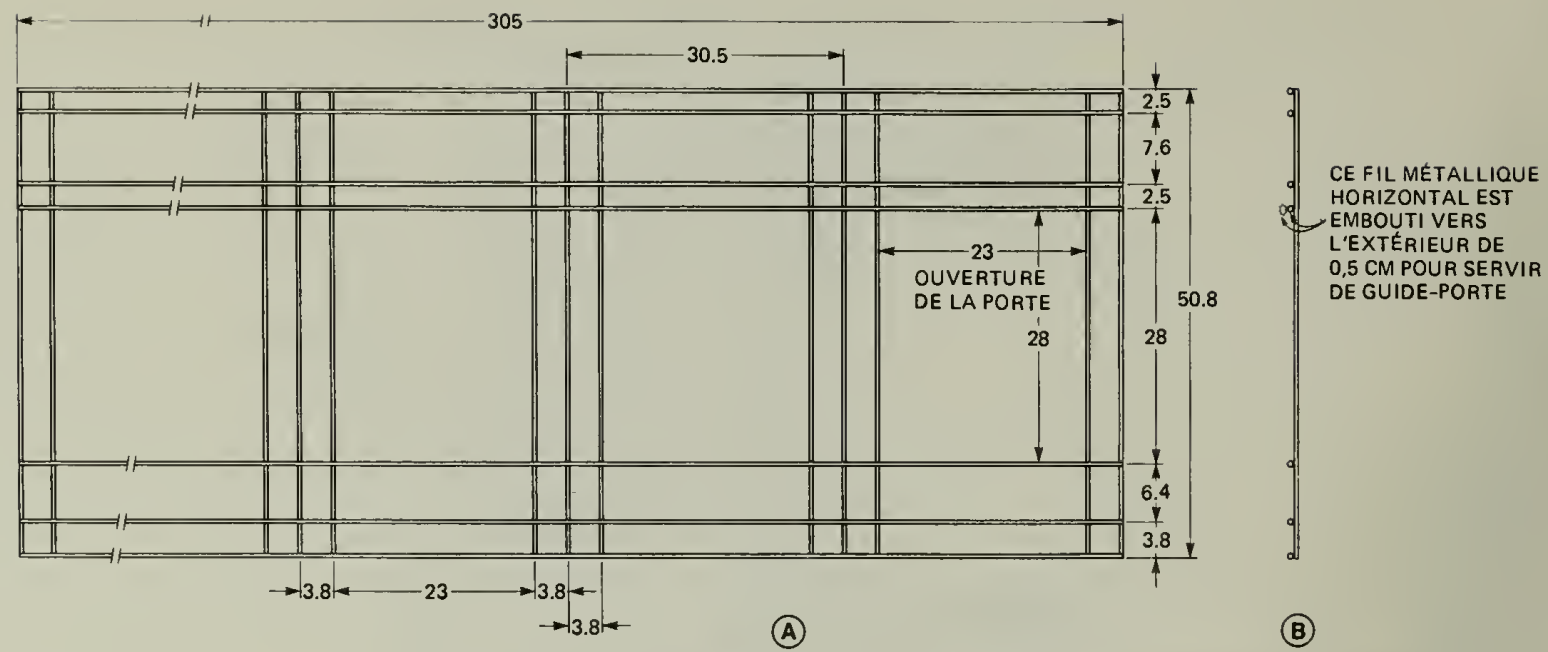

Figure 26. A. Le devant d'une rangée de cages.

B. Vue latérale du devant d'une cage.

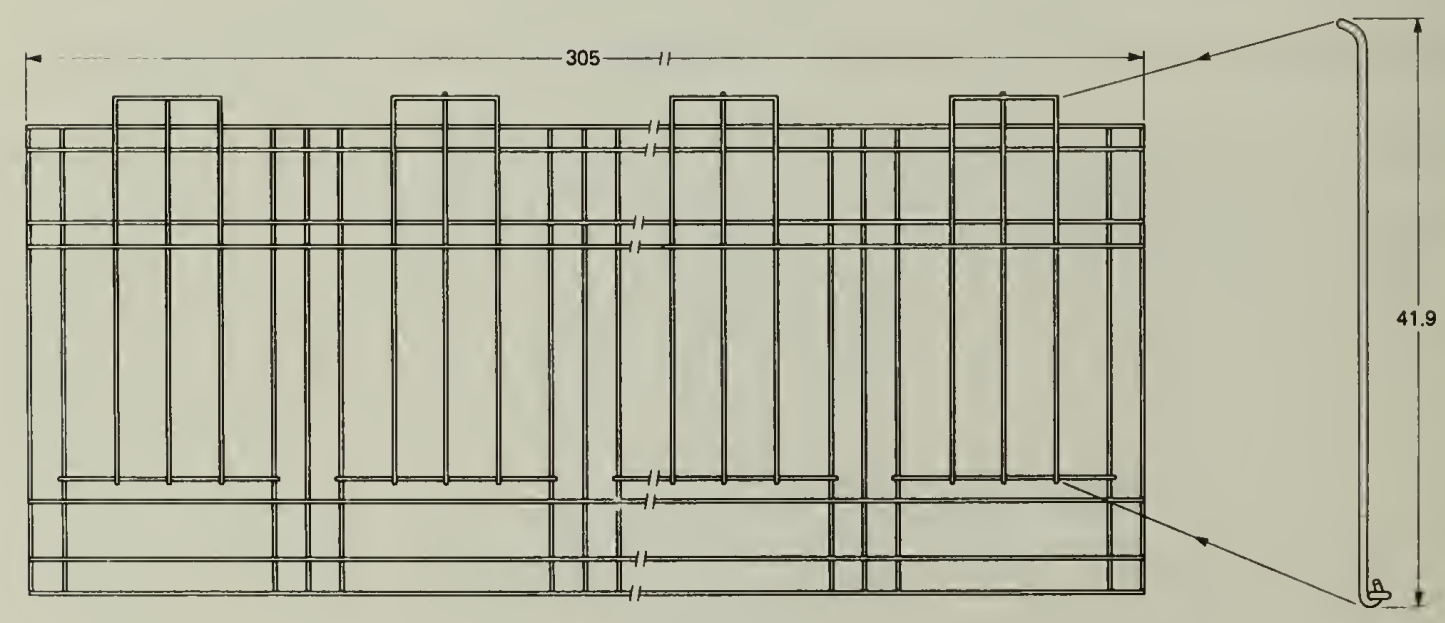

(A)
(B)
(B)
IQUE L'EXTERIEUR DE 0,5 CM POUR SERVIR DE GUIDE-PORTE 


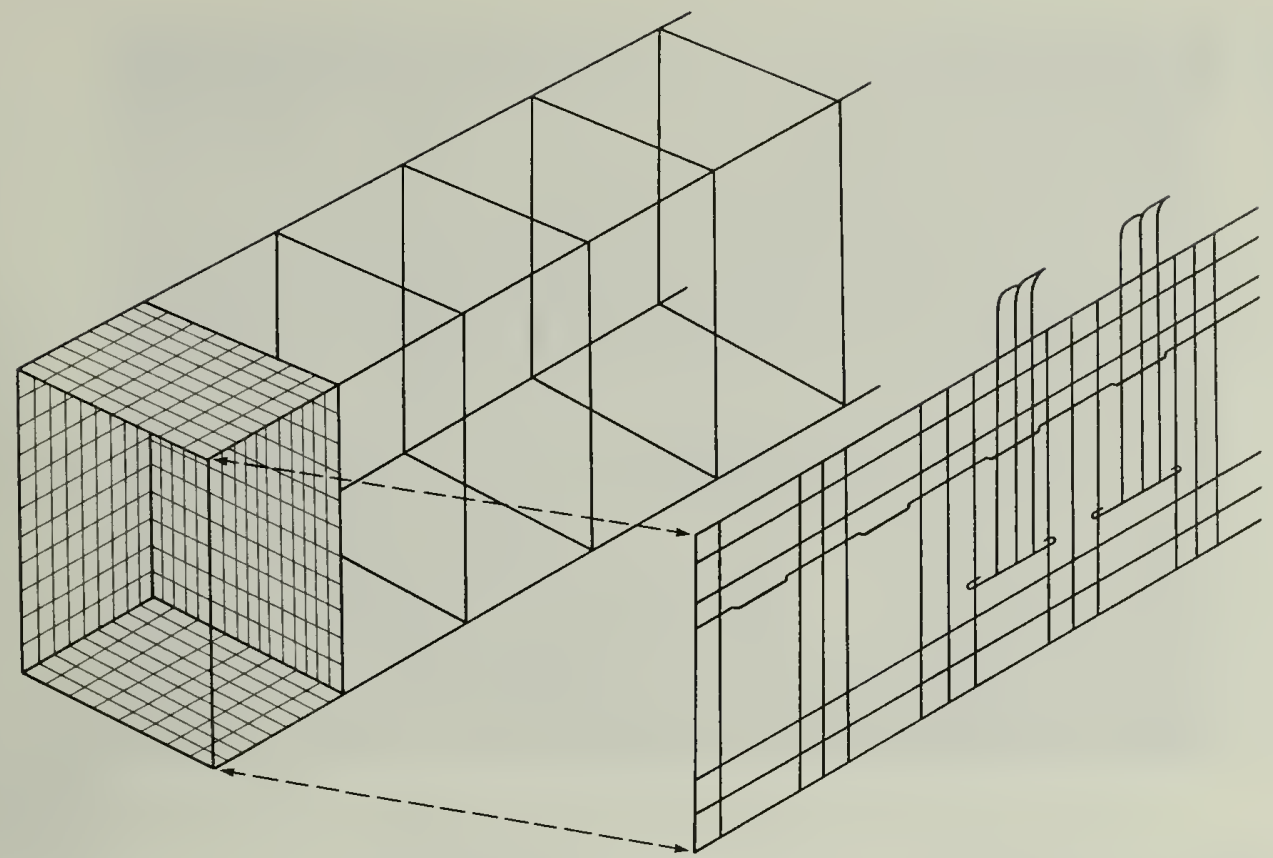

Figure 28. Le rapport entre le corps de la cage, les cloisons et le devant. Pour simplifier, seules 2 portes sont illustrées sur le devant.

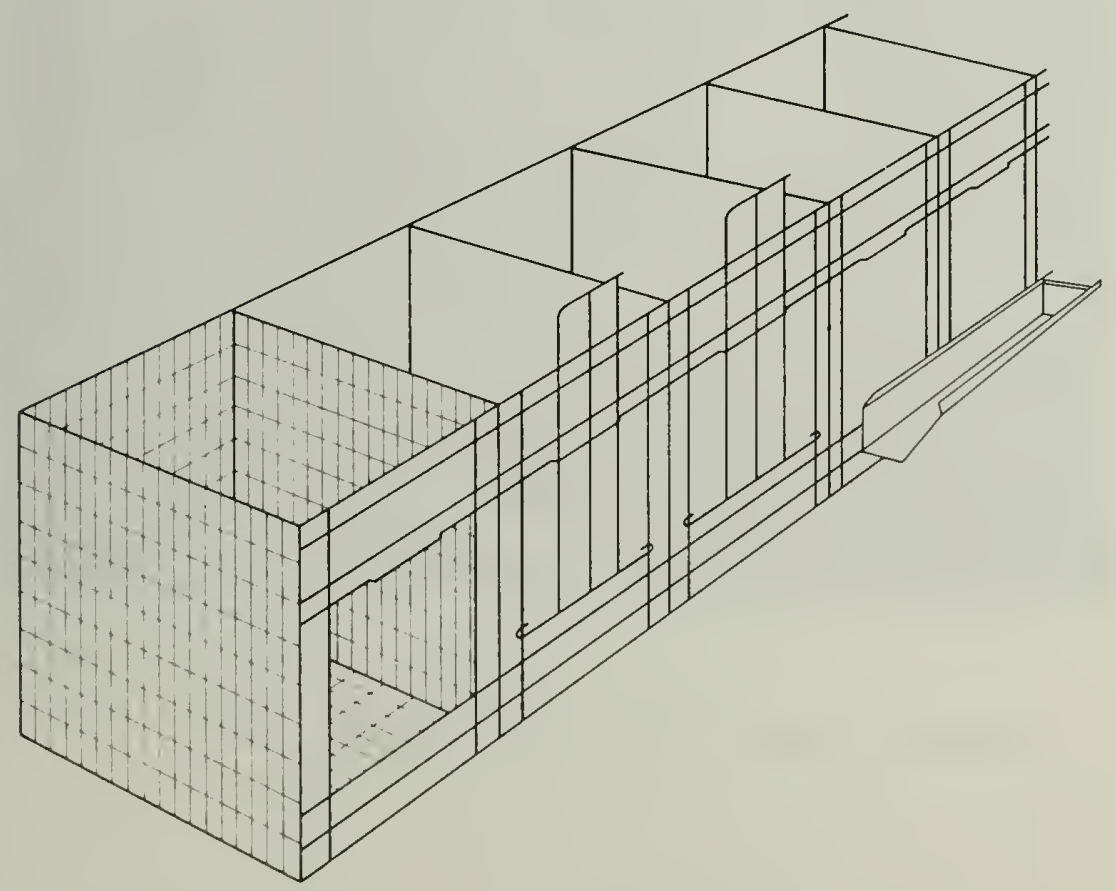

Figure 29. Cage assemblée avec mangeoire. 


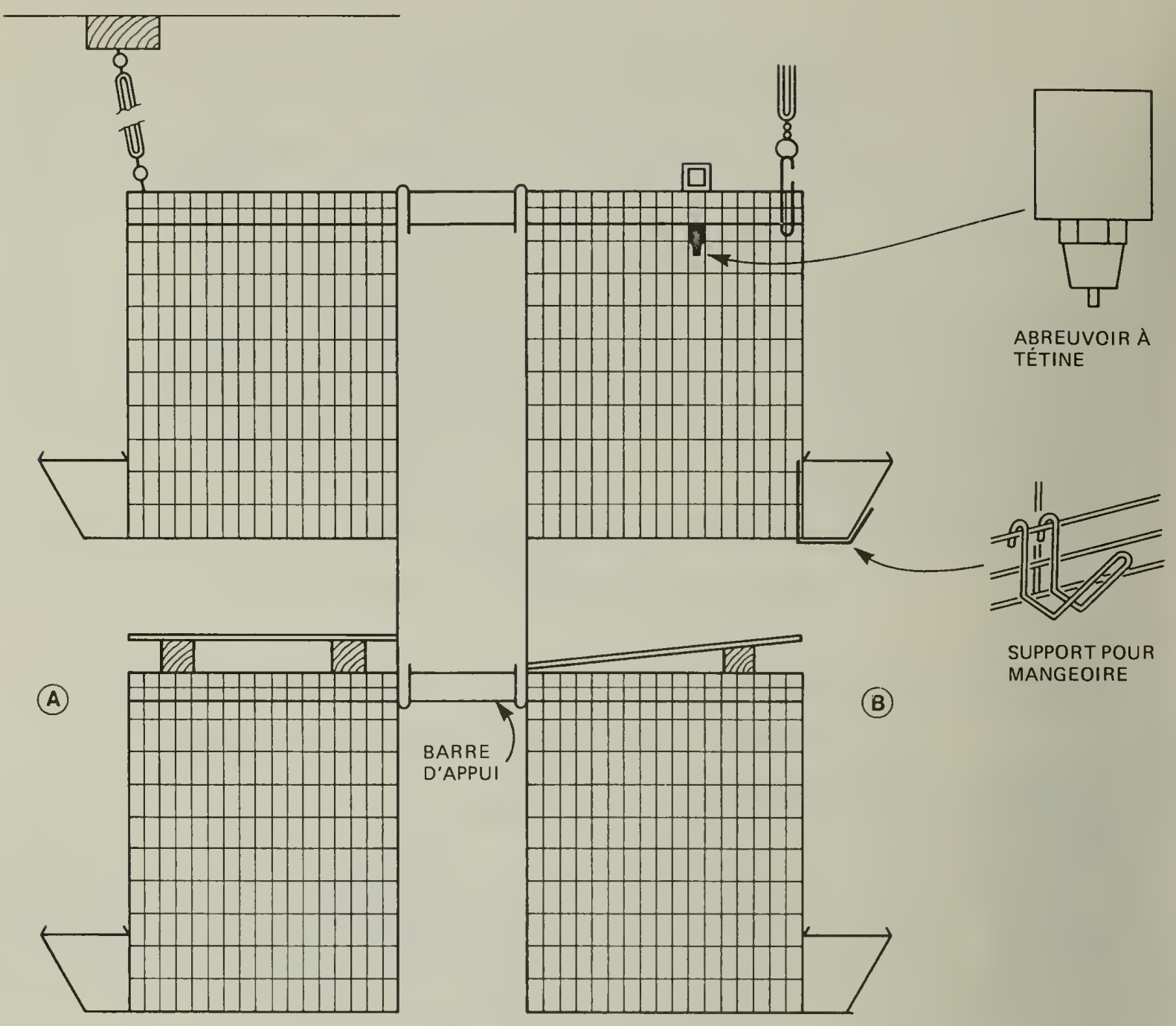

Figure 30. Vue latérale d'une batterie de 4 rangées de cages

à double étage illustrant (A) la position du support servant à retenir les plateaux de collecte de déjections et (B) ce support en position normale. 


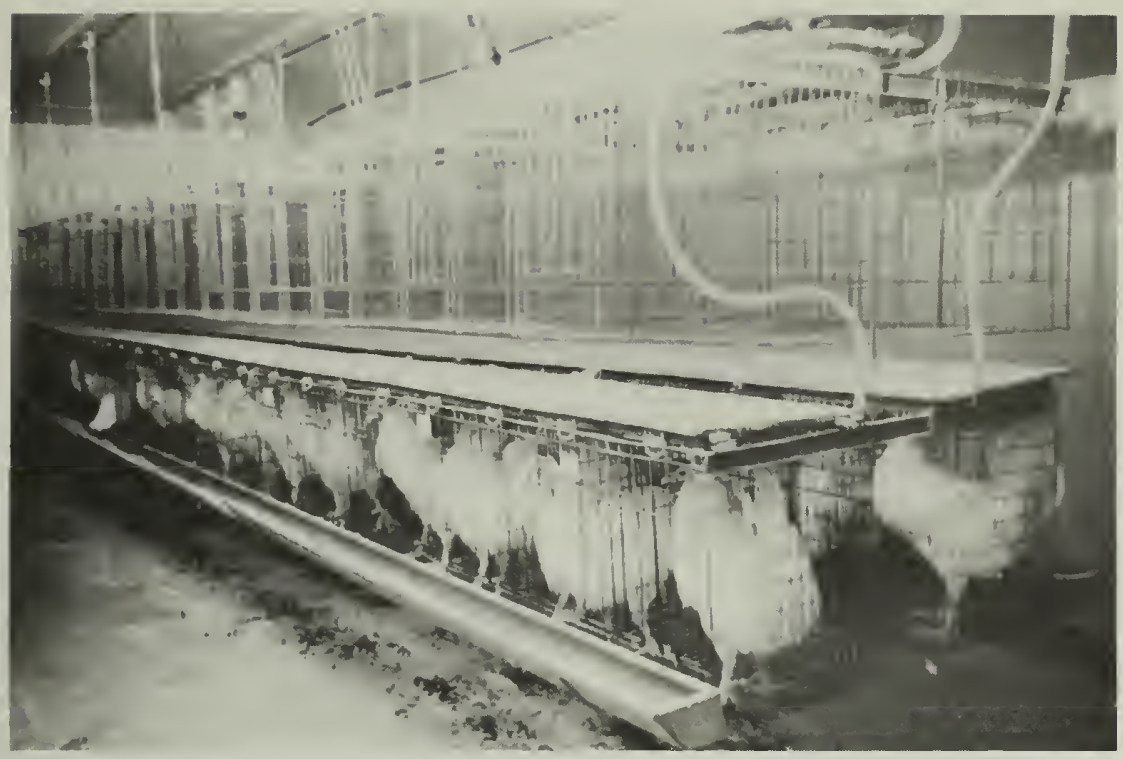

Figure 31. Cages utilisées pour loger les sujets entre les dosages.

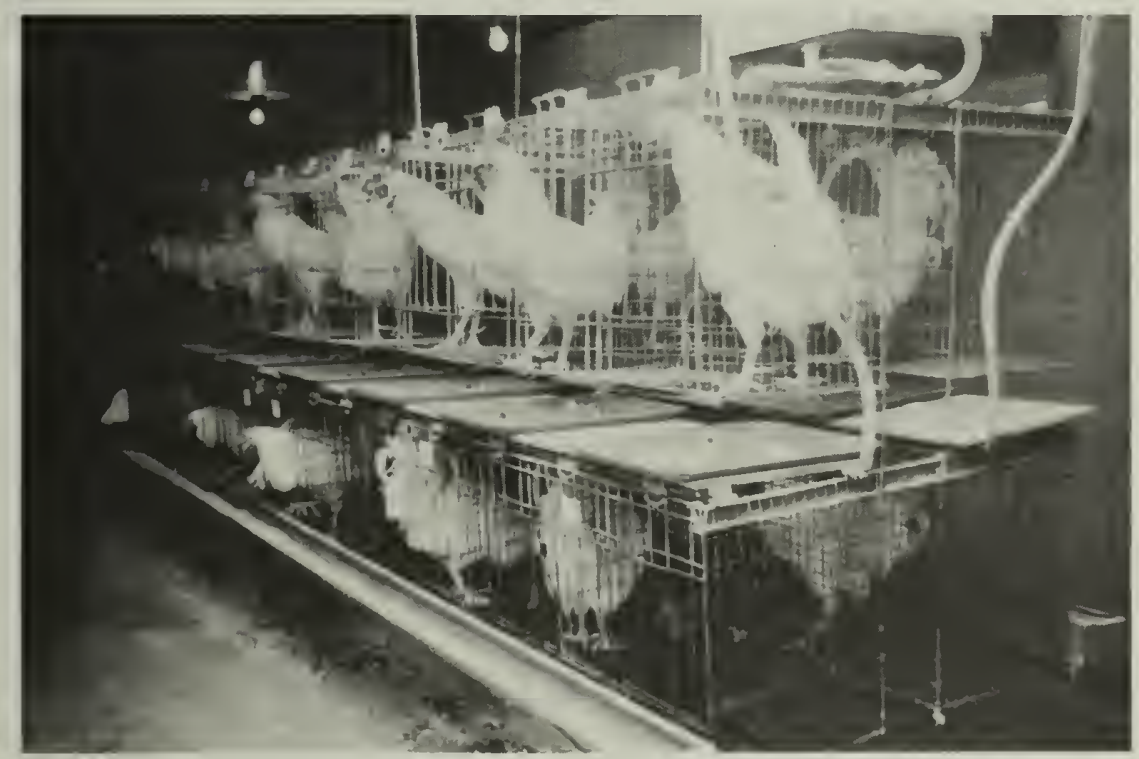

Figure 32. Sujets logés dans les cages de l'étage supérieure et utilisés pour un dosage. 



\section{COMPOSITION DES ALIMENTS}

Les aliments ont été dosés pour l'ÉMV et l'ÉMV ${ }_{n}$ par les méthodes décrites dans la présente publication. Le jeûne était de 24 heures, l'apport alimentaire était de $30 \mathrm{~g}$ de matière sèche ramenée au degré d'humidité atmosphérique et la période de collecte des déjections était de 48 heures. Les données ont toutes été obtenues après la publication d'un tableau antérieur (29), mais quelques données ont paru dans certaines publications de recherche de ce laboratoire.

La plupart des échantillons d'aliments proviennent de sources commerciales, mais une certaine quantité de graines nous a été fournie directement par des phytogénéticiens. Les descriptions des aliments sont parfois moins précises qu'on ne l'aurait voulu, mais les données de l'analyse immédiate aident à identifier leur composition. Le tableau (pages 38 à 48) est incomplet, mais est fait intentionnellement pour permettre l'addition de données à mesure qu'elles deviennent disponibles et pour éliminer les lignes incomplètes en temps voulu.

Le tableau résume les valeurs moyennes de chaque paramètre décrivant chaque échantillon. Il ne s'agit pas ici de présenter des moyennes pour divers groupes d'aliments. Ces moyennes sont facilement calculées, mais peuvent prêter à confusion, en particulier en cas d'inclusion d'un échantillon anormal. Par exemple, un échantillon de tourteau de colza (code $n^{\circ} 485$ ) affichant une teneur en extrait éthéré de $10,18 \%$ est anormal et son inclusion dans l'évaluation des moyennes est discutable. 


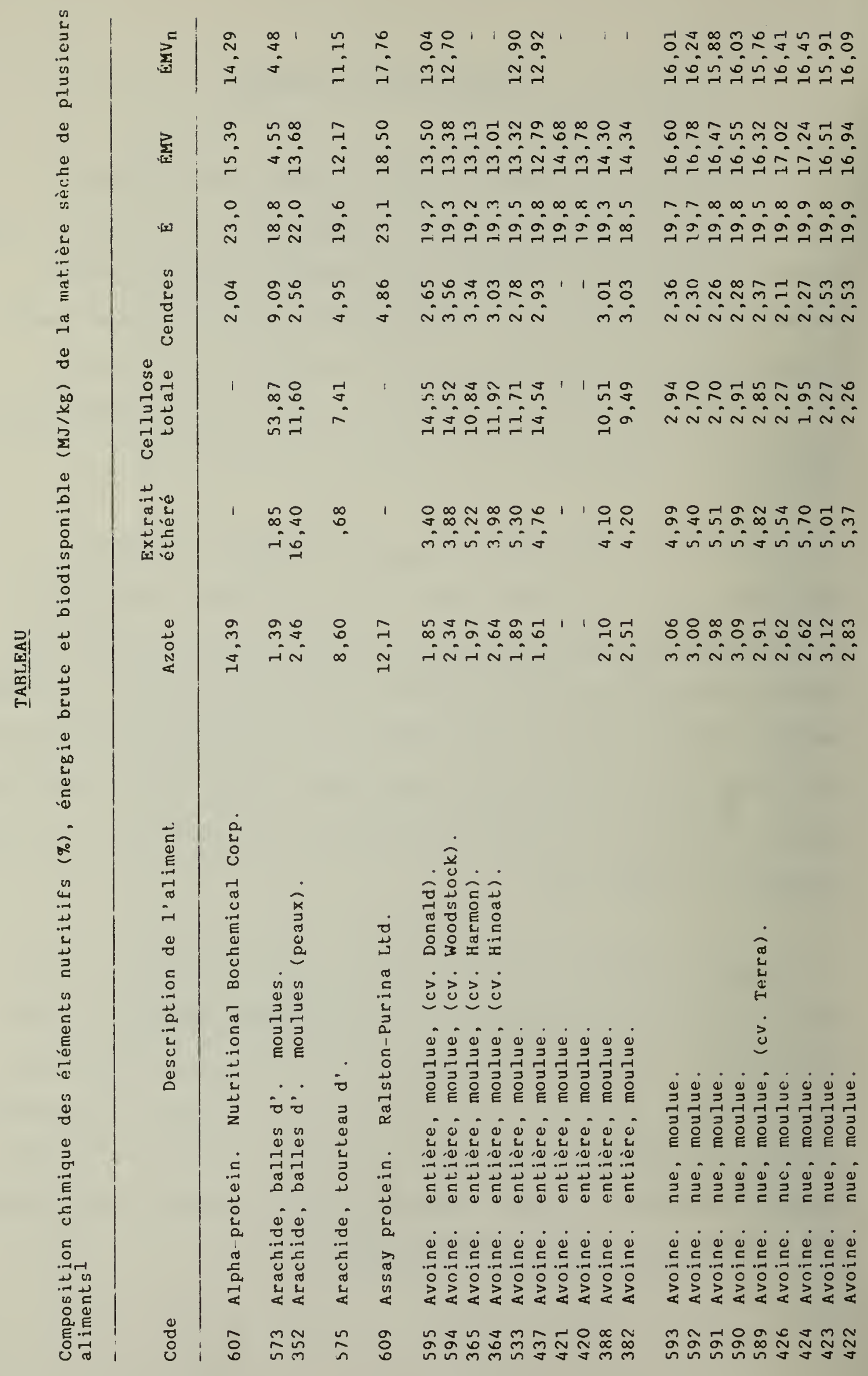




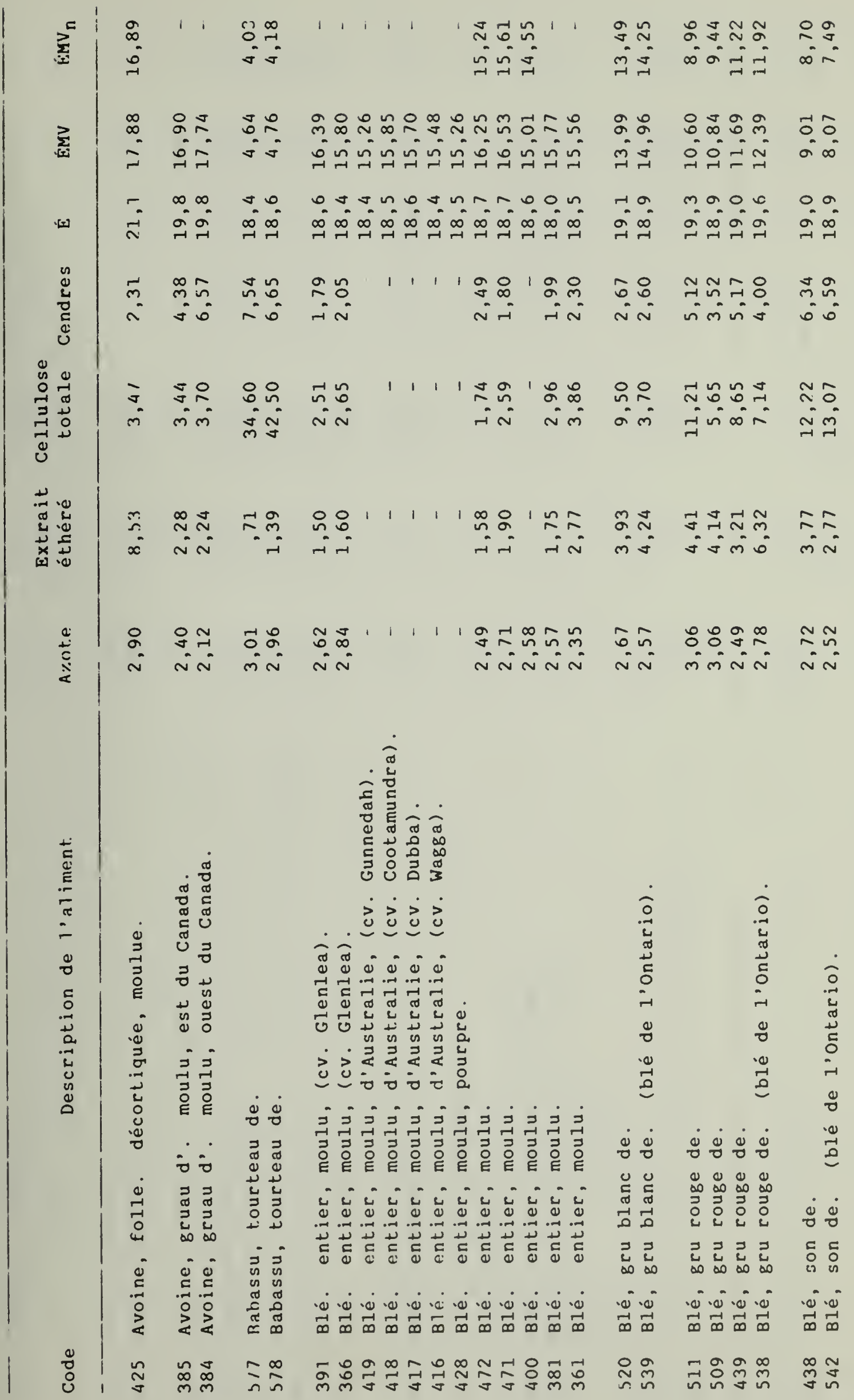




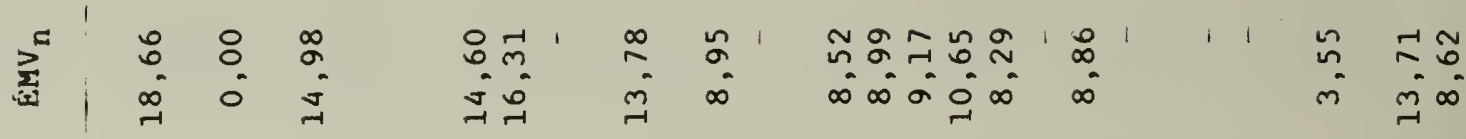

$\sum_{i=1} \mid$\begin{tabular}{lll}
0 & 8 & $\infty$ \\
0 & 0 & $\infty$ \\
\hdashline & $n$ & $n$
\end{tabular}

a $\mid \begin{array}{lll}n & n & n \\ n & n & n\end{array}$

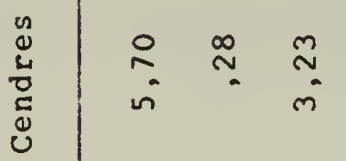

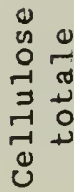

党:

芒

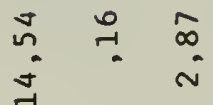

这

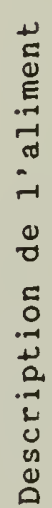

일

$\begin{array}{cccc}0 & 0 & 0 & 0 \\ 0 & 0 & 0 & 0 \\ & \Xi & 0 & 0 \\ 0 & \Xi & 0 \\ 0 & 0 & 0 \\ 0 & 0 & 0 & 0 \\ 0 & 0 & 0 & 0\end{array}$

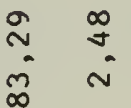

$\stackrel{\sim}{\sim}$

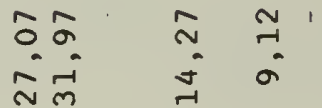

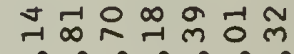

nNíñ

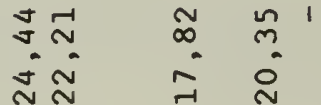

ำกㄴำำำ

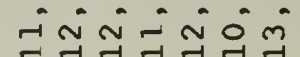

$\stackrel{\infty}{\sim} \stackrel{0}{\sim} \stackrel{\infty}{\sim} \infty$

$\sim \sim$

กํ. Э

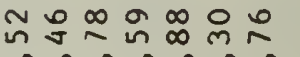

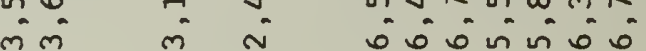

$\underset{n}{\infty} \stackrel{\infty}{\infty}$ ज $\pi$ ก $\approx$

$\begin{array}{ll}0 & 0 \\ 0 & 0 \\ 0 & 0 \\ 0 & 0 \\ 0 & 0 \\ 0 & 0 \\ 0 & 0\end{array}$

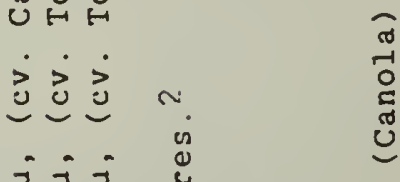

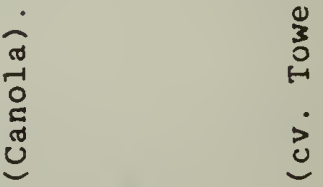

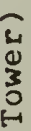

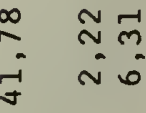

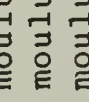

बिं

$\because \cdots$

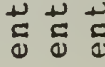

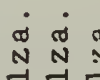

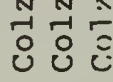

$m$
0
0
0
+0
$\frac{0}{0}$
0
0

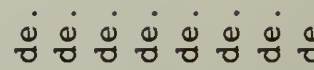

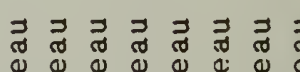

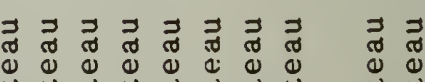

氙芯芯芯芯

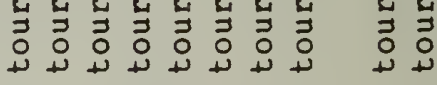

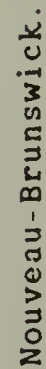

$\therefore$

ic

- 10.0

N

ن

¿

를

ชั

E

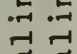

is is

0

岁哠

อ

出苍

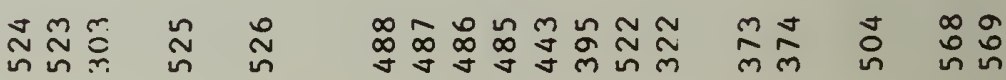




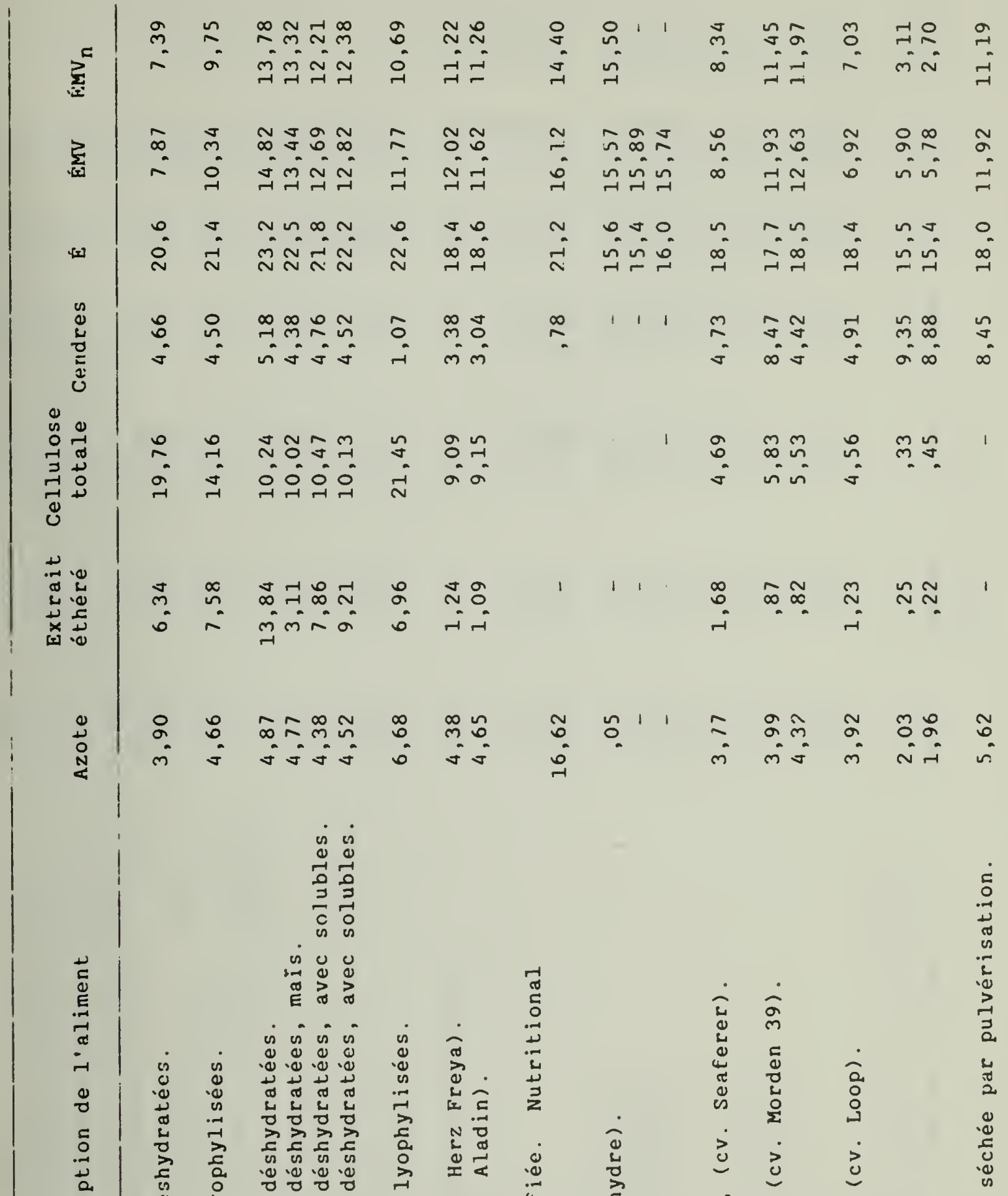

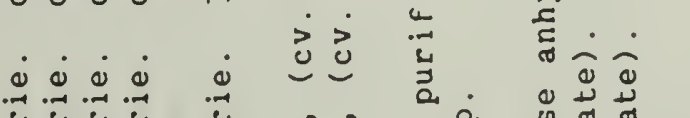

मे

थ

I.

(1)

䒠言

i.

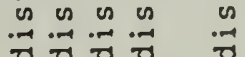

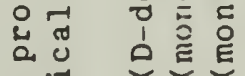

웜

is is

. E

도

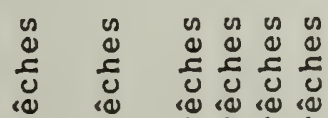

i)

is

थ $\frac{1}{0}$

$+\frac{\pi}{4} \cdot 0$

$\begin{array}{lll}0 & 0 & 0 \\ 0 & 0 & 0\end{array}$

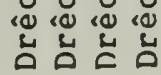

का क्ष

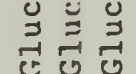

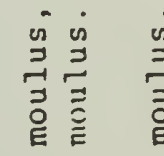

这 它

$\dot{0} \ddot{0} \ddot{0}$

1.

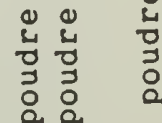

¿ั

กิ

융우웅

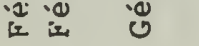

踏的品 


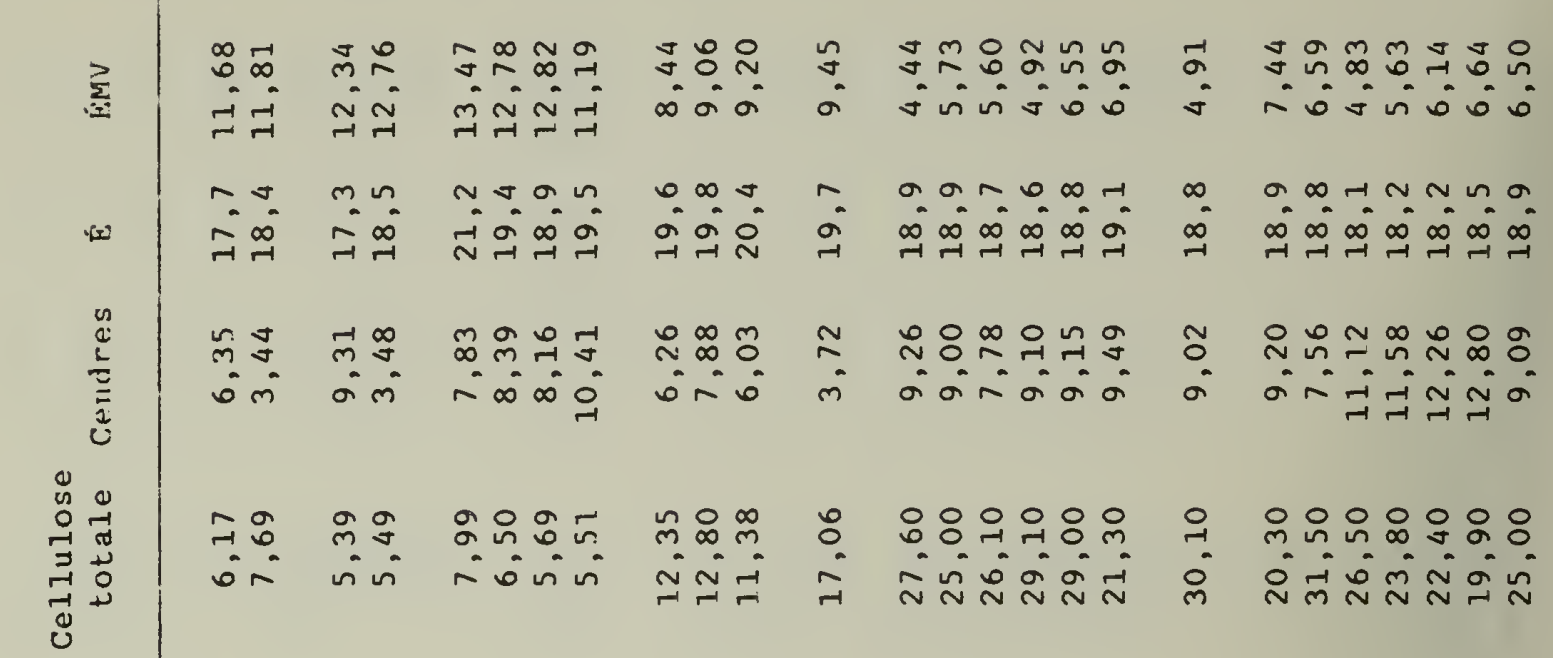

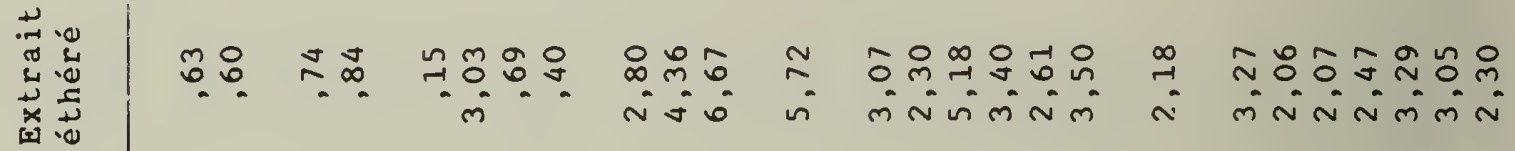

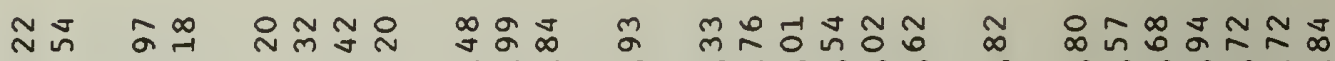
ज

ㅇำ $\exists \cong \stackrel{N}{N}$

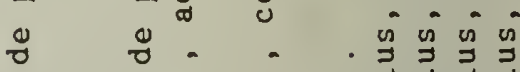

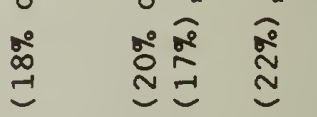

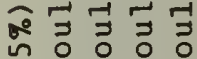
in 约 㤩 E

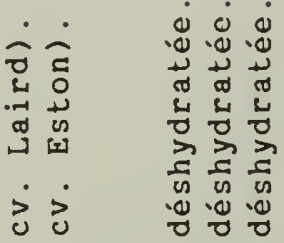

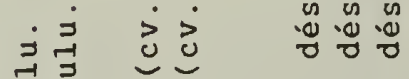

in is $\dot{0} \dot{0} \dot{0} \dot{0}$

1 0100 ช แ.

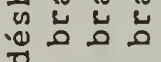

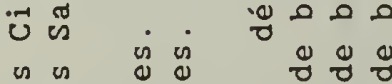
赵党 i 000 ว ส $+$

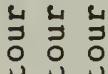
33 गु

$\sum_{i=1}^{\infty} \sum^{-}$

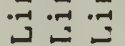

if in is is in is in

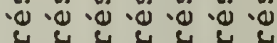
E E E E E E $\rightarrow-1+101-1$

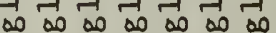

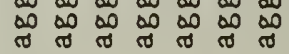

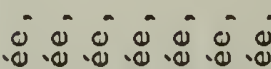
๘

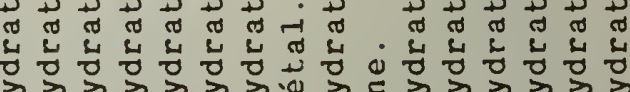
त

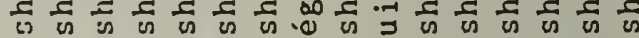

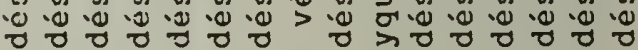
. E E E E E

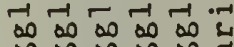

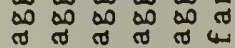

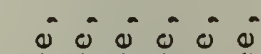

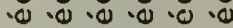

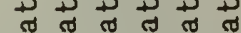
ง

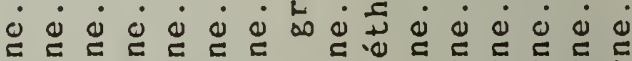

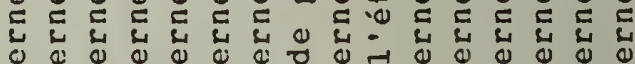

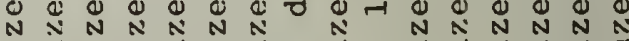

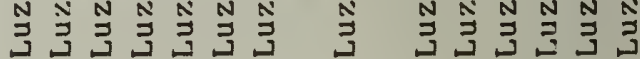

0 un $\infty \infty a-\infty a 0-10$

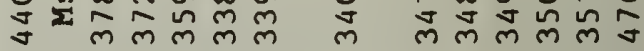

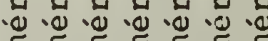

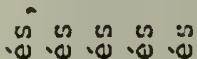




\begin{tabular}{|c|c|c|c|c|c|c|c|c|}
\hline$\sum_{i=1}^{5}$ & 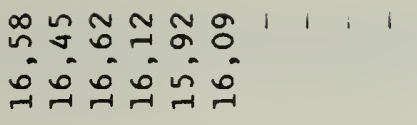 & \begin{tabular}{ll}
$n$ & $\infty$ \\
\hdashline & 0 \\
0 & 0
\end{tabular} & $\begin{array}{l}\tilde{a} \\
\tilde{\approx} \cong\end{array}$ & $\begin{array}{l}8:-1 \\
00 \\
\infty=10\end{array}$ & $\begin{array}{l}\infty \\
\infty \\
0\end{array}$ & 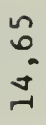 & $0_{0}^{0}$ & $\begin{array}{l}-100 \\
\stackrel{n}{n}=\end{array}$ \\
\hline 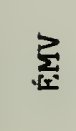 & 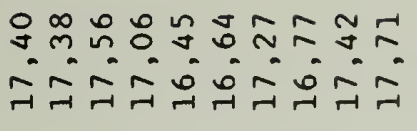 & 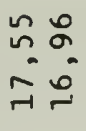 & $\begin{array}{l}m \infty \\
\sigma \\
\approx=-1\end{array}$ & 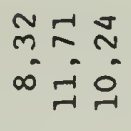 & $\underset{\infty}{\infty}$ & $\stackrel{\sim}{n}$ & $\begin{array}{l}\infty \\
c \\
0 \\
0 \\
-1\end{array}$ & 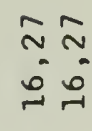 \\
\hline 42 & 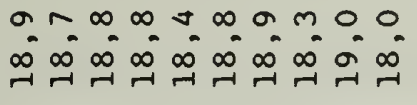 & $\ddot{n}$ & $\stackrel{\infty}{n}$ & क חं & $\underset{\sim}{\sim}$ & $\stackrel{\infty}{\infty}$ & $\stackrel{\infty}{\infty}$ & $\begin{array}{l}00 \\
\approx \approx\end{array}$ \\
\hline 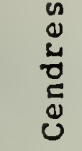 & 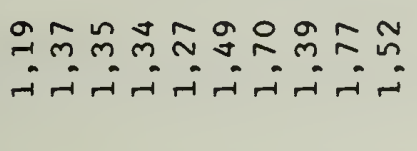 & น̊. & $\stackrel{ }{?} \underset{\sim}{\sim}$ & $\hat{m}$ & : & m & $\stackrel{\infty}{n}$ & $\begin{array}{l}-70 \\
0 \\
\sim\end{array}$ \\
\hline ن & 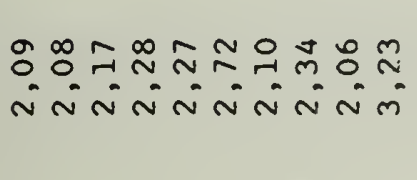 & $\vec{J}$ & 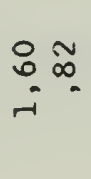 & 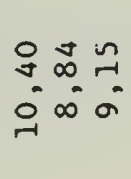 & $\stackrel{0}{\sim}$ & $\infty$ & $\begin{array}{l}\infty \\
\infty \\
\sim\end{array}$ & 1 \\
\hline
\end{tabular}

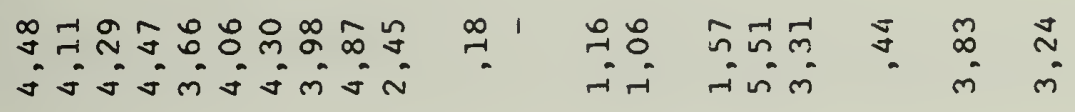

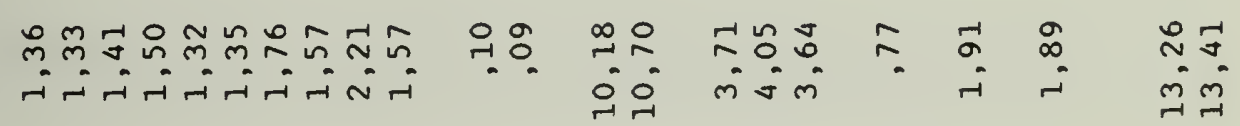

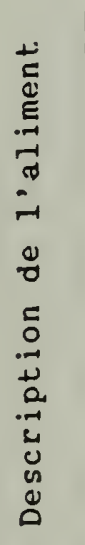

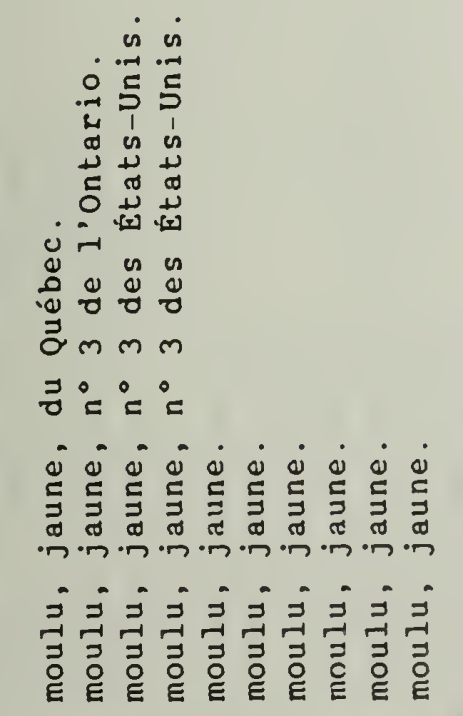

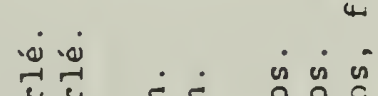

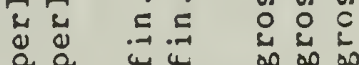

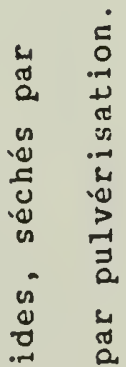

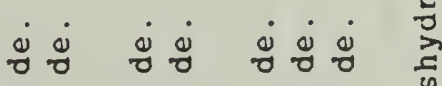

0

도

ᄃᄃ 5

苛武节

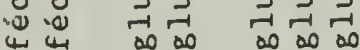

is is is is is is is is is is

in

is in

$-i$

मी

$\Sigma \frac{\pi}{\Sigma} \frac{\pi}{\Sigma} \frac{\pi}{2} \frac{\pi}{2} \frac{\pi}{\Sigma} \frac{\pi}{2} \Sigma$

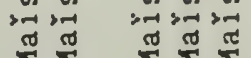

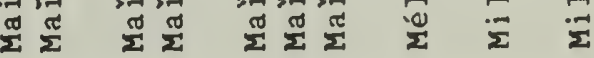

in en

क⿻

$\pm \infty$

究

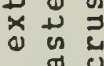

西

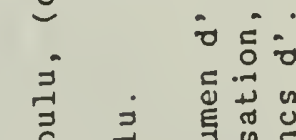

ב⿱一⿻上丨

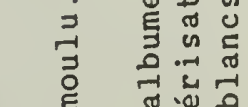

० ह त लू

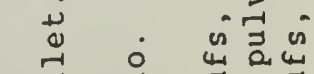

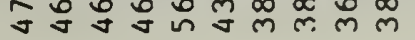


$\sum_{i=1}^{5}$

นึกสำ

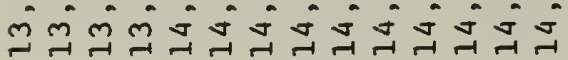

$\infty$ m $\infty \infty \infty$

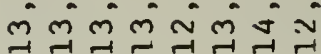

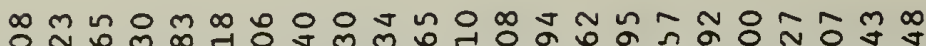

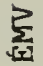

অं山

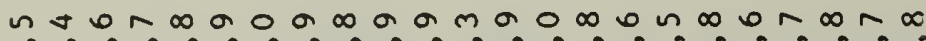

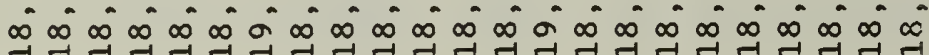

نَّ

$\stackrel{4}{\text { in }}$

$\stackrel{\sim}{=0}$

草

ब1

$\stackrel{0}{+}$

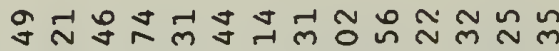

- .

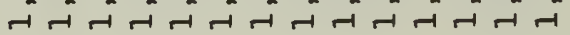

gำ

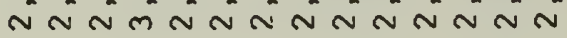

잉ำ

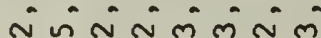

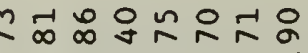
NัN

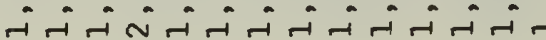

(1)

กิ $\stackrel{\infty}{\sim}$ ผ

i $i$ i i i

-

๓

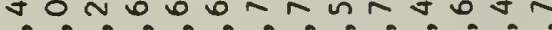

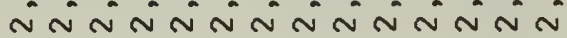

$\infty m \sim m \infty \sim \infty$ 1. $\infty, \infty, \infty$ NNNNNNNN g o g g g

लंभिं

भी

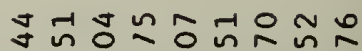

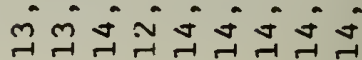

$\checkmark N m \checkmark n N N m$ $\infty \infty_{-1}^{\infty} \infty \infty \infty \infty \infty$

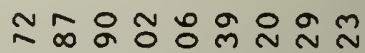
NंNंM

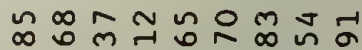
n

$\exists$ ต i- $-1-i-i-i$

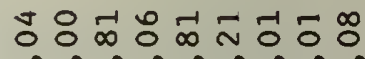
NNANANNNNN

○๊

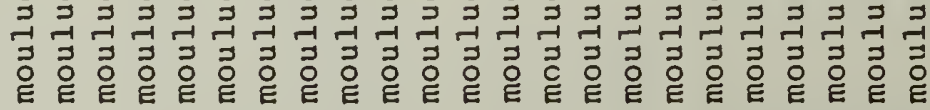

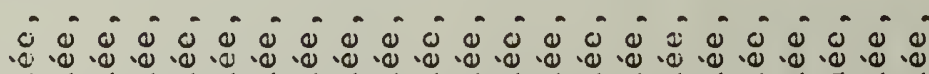
䓅

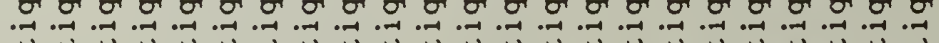

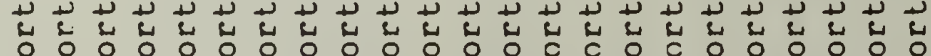
이이

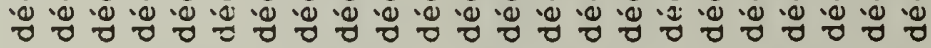

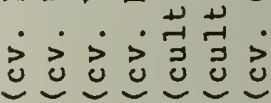

o 0000000

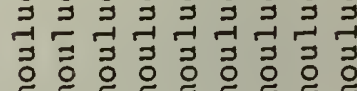
E E E E E E E

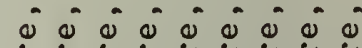

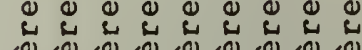

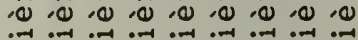

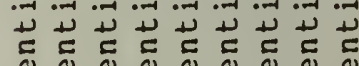

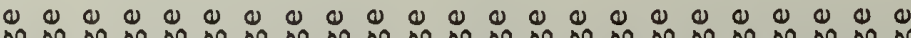

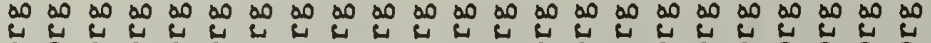

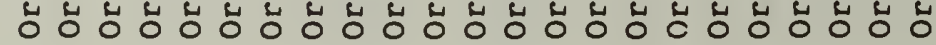

0000000000

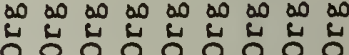
क

n n

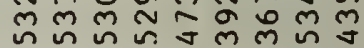




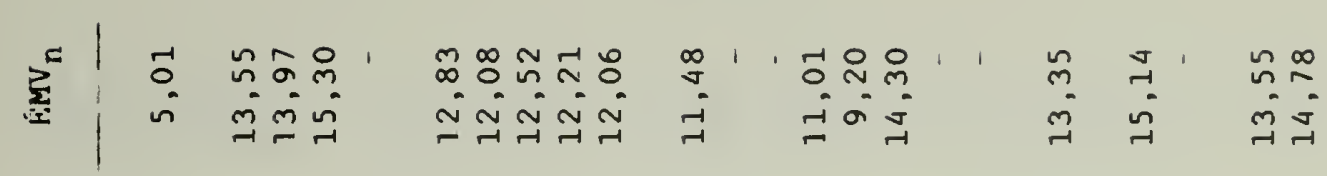

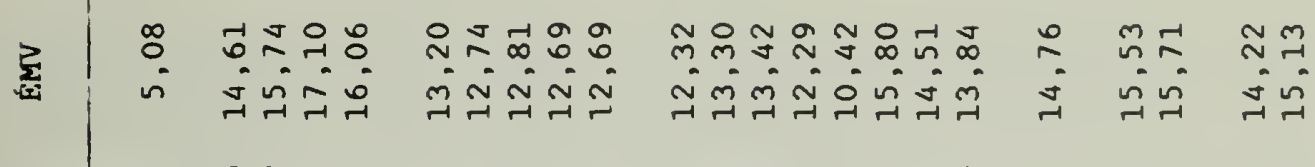

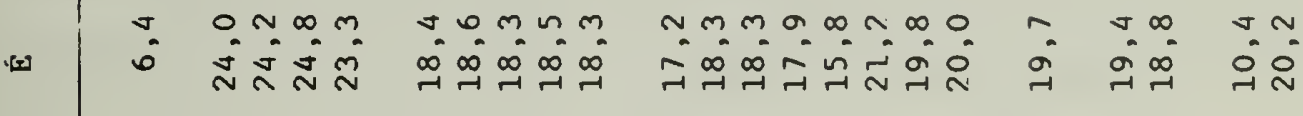

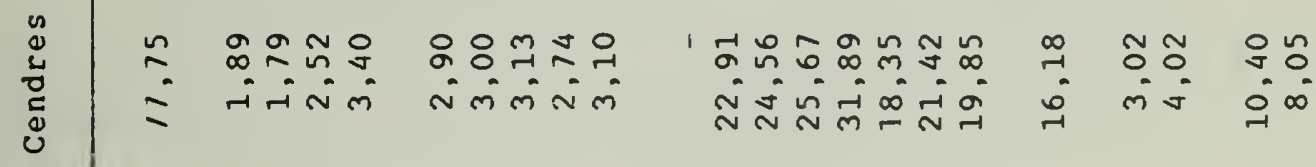

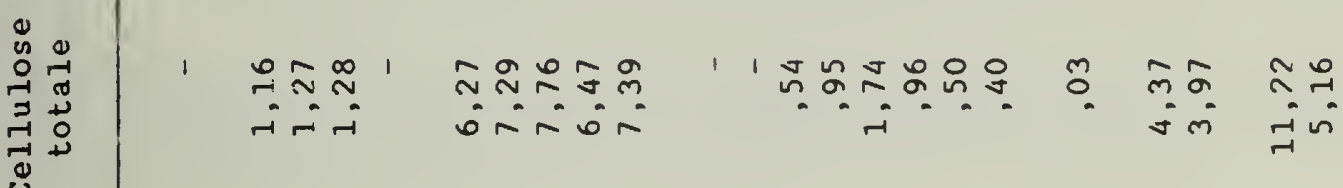

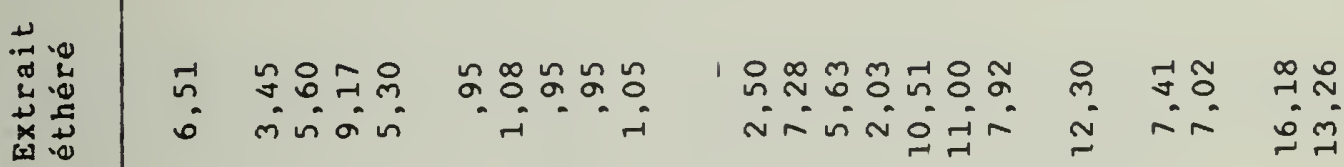

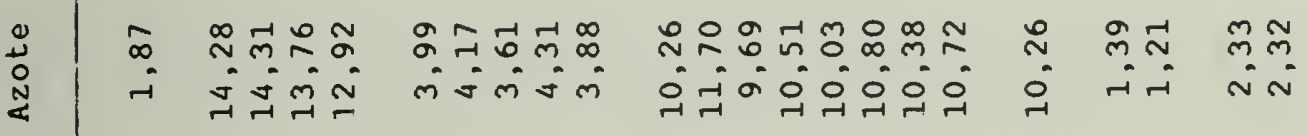

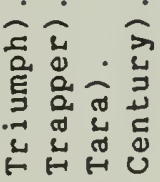 \\ ये己}

$\sin \frac{0}{0}$

क कृ

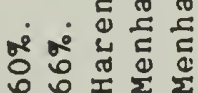

is is is is is

$\exists \exists \exists \exists$

$\dot{0} \ddot{0} \dot{0}$

可

$\dot{0} \dot{0} \dot{0} \dot{0} \dot{0} \dot{0} \dot{0} \dot{0}$

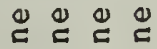

i० ${ }^{\circ}-$

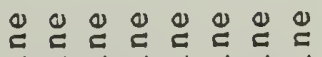

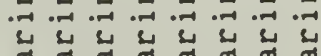

बत त

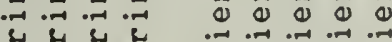

芹艺艺 芹

is is is is

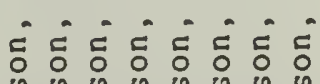

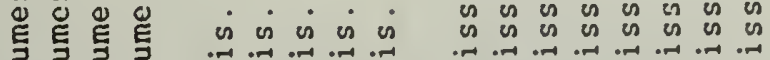

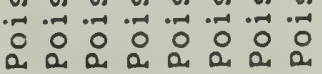

웅 웅

告

$\partial$

:

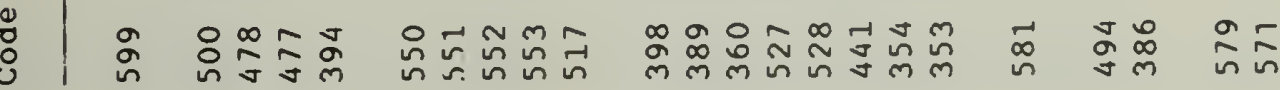

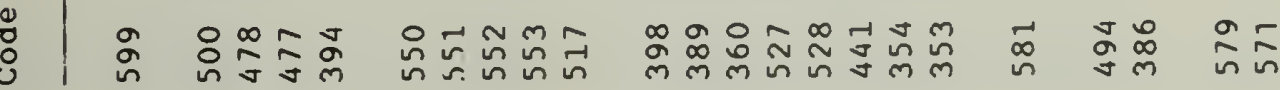

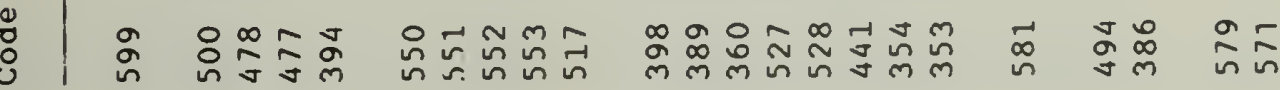

$\ddot{\oplus}$

(n)

峁

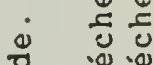

- i :

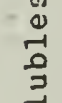

岁

د)

ปே ฮั वึ

도 응

थ n in in

总 总 N N

a a 


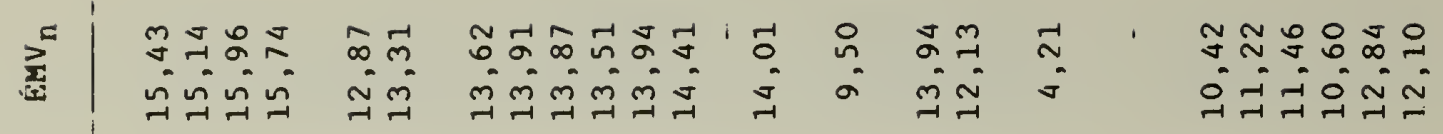

$\sum_{[:[1]}$

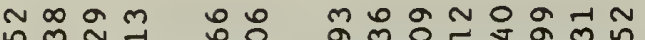

ก.? 0ำ

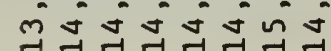

[s:

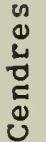

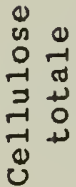

$\pm$

แ.

莫

|

|

กิำㅇำ घूa

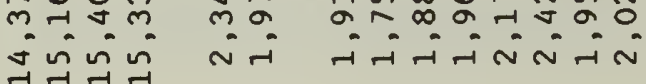

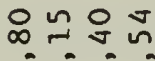
nก $\stackrel{m}{\sim} \stackrel{\infty}{\sim} \stackrel{\infty}{m}$ กั: $\underset{\substack{\infty \\ \rightarrow-1}}{\infty}$

$\stackrel{\infty}{\infty} \underset{\sim}{\infty} \stackrel{\infty}{\sim} \underset{\sim}{\infty} \underset{-1}{\infty} \stackrel{\infty}{\infty} \stackrel{\infty}{\sim} \stackrel{\infty}{\sim}$

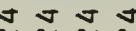

$\infty$

0 nin

ปัก

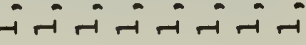

nก

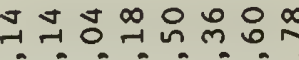

लmंm

-1
0
No

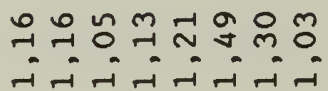

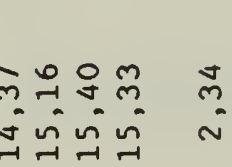

○ $\infty \infty \infty$

$\sim \sim$

$m m \sim m m \backsim v$

$\sim n \infty$

$\infty \overbrace{\infty}^{\infty}$ กิ

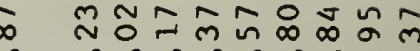

$\infty$
$\infty$
$\cdots$

$\infty \approx \sim-1$

$\cong$ in

$\stackrel{m}{\infty}$

o

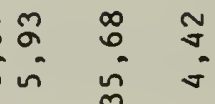

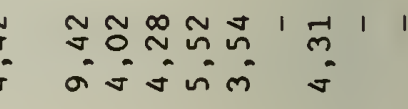

in

in

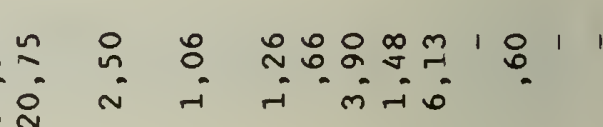

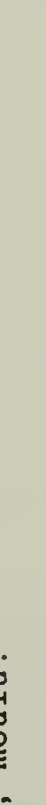

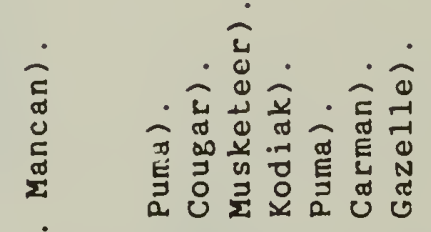

은 N

\section{$\simeq \infty$}

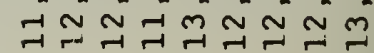

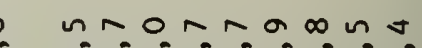




\begin{tabular}{|c|c|c|c|c|}
\hline$\sum_{i=1}^{5}$ & 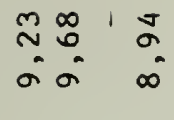 & 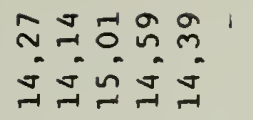 & 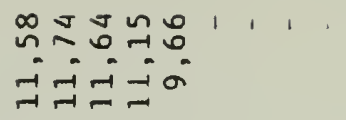 & $\begin{array}{l}m \\
m \\
m \\
\dot{-1}\end{array}$ \\
\hline$\sum_{.52}^{2}$ & 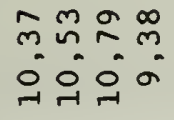 & 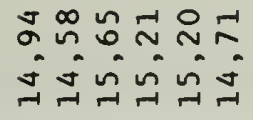 & 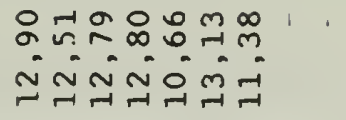 & $\begin{array}{l}0 \\
0\end{array}$ \\
\hline لs[أ & 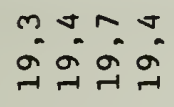 & 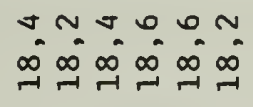 & 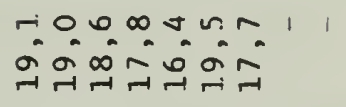 & $\begin{array}{l}\sim a \\
\sim \sim\end{array}$ \\
\hline Ũ & $\begin{array}{l}0 \\
0\end{array}$ & 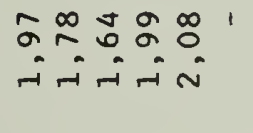 & 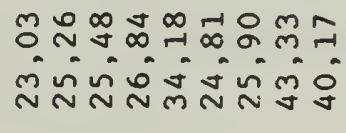 & mic \\
\hline$y$ & $\begin{array}{l}-10 \\
\infty \\
\sim\end{array}$ & 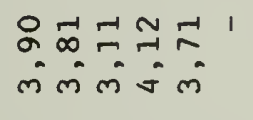 & 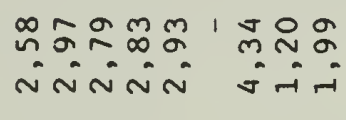 & $\begin{array}{ll}\infty & 0 \\
0 & 0 \\
\sim & \sim\end{array}$ \\
\hline
\end{tabular}

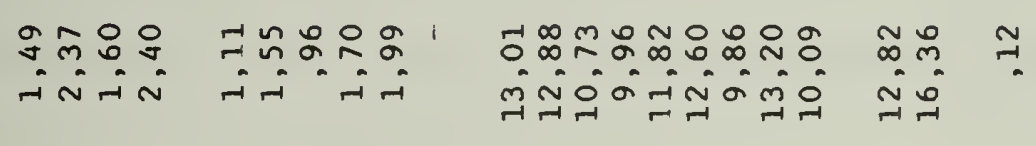

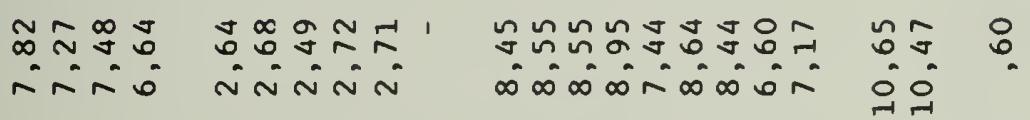

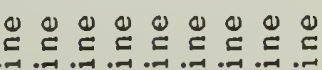

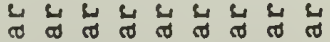
४⿻

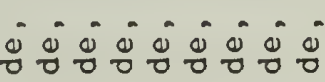

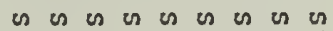

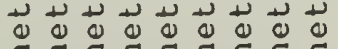

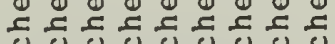

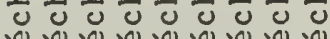

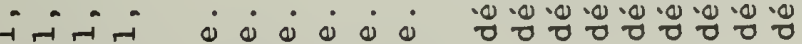
$\stackrel{\oplus}{\Xi}$ สุ สุ 责 \&

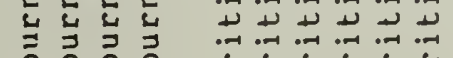

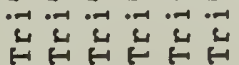

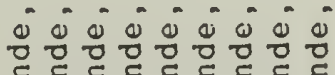

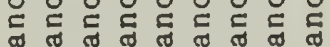

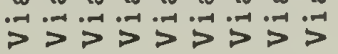

¿ें वं थี วี 응 岂莒 in es

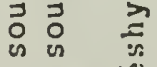
i. 20 $\rightarrow=1$ > 


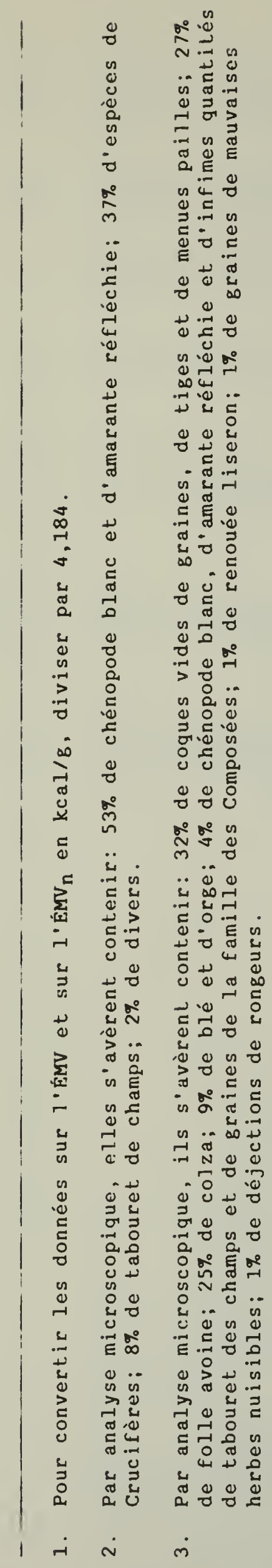


BIBLIOGRAPHIE

Les références bibliographiques sont disposées par année et par ordre alphabétique de noms d'auteurs dans une même année. Les résumés sont identifiés par des astérisques. Certaines références ont pu être oubliées et le lecteur est invité à en faire part à l'auteur pour lui permettre de les inclure dans les mises à jour ou révisions subséquentes de la publication.

$\underline{19} \underline{6} \underline{6}$

1 Harris, L.E., 1966. Biological Energy Interrelationships and Glossary of Energy Terms. Publ. 1411, National Academy of Science/National Research Council, Washington, U.S.A.

\section{$19 \underline{70}$}

2 Guillaume, J., and J.D. Summers, 1970. Maintenance energy requirement of the rooster and influence of plane of nutrition on metabolizable energy. Can. J. Anim. Sci. 50:363-369.

\section{$\underline{1975}$}

3 Sibbald, I.R., 1975. The effect of level of feed intake on metabolizable energy values measured with adult roosters. Poultry Sci. 54:1990-1997.

4 *Sibbald, I.R., 1975. The relationship between feed intake and metabolizable energy values. Poultry Sci. 54:1818. 
Sibbald, I.R., 1975. The measurement of metabolizable energy for poultry feedingstuffs. Proc. Arkansas Nutr. Conf., Fayetteville, U.S.A. pp. $53-68$.

6 Sibbald, I.R., 1975. The measurement of apparent and true metabolizable energy in poultry feedingstuffs. Proc. North Carolina Nutr. Conf., Charlotte, U.S.A. pp. 43-47.

7 Sibbald, I.R., 1975. Energy values in feed formulation. Proc. North Carolina Nutr. Conf., Charlotte, U.S.A. pp. 50-53.

8 Sibbald, I.R., and K. Price, 1975. Variation in the metabolizable energy values of diets and dietary components fed to adult roosters. Poultry Sci. $54: 448-456$.

\section{$\underline{1976}$}

9 Sibbald, I.R., 1976. A bioassay for true metabolizable energy in feedingstuffs. Poultry Sci. 55:303-308.

10 Sibbald, I.R., 1976. The effect of cold pelleting on the true metabolizable energy values of cereal grains fed to adult roosters and a comparison of observed with predicted metabolizable energy values. Poultry Sci. 55:970-974. 
11 Sibbald, I.R., 1976. The true metabolizable energy values of several feedingstuffs measured with roosters, laying hens, turkeys and broiler hens. Poultry Sci. 55:1459-1463.

12 Sibbald, I.R., 1976. The effect of duration of starvation of the assay bird on true metabolizable energy values. Poultry Sci. 55:1578-1579.

13 Sibbald, I.R., 1976. Energy in poultry nutrition, a bioassay for true metabolizable energy. Canadex 450.55, Agriculture Canada, Ottawa, Canada.

14 Sibbald, I.R., 1976. Energy in poultry nutrition, terminology and definitions. Canadex 450.55, Agriculture Canada, Ottawa, Canada.

15 Sibbald, I.R., 1976. The true metabolizable energy values of some feedingstuffs. Canadex 450.60, Agriculture Canada, Ottawa, Canada.

16 Sibbald, I.R., 1976. Shorter method to determine ME values. Feed Management 27(1):17-19.

17 Sibbald, I.R., 1976. The measurement of true metabolizable energy in poultry feedingstuffs. Proc. Guelph Nutr. Conf., Toronto, Canada. pp. $102-114$. 
18 Sibbald, I.R., and K. Price, 1976. True metabolizable energy values for poultry of Canadian barleys measured by bioassay and predicted from physical and chemical data. Can. J. Anim. Sci. 56:775-782.

19 Sibbald, I.R., and K. Price, 1976. Measurement of the true metabolizable energy values of poultry feeds and ingredients. Proc. 7th Symp. Energy Metab. in Farm Animals, Vichy, France. pp. 269-272.

1977

20 Featherston, W.R., 1977. Poultry nutrition research 1976. 25th Pfizer Annu. Res. Conf., Minneapolis, U.S.A. pp. 31-59.

21 Halloran, H.R., 1977. Metabolizable energy values of feed fats for broilers and turkeys. Proc. Maryland Nutr. Conf., Washington, U.S.A. pp. $26-31$.

22 Johns, D.C., and I.C. Edmundson, 1977. Metabolisable energy determinations. Proc. 23rd Annu. Poult. Conv., Massey Univ., Palmerston North, N.Z. pp. 84-91.

23 Muztar, A.J., S.J. S1inger and J.H. Burton, 1977. Metabolisable energy content of freshwater plants in chickens and ducks. Poultry sci. $56: 1893-1899$. 
24 Patchell, M.R., and I.C. Edmundson, 1977. Metabolisable energy. 3. Metabolisable energy of New Zealand ingredients. Summary of Final Reports and Current Research, Poult. Res. Centre, Massey Univ., Palmerston North, N.Z. pp. 48-50.

25 Patche11, M.R., and I.C. Edmundson, 1977. Metabolisable energy. 4/5. Metabolisable energy of New Zealand ingredients. Summary of Final Reports and Current Research, Poult. Res. Centre, Massey Univ., Palmerston North, N.Z. pp. 51-52.

26 Patchell, M.R., and I.C. Edmundson, 1977. Metabolisable energy. 6. Metabolisable energy of New Zealand ingredients. Summary of Final Reports and Current Research, Poult. Res. Centre, Massey Univ., Palmerston North, N.Z. p. 71 .

27 Salmon, R.E., and J.B. O'Neil, 1977. Effects of frost damage on physical and chemical characteristics and true metabolizable energy of wheat. Can. J. Anim. Sci. 57:755-760.

28 Sibbald, I.R., 1977. A test of the additivity of true metabolizable energy values of feedingstuffs. Poultry Sci. 56:363-366.

29 Sibbald, I.R., 1977. The true metabolizable energy values of some feedingstuffs. Poultry Sci. 56:380-382. 
30 Sibbald, I.K., 19/7. The true metabolizable energy values for poultry of rapeseed and of the meal and oil derived therefrom. Poultry Sci. $56: 1652-1656$,

31 Sibbald, I.R., 1977. The effect of level of feed input on true metabolizable energy values. Poultry Sci. 56:1662-1663.

32 Sibbald, I.R., 1977. The effect of steam pelleting on the true metabolizable energy values of poultry diets. Poultry sci. $56: 1686-1688$

33 *Sibbald, I.R., 1977. Effect of levels of input and of dietary inclusion on TME values. Poultry Sci. 56:1757.

34 Sibbald, I.R., 1977. The true metabolizable enorgy system. Part 1. Feedsturfs $49(42): 21-22$.

35 Sibbald, I.R., 1977. The true metabolizable energy system. Part 2. Feedsturfs $49(43): 23-24$.

36 Sibbald, I.R., 1977. Definition, measurement and usefulness of true metabolizable energy. Proc. 36th Seni-Annu. Meet. Am. Feed Manur. Assoc. Nutr. Council, Memphis, U.S.A. pp. 32-35.

37 Sibbald, I.R., 1977. The true metabolizable energy system of fecd evaluation. Proc. Maryland Nutr. Conf., Washington, U.S.A. pp. 32-35. 
38 Sibbald, I.R., and J.K.G. Kramer, 1977. The true metabolizable energy values of fats and fat mixtures. Poultry Sci. 56:2079-2086.

39 Sibbald, I.R., and K. Price, 1977. True and apparent metabolizable energy values for poultry of Canadian wheats and oats measured by bioassay and predicted from physical and chemical data. Can. J. Anim. Sci. $57: 365-374$.

40 Sibbald, I.R., and K. Price, 1977. The true metabolizable energy values of the seeds of Brassica campestris. B. hirta and B. napus. Poultry Sci. $56: 1329-1331$.

41 Sibbald, I.R, and K. Price, 1977. The effect of level of dietary inclusion and of calcium on the true metabolizable energy values of fats. Poultry Sci. 56:2070-2078.

\section{$\underline{1978}$}

42 Anonymous, 1978. pp. 9-15 in Poultry Research Centre Report for Year Ending 31st March 1978. Agricultural Research Council, London, U.K.

$43 \star$ Boldaji, F., W.B. Roush, H.S. Nakaue and G.H. Arscott, 1978. True metabolizable energy values of different varielies of wheat grown in Oregon, measured with normal size and dwarf white Leghorn roosters. Poultry Sci. 57:1119-1120. 
44 Edmundson, I.C., M.R. Patchell and R.D. King, 1978. Metabolisable energy. 7. Assays of ingredients and diets. Summary of Final Reports and Current Research, Poult. Res. Centre, Massey Univ., Palmerston North, N.Z. pp. 58-60.

45 Farrell, D.J., 1978. Rapid determination of metabolizable energy of foods using cockerels. Br. Poult. Sci. 19:303-308.

46 Farrell, D.J., 1978. Metabolizable energy of some local ingredients using a rapid bioassay. Proc. 2nd Australasian Poult. and Stockfeed Conv., Sydney, Australia. pp. 204-208.

47 Farre11, D.J., 1978. Energy systems in poultry, how well do they predict biological performance. Proc. 24th Annu. Poult. Conv., Massey Univ., Palmerston North, N.Z. pp. 96-105.

48 Johns, D.C., 1978. Chick nutrition 165 - Full-fat soybean meal. Summary of Final Reports and Current Research, Poult. Res. Centre, Massey Univ., Palmerston North, N.Z. p. 16 .

49 Kessler, J.W., and O.P. Thomas, 1978. An evaluation of the true metabolizable energy system. Proc. Maryland Nutr. Conf., Washington, U.S.A. pp. 18-21. 
50 King, R.D., 1978. Whole barley choice feeding. Summary of Final Reports and Current Research, Poult. Res. Centre, Massey Univ., Palmerston North, N.Z. pp. 19-21.

51 King, R.D., 1978. Comparisons of dietary costs of AME and TME based formulations. Summary of Final Reports and Current Research, Poult. Res. Centre, Massey Univ., Palmerston North, N.Z. pp. 80-90.

52 Likuski, H.J.A., and H.G. Dorrell, 1978. A bioassay for rapid determination of amino acid availability values. Poultry Sci. $57: 1658-1660$.

53 *miles, R.D., A.S. Arafa, R.J. Bloomer and R.H. Harms, 1978. The true metabolizable energy of turkey poult diets containing dietary fillers. Poultry Sci. $57: 1107$.

54 Mutzar, A.J., H.J. Likuski and S.J. Slinger, 1978. Metabolizable energy content of Tower and Candle rapeseeds and rapeseed meals determined in two laboratories. Can. J. Anim. Sci. 58:485-492.

55 Sell, J.L., 1978. Poultry nutrition research 1977. 26th Pfizer Annu. Res. Conf., Las Vegas, U.S.A. pp. 27-70.

56 Sibbald, I.R., 1978. The effect of the duration of the time interval between assays on true metabolizable energy values measured with adult roosters. Poultry Sci. 57:455-460. 
57 Sibbald, I.R., 1978. The true metabolizable energy values of mixtures of tallow with either soybean oil or lard. Poultry Sci. 57:473-477.

58 Sibbald, I.R., 1978. The effect of the age of the assay bird on the true metabolizable energy values of feedingstuffs. Poultry sci. $57: 1008-1012$.

59 Sibbald, I.R., 1978. Scientists study metabolizable energy variations in swine and poultry diets. Feedstuffs 50(48):20-22.

60 Sibbald, I.R., 1978. True metabolizable energy determination and application. Proc. Georgia Nutr. Conf., Atlanta, U.S.A. pp. 105-109.

61 Sibbald, I.R., and J.K.G. Kramer, 1978. The effect of the basal diet on the true metabolizable energy value of fat. Poultry Sci. 57:685-691.

62 Sibbald, I.R., and K. Price, 1978. The metabolic and endogenous energy losses of adult roosters. Poultry Sci. 57:556-557.

63 *Tennesaca, L.G., and J.L. Sell, 1978. Influence of indigestible material on energy excretion and true metabolizable energy of corn. Poultry Sci. $57: 1167$. 


\section{9}

64 Cid Diaz, J.M., 1979. La Energía Metabolisable Aparente Y Verdadera, En Avicultura: Situacion Actual. Academia de Ciencias Veterinarias de Madrid, Spain.

$65 *$ Coon, C., M. Scheibel and K. Kelley, 1979. The heat increment and net available and true metabolisable energy of poultry feeds. Poultry Sci. $58: 1046$.

66 Edmundson, I.C., 1979. True metabolisable energy trial ME/9. Summary of Final Reports and Current Research, Poult. Res. Centre, Massey Univ., Palmerston North, N.Z. pp. 82-84.

67 Edmundson, I.C., 1979. True metabolisable energy trial ME/10. Sunmary of Final Reports and Current Research, Poult. Res. Centre, Massey Univ., Palmerston North, N.Z. pp. 104-105.

68 Edmundson, I.C., 1979. True metabolisable energy trial ME/11. Sunmary of Final Reports and Current Research, Poult. Res. Centre, Massey Univ., Palmerston North, N.Z. p. 106.

69 Edmundson, I.C., 1979. True metabolisable energy trial ME/12. Sunmary of Final Reports and Current Research, Poult. Res. Centre, Massey Univ., Palmerston North, N.Z. p. 107.

70 Farre11, D.J., 1979. Energy systems for pigs and poultry: a review. J. Aust. Inst. Agric. Sci. 45:21-34. 
71 Halloran, H.R., and I.R. Sibbald, 1979. Metabolizable energy values of fats measured by several procedures. Poultry Sci. 58:1299-1307.

72 Härtel, H., 1979. Methods to calculate the energy of mixed fecds. Proc. 2nd European symp. Poult. Nutr., Beekbergen, The Netherlands. pp. 6-13.

73 Hulan, H.W., F.G. Proudfoot and C.G. Zarkadas, 1979. The nutritional value and quality of squid (Illex illecebrosus) meal as source of dietary protein for broiler chicken. Br. J. Nutr. 41:163-173.

74 Jones, J.D., and I.R. Sibbald, 1979. The true metabolizable energy values for poultry of fractions of rapeseed (Brassica napus cv. Tower). Poultry Sci. 58:385-391.

75 *Kessler, J.W., and O.P. Thomas, 1979. An evaluation of the "true metabolizable energy" system. Poultry Sci. 58:1072-1073.

76 Kessler, J.W., and O.P. Thomas, 1979. A further evaluation of the true metabolizable energy system. Proc. Maryland Nutr. Conf., Washington, U.S.A. pp. $83-87$.

77 Kratzer, F.H., 1979. Poultry nutrition rescarch 1978. 27th Pfizer Annu. Res. Conf., St. Louis, U.S.A. pp. 7-52. 
78 Kussaibati, R., 1979. Influence of dietary intake level on the metabolizable energy and digestibility of lipids in the growing chicks and the adult cockerel. Proc. 2nd European Symp. Poult. Nutr., Beekbergen, The Netherlands. pp. 14-18.

79 Lopez, C.V., 1979. Energĺa metabolizable aparante y verdadera de materias primas utilizadas en raciones para aves en Columbia. Revista Instituto Columbiano Agropécuario 14(Suppl.):312.

80 Martinez, R.I.A., 1979. Determinación de energía metabolizable verdadera de materias primas Columbianas en aves. (Thesis summary). Revista Instituto Columbiano Agropécuario 14(Suppl.):307.

81 Mutzar, A.J., and S.J. Slinger, 1979. Some factors affecting the true metabolizable energy values of soybean meal and rapeseed meals. Can. J. Anim. Sci. 59:317-321.

82 Mutzar, A.J., and S.J. Slinger, 1979. Effect of length of excreta collection period and feed input level on the true metabolizable energy value of rapeseed meal. Nutr, Rep. Int. 19:689-694.

$83 \star$ Roitz, D.O., and H.L. Fuller, 1979. A comparison of methods for determining biological value of oilseed meals. Poultry Sci. 58:1099. 
84 Salmon, R.E., K.K. Klein and E. Larmond, 1979. Low glucosinolate rapeseed meal in turkey broiler diets of varying nutrient densily. Poultry Sci. $58: 1514-1523$.

85 Scheibel, M.S., C.N. Coon and K.W. Kelley, 1979. The heat increment of feeds used in poultry diets. Nutr. Rep. Int. 20:871-881.

86 Shires, A., A.R. Robblee, R.T. Hardin and D.R. Clandinin, 1979. Effect of previous diet, body weight, and duration of starvation of the assay bird on the true metabolizable energy value of corn. Poultry sci. $58: 602-608$.

87 Sibbald, I.R., 1979. Passage of feed through the adult rooster. Poultry Sci. $58: 446-459$.

88 Sibbald, I.R., 1979. A bioassay for available amino acids and true metabolizable energy in feedingstuffs. Poultry Sci. 58:668-675.

89 Sibbald, I.R., 1979. The effect of the duration of the excreta collection period on the true metabolizable energy values of feedingstuffs with slow rates of passage. Poultry Sci. 58:896-899.

90 Sibbald, I.R., 1979. Bioavailable amino acids and true metabolizable energy of cereal grains. Poultry Sci. 58:934-939. 
91 Sibbald, I.R., 1979. Effect of level of feed input, dilution of test material and duration of excreta collection on true metabolizable energy values. Poultry Sci. 58:1325-1329.

92 Sibbald, I.R., 1979. The effect of the drying procedure on excreta energy values for poultry and other species. Poultry Sci. 58:1392-1394.

93 Sibbald, I.R., 1979. Bioavailable amino acids in feedingstuffs. p. 6 in A.P. Williams, ed. ARC Protein Evaluation Group News Shect \#5. ARC., London, U.K.

94 Sibbald, I.R., 1979. Metabolizable energy in poultrydiets. pp. $35-49$ in W. Haresign and D. Lewis, eds. Recent Advances in Animal Nutrition 1979. Butterworths, London, U.K.

95 Sibbald, I.R., 1979. True metabolizable energy. Proc. 2nd European Symp. Poult. Nutr., Beekbergen, The Netherlands. pp. 25-30.

96 *Tenesaca, G.L., and J.L. Sell, 1979. True metabolizable energy of corn and oats. Poultry Sci. 58:1115.

\section{$\underline{1980}$}

97 *arvat, V., J. Lyons and J.M. Vanderpopuliere, 1980. A comparison of metabolizable energy and true metabolizable energy. Poultry sci. $59: 1579$. 
98 Chami, D.B., P. Vohra and F.H. Kratzer, 1980. Evaluation of a method for determination of true metabolizable energy of feed ingredients. Poultry Sci. 59:569-571.

99 Chand, S., V.R. Sadagopan and V.R. Reddy, 1980. Utilization of solvent extracted mustard-cake in chicks and its true metabolizable energy content. Ind. J. Anim. Sci. 50:521-524.

100 Christison, G.I., and J.M. Bell, 1980. Evaluation of Terra, a new cultivar of naked oats (Avena nuda), when fed to young pigs and chicks. Can. J. Anim. Sci, 60:465-471.

101 Dale, N.M., and H.L. Fuller, 1980. Additivity of true metabolizable energy values as measured with roosters, broiler chicks and poults. Poultry Sci. $59: 1941-1942$.

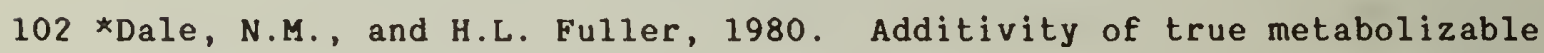
energy values as measured with roosters, broiler chicks and poults. Poultry Sci. 59:1561.

$103 *$ Dale, N.M., and H.L. Fuller, 1980. A comparison of apparent and true metabolizable energy systems in evaluating the calorie content of broiler diets. Poultry Sci. 59:1598-1599. 
104 *Dudley, W.A., S.M. Kim and M. Winegardener, 1980. The use of gelatin capsules for measuring true metabolizable energy. Poultry sci. $59: 1601$

105 Edmundson, I.C., 1980. The true metabolisable energy of meat and bone meal determined at different levels. Proc. South Pacific Poult. Sci. Conv., Auckland, N.Z. pp. 20-25.

106 Edmundson, I.C., 1980. True metabolisable energy trial ME/12(a). Summary of Final Reports and Current Research, Poult. Res. Centre, Massey Univ., Palmerston North, N.Z. pp. 95-98.

107 Edmundson, I.C., 1980. True metabolisable energy trial ME/13(c). Summary of Final Reports and Current Research, Poult. Res. Centre, Massey Univ., Palmerston North, N.Z. pp. 99-100.

108 *Emebo, G.O., and R.H. Roberson, 1980. The true amino acid availability of feedstuffs for poultry. Poultry Sci. 59:1604.

109 Farrell, D.J., 1980. Feeding standards for poultry. Proc Aust. Soc. Anim. Prod. 13:26-31.

110 Farrell, D.J., 1980. True metabolizable energy (TME) and the alternative. pp. 146-153 in D.J. Farrell, ed. Recent Advances in Animal Nutrition in Australia 1980. Univ. New England Publ. Unit, Armidale, Australia. 
111 Farrell, D.J., 1980. The case for retaining the apparent metabolizable energy system because of variation in endogenous excreta. Proc. Poult. Husb. Res. Found. Symp., Sydney, Australia. 11 pp.

112 Fekete, S., 1980. Energetikai takarmanyértékelés (Irodalmi attekintés). Magyar Allatorvosok Lapja 35:472-479.

113 Fenwick, G.R., and R.F. Curtis, 1980. Rapeseed meal and its use in poultry diets. A review. Anim. Feed Sci. Technol. 5:255-298.

114 Fuller, H.L., 1980. Poultry nutrition research 1979. 28th Pfizer Annu. Res. Conf., Atlanta, U.S.A. pp. 91-127.

115 Halloran, H.R., 1980. Comparison of metabolizable energy methods on identical ingredient samples. Poultry Sci. 59:1552-1553.

116 Johnsson, G., 1980. Nutritive value of grassmeal for poultry. M. Phil. Thesis, Univ. of Edinburgh, Edinburgh, U.K.

117 Kessler, J.W., 1980. An investigation of the "true" metabolizable energy system. Ph.D. Thesis, Univ. of Maryland, College Park, U.S.A.

118 Kessler, J.W., and O.P. Thomas, 1980. The influence of time and cecectomy on the true metabolizable energy. Proc. Maryland Nutr. Conf., Washington, U.S.A. Pp. 27-31. 
119 King, R.D., 1980. Layer nutrition 140- Within flock performance. Summary of Final Reports and Current Research, Poult. Res. Centre, Massey Univ., Palmerston North, N.Z. pp. 64-66.

120 King, R.D., 1980. Layer nutrition 142- Dietary energy levels. Summary of Final Reports and Current Research, Poult. Res. Centre, Massey Univ., Palmerston North, N.Z. pp. 69-70.

121 King, R.D., 1980. Layer nutrition 151- Dietary energy levels. Summary of Final Reports and Current Research, Poult. Res. Center, Massey Univ., Palmerston North, N.Z. p. 117 .

$122 \star$ Luis, E.S., T.W. Sullivan and L.A. Nelson, 1980. The nutritional value of three varieties of proso millet and bird resistant sorghum for poultry. Poultry Sci. 59:1632.

123 Mahlotra, N.K., V.R. Sadagopan, V.R. Reddy and B. Panda, 1980. Metabolizable energy and utilization of treated deoiled salseed-meal in chicks. Ind. J. Anim. Sci. 50:437-443.

124 Mateos, G.G., and J.L. Sell, 1980. Influence of fat and carbohydrate source on energy utilization by laying hens. Nutr. Rep. Int. 22:79-89.

125 Mateos, G.G., and J.L. Se11, 1980. True and apparent metabolizable energy value of fat for laying hens: influence of level of use. Poultry Sci. $59: 369-373$. 
126 Muztar, A.J., and S.J. Slinger, 1980. The effect of level of feed input in a short term assay for determining apparent metabolizable energy of some feedingstuffs. Nutr. Rep. Int. 22:117-122.

127 Muztar, A.J., and S.J. Slinger, 1980. Effect of body weight and duration of fast on metabolic and endogenous excretion by the mature rooster. Nutr. Rep. Int. 22:147-156.

128 Muztar, A.J., and S.J. Slinger, 1980. The effect of fiber on metabolic and endogenous energy losses in mature cockerels. Nutr. Rep. Int. $22: 183-186$

129 Muztar, A.J., and S.J. Slinger, 1980. Rate of passage of feedstuffs through mature roosters and effect on true metabolizable energy. Nutr. Rep. Int. 22:361-367.

130 Muztar, A.J., and S.J. Slinger, 1980. Effect of length of collection period on the metabolizable energy values in short term assays. Nutr. Rep. Int. 22:589-595.

131 Muztar, A.J., and S.J. Slinger, 1980. An evaluation of the rapid apparent metabolizable energy assay in relation to feed intake using mature cockerels. Nutr. Rep. Int. 22:745-750. 
132 Muztar, A.J., and S.J. Slinger, 1980. Effect of level of dietary fiber on nitrogen and amino acid excretion in the fasted mature rooster. Nutr. Rep. Int. $22: 863-868$.

133 Muztar, A.J., and S.J. Slinger, 1980. The effect of dry matter on metabolic and endogenous amino acid excretion in mature cockerels. Nutr. Rep. Int. 22:901-906.

134 Muztar, A.J., and S.J. Slinger, 1980. Bioavailable amino acids in corn and alfalfa as measured by applying the true metabolizable energy assay. Poultry Sci. 59:1873-1877.

135 Muztar, A.J., S.J. Slinger, H.J.A. Likuski and H.G. Dorrell, 1980. True amino acid availability values for soybean meal and Tower and Candle rapeseed and rapeseed meals determined in two laboratories. Poultry Sci. $59: 605-610$.

136 *Parsons, C.M., and L.M. Potter, 1980. True metabolizable energy and amino acid digestibility of dehulled soybean meals. Poultry sci. $59: 1648-1649$.

137 Patchell, M.R., 1980. The minimum energy intake of layers. Proc. South Pacific Poult. Sci. Conv., Auckland, N.Z. pp. 163-170. 
138 Patchell, M.R., 1980. Chick nutrition 186-Feeding a starter diet for 4 or 8 weeks. Summary of Final Reports and Current Research, Poult. Res. Centre, Massey Univ., Palmerston North, N.Z. pp. 1-2.

139 Patche11, M.R., 1980. Chick nutrition 187 a-Feed restriction during rearing. Summary of Final Reports and Current Research, Poult. Res. Centre, Massey Univ., Palmerston North, N.Z. pp. 5-6.

140 Patchell, M.R., 1980. Layer nutrition 123-Effect of split diets during rearing. Summary of Final Reports and Current Research, Poult. Res. Centre, Massey Univ., Palmerston North, N.Z. pp. 36-37.

141 Patchell, M.R., 1980. Layer nutrition 128-Energetic efficiencies of maintenance and production of laying diets. Summary of Final Reports and Current Research, Poult. Res. Centre, Massey Univ., Palmerston North, N.Z. pp. 41-48.

142 Patchell, M.R., 1980. Layer nutrition 129- True metabolisable energy intakes. Summary of Final Reports and Current Research, Poult. Res. Centre, Massey Univ., Palmerston North, N.Z. pp. 49-51.

143 Patchell, M.R., 1980. Layer nutrition 132-Energy intake. Sunmary of Final Reports and Current Research, Poult. Res. Centre, Massey Univ., Palmerston North, N.Z. pp. 52-54. 
144 Patchell, M.R., 1980. Layer nutrition 133-Energy intake. Summary of Final Reports and Current Research, Poult. Res. Centre, Massey Univ., Palmerston North, N.Z. pp. 55-57.

145 Patche11, M.R., 1980. Layer nutrition 134-Energy intake (sand). Summary of Final Reports and Current Research, Poult. Res. Centre, Massey Univ., Palmerston North, N.Z. pp. 58-59.

146 Patche11, M.R., 1980. Layer nutrition 141-Energy intake (sand). Summary of Final Reports and Current Research, Poult. Res. Centre, Massey Univ., Palmerston North, N.Z. pp. 67-68.

147 Patchell, M.R., 1980. Layer nutrition 143-Energry intake. Sumuary of Final Reports and Current Research, Poult. Res. Centre, Massey Univ., Palmerston North, N.Z. pp. 71-74.

148 Patchell, M.R., 1980. Chick nutrition 190-Energy allowance for growers. Summary of Final Reports and Current Research, Poult. Res. Centre, Massey Univ., Palmerston North, N.Z. pp. 101-102.

149 Patchell, M.R., 1980. Layer nutrition 135- The energy requirements of four strains. Summary of Final Reports and Current Research, Poult. Res. Centre, Massey Univ., Palmerston North, N.Z. pp. 105-108. 
150 Patchell, M.R., 1980. Layer nutrition 148- Body weight and energy intake. Summary of Final Reports and Current Research, Poult. Res. Centre, Massey Univ., Palmerston North, N.Z. pp. 112-114.

151 Patchell, M.R., and M. Fraser, 1980. Apex meal. Summary of Final Reports and Current Research, Poult. Res. Centre, Massey Univ., Palmerston North, N.Z. pp. 9-10.

152 Shires, A., A.R. Robblee, R.T. Hardin and D.R. Clandinin, 1980. Effect of age of chicken on the true metabolizable energy values of feed ingredients. Poultry sci. 59:396-403.

153 *Shices, A., A.R. Robblee, R.T. Hardin and D.R. Clandinin, 1980. Effect of age on the true metabolizable energy values of feedingstuffs. Can. J. Anim. Sci. 58:810.

154 Sibbald, I.R., 1980. Metabolizable energy in poultry nutrition. Bioscience $30: 736-741$.

155 Sibbald, I.R., 1980. The clearance time and rate of passage of feed residues. Poultry Sci. 59:374-377.

156 Sibbald, I.R., 1980. The effects of dietary cellulose and sand on the combined metabolic plus endogenous energy and amino acid output of adult cockerels. Poultry Sci. 59:836-844. 
157 Sibbald, I.R., 1980. Gut clearance and true metabolizable energy value of dehydrated alfalfa supplemented with sodium chloride. Poultry Sci. $59: 939-940$.

158 sibbald, I.R., 1980. The passage of oat and other feed residues through the adult cockerel. Poultry Sci. 59:2136-2144.

159 sibbald, I.R., 1980. The effect of heat treatment on the clearance time, true metabolizable energy and true available amino acids of raw soybean flakes. Poultry Sci. 59:2358-2360.

160 Sibbald, I.R., 1980. A new technique for estimating the ME content of feeds for poultry. pp. 38-43 in W.J. Pidgen, C.C. Balch and M. Graham, eds. Standardization of Analytical Methodology for Feeds. IDRC 134e, Ottawa, Canada.

161 Sibbald, I.R., 1980. Amino acid availability. Feed Management 31(10):26.

162 Sibbald, I.R., 1980. Amino acid availability. Poultry Digest 39:604.

163 Sibbald, I.R., 1980. Selection of a bioassay for available energy. Proc. Poult. Husb. Res. Found. Symp., Sydney, Australia. 13 pp.

164 Sibbald, I.R., 1980. Selection of a bioassay for available energy. Proc. South Pacific Poult. Sci. Conv., Auckland, N.Z. pp. 10-19. 
165 Sibbald, I.R., and J.K.G. Kramer, 1980. The effect of the basal diet on the utilization of fat as a source of true metabolizable energy, lipid and fatty acids. Poultry Sci. 59:316-324.

166 Sibbald, I.R., and J.K.G. Kramer, 1980. The effects of fractions of yellow corn on the true metabolizable energy of beef tallow. Poultry Sci. 59:1505-1509.

167 Sibbald, I.R., and K. Price, 1980. Variability in metabolic plus endogenous energy losses in adult cockerels and in true metabolizable energy values and rates of passage of alfalfa. Poultry Sci. $59: 1275-1279$.

168 Sibbald, I.R., J.P. Barrette and K. Price, 1980. Predicting true metabolizable energy, gross energy, carbohydrate and proximate analysis values by assuming additivity. Poultry Sci. 59:805-807.

169 Sibbald, I.R., K. Price and J.P. Barrette, 1980. True metabolizable energy for poultry of commercial diets measured by bioassay and predicted from chemical data. Poultry Sci. 59:808-811.

170 SIinger, S.J., and A.J. Muztar, 1980. Energy measures for poultry and swine, practical application. Proc. Guelph Nutr. Conf., Toronto, Canada. pp. 103-109. 
171 Van Es, A.J.H., 1980. Feed evaluation, a survey. pp. 85-92 in L.E. Mount, ed. Energy Metabolism. Butterworths, London, U.K.

172 Wehner, G.R., R.L. Harrold and M. Wanapat, 1980. True metabolizable energy of sprouted wheat. North Dakota Farm Res. Bull. 47.

173 *Willis, G.M., and D.H. Baker, 1980. Evaluation of turfgrass clippings as a dietary ingredient for the growing chick. Poultry Sci. 59:404-411.

\section{$\underline{1981}$}

174 Allen, N.K., 1981. Nutrition of growing geese. Proc. Minnesota Nutr. Conf., Minneapolis, U.S.A. pp. 119-123.

175 Boldaji, F., W.B. Roush, H.S. Nakaue and G.H. Arscott, 1981. True metabolizable energy values of corn and different varieties of wheat and barley using normal and dwarf single comb white Leghorn roosters . Poultry Sci. $60: 225-227$.

176 Campbe1l, L.D., B.O. Eggum and I. Jacobsen, 1981. Biological value, amino acid availability and true metabolizable energy of low-glucosinolate rapeseed meal (Canola) determined with rats and/or roosters. Nutr. Rep. Int. 24:791-797.

177 Dale, N.M., 1981. Energía metabolizable "Verdadera". Industria Avicola $28(9): 78-86$ 
178 Dale, N.M., and H.L. Fuller, 1981. Effect of carrier on the true metabolizable energy of corn oil. Poultry Sci. 60:1504-1508.

$179 *$ Dale, N.M., and H.L. Fuller, 1981. Applicability of the true metabolizable energy system in practical feed formulation. Poultry Sci. $60: 1598$

$180 *$ Dale, N.M., and H.L. Fuller, 1981. Studies on the true metabolizable energy of fats at low-level dietary inclusion. Poultry Sci. 60:1643.

181 Dale N.M., and H.L. Fuller, 1981. The use of true metabolizable energy (TME) in formulating poultry rations. Proc. Georgia Nutr. Conf., Atlanta, U.S.A. pp. 50-57.

182 Davidson, J., and S. Graham, 1981. The estimation of metabolizable energy in maize and in wheat by-products using chickens, with observations on problems of prediction from chemical composition. J. Agric. Sci. Camb. $96: 221-225$.

183 Edmundson, I.C., 1981. True metabolisable energy trial ME/13. Summary of Final Reports and Current Research, Poult. Res. Centre, Massey Univ., Palmerston North, N.Z. pp. 97-98.

184 Engster, H.M., D.C. Snetsinger and J.W. Kessler, 1981. Commercial application of the TME system. Proc. 3rd European Symp. Poult. Nutr., Peebles, U.K. Pp. 56-63. 
185 Farrel1, D.J., 1981. An assessment of quick bioassays for determining the true metabolizable energy and apparent metabolizable energy of poultry feedstuffs. World's Poult. Sci. J. 37:72-83.

186 *Fuller, H.L., and N.M. Dale, 1981. Endogenous energy losses of fed vs. fasted roosters in true metabolizable energy assays. Poultry sci. $60: 1601$

187 *Fuller, H.L., and N.M. Dale, 1981. Influence of the ratio of basal fat to test fat on the true metabolizable energy of several fats. Poultry Sci. $60: 1659$.

188 Johns, D.C., 1981. Maize quality and heat treatment. Summary of Final Reports and Current Research, Poult. Res. Centre, Massey Univ., Palmerston North, N.Z. pp. 4-6.

189 Kessler, J.W., and O.P. Thomas, 1981. The effect of cecectomy and extension of the collection period on the true metabolizable energy values of soybean meal, feather meal, fish meal and blood meal. Poultry Sci. 60:2639-2647.

190 Kessler, J.W., T.H. Nguyen and O.P. Thomas, 1981. The amino acid excretion values in intact and cecectomized negative control roosters used for determining metabolic plus endogenous urinary energy losses. Poultry Sci. 60:1576-1577. 
191 Kienholz, E.W., and R.E. Moreng, 1981. A new brewery by-product for turkey diets. Poultry Sci. 60:1879-1883.

192 King, R.D., 1981. Dietary energy levels. Summary of Final Reports and Current Research, Poult. Res. Centre, Massey Univ., Palmerston North, N.Z. pp. $48-49$.

193 Latshaw., J.D., 1981. Counting calories in poultry feed. Ohio Poultry Pointers, May 1981 .

194 Low, A.G., and I.G. Partridge, 1981. The value of in vivo and in vitro digestibility measurements of amino acids as predictors of performance and carcass composition in pigs. Proc. 6th Int. Symp. on Amino Acids, Serock, Poland. pp. 1-9.

195 McNab, J.M., and C. Fisher, 1981. The choice between apparent and true metabolizable energy systems - recent evidence. Proc. 3rd European Symp. Poult. Nutr., Peebles, U.K. pp. 45-55.

196 McNab, J.M., J.C. Blair, W.A. Dewar and J.N. Downie, 1981. The effects of different dietary $(\mathrm{Na}+\mathrm{K}+\mathrm{Cl})$ contents on the performance of young broilers and on the metabolizable energy values of their diets. Proc. 3rd European Symp. Poult. Nutr., Peebles, U.K. pp. 132-136. 
197 Miles, R.D., A.S. Arafa, R.J Bloomer and R.H. Harms, 1981. The influence of certain dietary fillers on the true metabolizable energy of diets for turkeys. Br. Poult. Sci. 22:411-414.

198 Minaar, A. du P., and J. Erasmus, 1981. True metabolizable energy with nitrogen corrections to improve additivity in poultry diets. South African J. Anim. Sci. 11:279-283.

199 Miski, A.M.A., and S. Quazi, 1981. Influence of age and sex of growing broiler chicks and body weight of roosters on their endogenous and metabolic energy losses. Poultry Sci. 60:781-785.

200 Mollah, Y., W.L. Bryden, D. Balnave and E.F. Annison, 1981. Studies of low - ME wheats. Proc. 4th Australasian Poult. Stockfeed Conv., Perth, Australia. pp. 264-265.

201 Moran, E.T., 1981. Poultry nutrition research 1980. 29th Pfizer Annu. Res. Conf., St. Louis, U.S.A. pp. 91-130.

202 Muztar, A.J., and S.J. Slinger, 1981. A study of the metabolic fecal and endogenous amino acid excretion in fasted mature cockerels with time. Nutr. Rep. Int. 23:465-469. 
203 Muztar, A.J., and S.J. Slinger, 1981. An evaluation of the true metabolizable energy assay for monitoring the apparent metabolizable energy values of poultry diets. Poultry Sci. 60:598-602.

204 Muztar, A.J., and S.J. Slinger, 1981. A comparison of the true and apparent metabolizable energy measures using corn and soybean meal samples. Poultry Sci. 60:611-616.

205 Muztar, A.J., and S.J. Slinger, 1981. Relationship between body weight and amino acid excretion in fasted mature cockerels. Poultry Sci. $60: 790-794$.

206 Muztar, A.J., and S.J. Slinger, 1981. An evaluation of the nitrogen correction in the true metabolizable energy assay. Poultry Sci. $60: 835-839$.

207 Muztar, A.J., S. Leeson and S.J. Slinger, 1981. Effect of blending and level of inclusion on the metabolizable energy of tallow and Tower rapeseed soapstocks. Poultry Sci. 60:365-372.

208 Muztar, A.J., H.J.A. Likuski and S.J. Slinger, 1981. True metabolizable energy values of a number of feedingstuffs and complete diets as determined in two laboratories. Poultry Sci. 60:373-377. 
$209{ }^{*} \mathrm{NgOu}$, J.D., P.M. Mairorino and B.L. Reid, 1981. Évaluation of jojoba meal for poultry diets. Poultry Sci. 60:1703.

210 Okumura, J., Y. Isshiki and N. Nakahiro, 1981. Some factors affecting urinary and faecal nitrogen loss by chickens fed on a protein-free diet. Br. Poult. Sci. 22:1-7.

211 Parsons, C.M., 1981. Evaluation of a procedure for determination of amino acid digestibility and metabolizable energy of feedstuffs for poultry. Ph.D. Thesis, Virginia Polytech. Inst. and State Univ., Blacksburg, U.S.A.

212 Parsons, C.M., L.M. Potter and R.D. Brown, Jr., 1981. True metabolizable energy and amino acid digestibility of dehulled soybean meal. Poultry Sci. $60: 2687-2696$.

213 *Parsons, C.M., L.M. Potter and R.D. Brown Jr., 1981. Effects of dietary protein and carbohydrate and of intestinal microflora on excretion of amino acids by poultry. Poultry Sci. 60:1709-1710.

214 *Parsons, C.M., L.M. Potter, R.D. Brown Jr., T.D. Wilkins and B.A. Bliss, 1981. Microbial contribution to dry matter and amino acid content of poultry excreta. Poultry Sci. 60:1709. 
215 Patche11, M.R., 1981. Energy allowance for growers. Summary of Final Reports and Current Research, Poult. Res. Centre, Massey Univ., Palnerston North, N.Z. pp. 1-3.

216 Patche1l, M.R., 1981. Energy allowance for growers. Sumimary of Final Reports and Current Research, Poult. Res. Centre, Massey Univ., Palmerston North, N.Z. pp. 21-23.

217 Patche11, M.R., 1981. Apex paunch meal. Sumnary of Final Reports and Current Research, Poult. Res. Centre, Massey Univ., Palmerston North, N.Z. pp. $24-25$.

218 Patche11, M.R., 1981. The energy requiremenl of rour strains. Summary of Final Reports and Current Research, Poull. Res. Centre, Massey Univ., Palmerston North, N.Z. pp. 28-31.

219 Patchel., M.R., 1981. Body weight and energy intake. Summary of Final Reports and Current Research, Poult. Res. Centre, Massey Univ., Palmerston North, N.Z. pp. 37-40.

220 Patche11, M.R., 1981. Fnergy level of diets. Summary of Final Reports and Current Research, Poult. Res. Centre, Massey Univ., Palmerston North, N.Z. pp. 69-72. 
221 Patchell, M.R., 1981. Amino acid levels - energy and state of lay. Summary of Final Reports and Current Research, Poult. Res. Centre, Massey Univ., Palmerston North, N.Z. pp. 73-76.

222 Pearson, R.A., and K.M. Herron, 1981. Effects of energy and protein allowances during lay on the reproductive performance of broiler breeder hens. Br. Poult. Sci. 22:227-239.

223 du Preez, J.J., J.P. Hayes and J.S. Duckitt, 1981. Endogenous energy, a cause of biased true metabolizable energy values. South African J. Anim. Sci. 11:269-272.

224 Raharjo, Y., and D.J. Farrel1, 1981. The determination of amino acid digestibility in poultry feedstuffs. Recent Advances in Animal Nutrition in Australia 1981. U. New England Pub. Unit, Armidale, Australia. pp. 197-218.

225 Ranaweera, K.N.P., and W.E. Nano, 1981. True and apparent metabolizable energy of some indigenous feedstuffs and finished feeds determined by modified rooster bioassay techniques. J. Agric. Sci. Camb. 97:403-407.

$226 \star$ Ravindran, V., E.T. Kornegay, L.M. Potter, K.E. Webb, Jr. and C.M. Parsons, 1981. Nutrient composition and true metabolizable energy values of three tropical feedstuffs. J. Anim. Sci. 53(Suppl. 1):258. 
227 Reid, B.L., 1981. Fat levels in layer feeds. J. Am. Oil Chem. Soc. $58: 306-309$

228 Salmon, R.E., and T.I. Szabo, 1981. Dried bee meal as a feedstuff for growing turkeys. Can. J. Anim. Sci. 61:965-968.

229 Salmon, R.E., E.E. Gardiner, K.K. Klein and E. Larmond, 1981. Effect of Canola (low glucosinolate rapeseed) meal, protein and nutrient density on performance, carcass grade, and meat yield, and of Canola meal on sensory quality of broilers. Poultry Sci. 60:2519-2528.

230 *Salmon, R.E., E.E. Gardiner, K.K. Klein and E. Larmond, 1981. Canola meal in diets for broiler chickens. Poultry Sci. 60:1723.

231 *Schang, M.J., and R.M.G. Hamilton, 1981. Comparison of two direct bioassays using adult cockerels for estimating the available energy content of 13 feedingstuffs. Poultry Sci. 60:1726-1727.

232 *Schang, M.J., R.M.G. Hamilton, J.D. Summers and M.F. Bonino, 1981. Estimation of available energy in feedstuffs from metabolizable dry matter. Poultry Sci. 60:1726.

233 Shires, A., J.M. Bell and A.R. Robblee, 1981. Effect of the age of chickens on the true metabolizable energy values of feedstuffs. 60 th Annu. Feeder's Day Rept., U. of Alberta, Edmonton, Canada. pp. 78-79. 
234 Sibbald, I.R., 1981. Valores de energía de grasas para alimentas aves. Industria Avicola $28(11): 8-20$.

235 Sibbald, I.R., 1981. Metabolic plus endogenous energy and nitrogen losses of adult cockerels: the correction used in the bioassay for true metabolizable energy. Poultry Sci. 60:805-811.

236 Sibbald, I.R., 1981. Metabolic plus endogenous energy excretion by fowl. Poultry Sci. 60:2672-2677.

237 *Sibbald, I.R., 1981. Basic assumptions of the true metabolizable energy (TME) bioassay. Poultry Sci. 60:1733.

238 Sibbald, I.R., 1981. Bioassays Based on Precision Feeding of Poultry/Dosage Biologique en Cage Métabolique chez la Volaille. ARC/CRZ Tech. Bull. No.3, Agriculture Canada, ottawa, Canada. 34 pp.

239 Sibbald, I.R., 1981. Energy values of feeding fats for poultry. Feedstuffs $53(23): 19-20$.

240 Sibbald, I.R., 1981. Energy values of feeding fats for poultry. Poultry Digest $40: 262-266$

241 Sibbald, I.R., 1981. The true metabolizable energy and related bioassays. Proc. Minnesota Nutr. Conf., Minneapolis, U.S.A. pp. 105-112. 
242 Sibbald, I.R., 1981. Advantages of the TME system. Proc. Minnesota Nutr. Conf., Minneapolis, U.S.A. pp. 113-118.

243 Sibbald, I.R., 1981. Energy values of feeding fats for poultry. Proc. Nat1. Renderers Assoc. Nutr. Conf., Atlanta, U.S.A.

244 Sibbald, I.R., 1981. Sistema para la evaluacion de las materias primas en las aves. Proc. Symp. Cientifico, Seccion Española, Asoc. Mundial Avicult. Cientif., Barcelona, Spain. pp. 337-361.

245 *Storey, M.L., and N.K. Allen, 1981. Effect of duration of fasting on the true metabolizable energy of corn for Embden geese. Poultry Sci. $60: 1739$.

246 *Storey, M.L., and N.K. Allen, 1981. True metabolizable energy of feedstuffs for Embden geese. Poultry Sci. 60:1739-1740.

247 Tenesaca, L.G., and J.L. Sell, 1981. Influence of an indigestible material on energy excretion by roosters and on true metabolizable energy of corn. Poultry Sci. 60:623-630.

248 Tyrrell, H.F., L.S. Bull, W.N. Garrett, I.R. Sibbald and R.R. Smith, 1981. Nutritional Energetics of Domestic Animals and Glossary of Energy Terms. National Academy Press, Washington, U.S.A. 54 pp. 
249 Van Es; A.J.H., 1981. Poultry production in relation to energy utilization and environment. pp. 4l-53 in C.W. Scheele and C.H. Veerkamp, eds. World Poultry Production Where and How? Spelderholt Inst. for Poult. Res., Beekbergen, The Netherlands.

\section{$\underline{1982}$}

250 Anonymous, 1982. TME tests urged on non-U.S. feedstuffs. Feedstuffs $54(5): 13$.

251 Anonymous, 1982. Purina introduces new Turkey Chow. Feedstuffs $54(10): 57$.

252 Atwal, A.S., and S.C. Stothers, 1982. Assay of amino acid availability in swine and poultry. Proc. Nutr. Conf. Feed Manuf., Toronto, Canada. pp. 59-65.

253 Bilgili, S.F., and G.H. Arscott, 1982. The effect of initial fasting period on gut clearances and on endogenous energy outputs of adult roosters. Nutr. Rep. Int. 25:613-619.

254 Bilgili, S.F., G.H. Arscott and R. Kellems, 1982. True metabolizable energy value of hydrolyzed Pacific Whiting (Merluccius productus) as determined with gelatin capsules in roosters. Nutr. Rep. Int. $25: 639-642$. 
$255{ }^{*}$ Bilgili, S.F., M.P. Goeger and G.H. Arscott, 1982. Effect of inorganic matter (granite grit) on endogenous energy and true metabolizable energy values. Poultry Sci. 61:1417-1418.

256 Campbe11, L.D., B.O. Eggum and J. Wolstrup, 1982. Influence of dietary antibiotics on nitrogen, amino acid and energy digestion by rats and adult roosters. Can. J. Anim. Sci. 62:537-545.

257 Dale, N.M., and H.L. Fuller, 1982. Applicability of the true metabolizable energy system in practical feed formulation. Poultry Sci. $61: 351-356$.

258 Dale, N.M., and H.L. Fuller, 1982. Endogenous energy losses of fed versus fasted roosters. Poultry Sci. 61:898-901.

259 Dale, N.M., and H.L. Fuller, 1982. True metabolizable energy of fats at low levels of dietary inclusion. Poultry Sci. 61:2415-2420.

$260 \star$ Dale, N.M., and H.L. Fuller, 1982. True metabolizable energy and fatty acid absorption of fats at low level dietary inclusion. Poultry Sci. $61: 1445$.

$261 \star$ Delfino, F.J., A.R. Urias, L.G. Schmid, F.L. Prouty, R.S. Swingle and B.L. Reid, 1982. Variation in chemical composition and TME of grain from different wheat genotypes. Poultry Sci. 61:1448. 
262 Donaldson, W.E., 1982. Poultry nutrition research 1981. 30th Pfizer Annu. Res. Conf., Dallas, U.S.A. pp. 73-100.

$263 *$ E1 Husseiny, 0., 1982. True metabolizable energy of some Egyptian fats. Poultry Sci. $61: 1459$.

264 Farre11, D.J., 1982. True metabolizable energy. Is it a significant advance in poultry energy systems? Proc. 1982 Maryland Nutr. Conf., Washington, U.S.A. PP. 79-87.

265 Farre11, D.J., 1982. Amino acid digestibility of Australian feedstuffs determined with cockerels. Proc. Poult. Husb. Res. Found. Symp., Sydney, Australia. $11 \mathrm{pp}$.

266 Fisher, C., 1982. Energy evaluation of poultry rations. pp. 113-139 in W. Haresign and D. Lewis, eds. Recent Advances in Animal Nutrition 1982. Butterworths, London, U.K.

267 Fisher, C., 1982. Energy values of compound poultry feeds. Occasional Publication No. 2, ARC Poultry Research Centre, Roslin, U.K.

268 Fuller, H.L., and N.M. Dale, 1982. Effect of ratio of basal diet fat to test fat on the true metabolizable energy of the test fat. Poultry Sci. $61: 914-918$. 
$269{ }^{*}$ Fuller, H.L., and N.M. Dale, 1982. The value of brewers condensed solubles in broiler and layer rations. Poultry Sci. 61:1468.

270 Gous, R.M., M. Kuyper and C. Dennison, 1982. The relationship between tannic acid content and metabolisable energy concentration of some sorghum culiivars. South African J. Anim. Sci. 12:39-44.

271 *Halley, J.T., T.S. Nelson, L.K. Kirby and Z.B. Johnson, 1982. Relation between dry matter digestion and metabolizable energy. Poultry sci. $61: 1474$.

272 Kussaibati, R., J. Guillaume and B. Leclercq, 1982. The effects of age, dietary fat and bile salts, and feeding rate on apparent and true metabolisable energy values in chickens. Br. Poult. Sci. 23:393-403.

273 Kussaibati, R., J. Guillaume and B. Leclercq, 1982. The effects of endogenous energy, type of diet, and addition of bile salts on true metabolizable energy values in young chicks. Poultry sci. $61: 2218-2223$

274 Kussaibati, R., J. Guillaume, B. Leclercq and J.P. Lafont, 1982. Effects of the intestinal microflora and added bile salts on the metabolizable energy and digestibility of saturated fats in the chicken. Arch. Geflugelk. $\quad 46: 42-46$. 
275 Lessire, M., and B. Leclercq, 1982. Metabolizable energy value of fats in chicks and adult cockerels. Anim. Feed Sci. Technol. 7:365-374.

276 Likuski, H.J.A., 1982. Bioavailabilities of amino acids in poultry feedstuffs as determined by precision-fed rooster assays. Proc. Nutr. Conf. Feed Manuf., Toronto, Canada. pp. 50-58.

277 Luis, E.S., T.W. Sullivan and L.A. Nelson, 1982. Nutrient composition and feeding value of proso millets, sorghum grains and corn in broiler diets. Poultry Sci. 61:311-320.

278 McNab, J.M., 1982. The choice between apparent and true metabolizable energy systems for poultry. Recente toename van het gebruik van olien en velten in de veevoeding. Am. Soybean Assoc. Conf., Arnhen, The Netherlands. pp. 1-8.

279 Mollah, Y., W.L. Bryden, D. Balnave and E.F. Annison, 1982. Comparison of methods for the bioassay of the metabolizable energy of wheat-based poultry diets. Proc. Poult. Husb. Res. Found. Symp., Sydney, Australia. 6 pp.

280 Muztar, A.J., and S.J. Slinger, 1982. The true metabolizable energy and amino acid content of Candle, Altex and Regent Canola meals. Can. J. Anim. Sci. $62: 521-525$. 
281 Ngoupayou, J.D.N., F.M. Maiorino and B.L. Reid, 1982. Jojoba meal in poultry diets. Poultry Sci. 61:1692-1696.

282 Okumura, J., Y. Isshiki and Y. Nakahira, 1982. Influence of dietary cellulose and indigestible dry matter on metabolic and endogenous nitrogen excretion in chickens. Jap. Poult. Sci. 19:300-303.

283 Parsons, C.M., L.M. Potter and B.A. Bliss, 1982. True metabolizable energy corrected to nitrogen equilibrium. Poultry Sci. 61:2241-2246.

284 *Parsons, C.M., L.M. Potter and B.A. Bliss, 1982. True metabolizable energy corrected to nitrogen equilibrium. Poultry Sci. 61:1523.

285 Parsons, C.M., L.M. Potter and R.D. Brown, Jr., 1982. Effects of dietary protein and intestinal microflora on excretion of amino acids in poultry. Poultry Sci. 61:939-946.

286 Parsons, C.M., L.M. Potter, R.D. Brown, Jr., T.D. Wilkins and B.A. Bliss, 1982. Microbial contribution to dry matter and amino acid content of poultry excreta. Poultry Sci. 61:925-932.

287 Pearson, A.R., and K.M. Herron, 1982. Relationship between energy and protein intakes and laying characteristics in individually-caged broiler breeder hens. Br. Poult. Sci. 23:145-159. 
288 Pesti, G.M., and H.M. Edwards, Jr., 1982. Metabolizable energy:

Questions of nomenclature and application. Poultry Digest 41:228-231.

289 Pesti, G.M., and H.M. Edwards, Jr., 1982. Metabolizable energy:

questions of nomenclature and application. Proc. Georgia Nutr. Conf., Atlanta, U.S.A. pp. 69-73.

290 Schang, M.J., and R.M.G. Hamilton, 1982. Comparison of two direct bioassays using adult cocks and four indirect methods for estimating the metabolizable energy content of different feedingstuffs. Poultry Sci. $61: 1344-1353$.

291 Schang, M.J., S. Leeson and J.D. Summers, 1982. Effect of starvation and force feeding on body weight recovery time of adult roosters. Can. J. Anim. Sci. $62: 307-309$.

292 Schang, M.J., S. Leeson and J.D. Summers, 1982. Effect of double force feeding on true metabolizable energy. Can. J. Anim. Sci. 62:963-965.

293 Shannon, D.W.F., 1982. Developments in ME methodology and their implications for practical poultry feeding. Proc. Poult. Husb. Res. Found. Symp., Sydney, Australia. $9 \mathrm{pp}$.

294 * Shen, T., and W.F. Dean, 1982. True metabolizable energy value of corn and soybean meal for ducks. Poultry Sci. 61:1543. 
295 *Shires, A., and J.M. Bell, 1982. Effect of the age of chickens, duration of excreta collection and glucosinolate content on the true metabolizable energy values of rapeseed meal. Poultry sci. $61: 1543-1544$.

296 sibbald, I.R., 1982. Measurement of bioavailable energy in poultry feedingstuffs. Can. J. Anim. Sci. 62:983-1048.

297 Sibbald, I.R., 1982. Effects of tea and coffee on excretion of energy and nitrogen by cockerels. Nutr. Rep. Int. 25:133-137.

298 Sibbald, I.R., 1982. Measurement of mineral bioavailability: extension of true metabolizable energy methodology. Poultry Sci. 61:485-487.

299 Sibbald, I.R., 1982. The effect of grinding on the true metabolizable energy value of hull-less barley. Poultry Sci. 61:2509-2511.

300 Sibbald, I.R., 1982. Evolution of the TME system. Feed International $3(2): 51-52$.

301 Sibbald, I.R., 1982. Evolution of the TME system. Feed Management $33(1): 12-18$.

302 Sibbald, I.R., and P.M. Morse, 1982. Variation among gross energy values measured by two modes of adiabatic oxygen bomb calorimetry. Poultry Sci. 61:994-997. 
303 Sibbald, I.R., and P.M. Morse, 1982. Pooling excreta prior to calorimetry in the bioassay for true metabolizable energy: the effects on estimates of variance. Poultry Sci. 61:1853-1858.

$304 \star$ Sibbald, I.R., and P.M. Morse, 1982. Effects of feed input and excreta collection time on estimates of metabolic plus endogenous energy losses. Poultry Sci. 61:1544.

$305 \star$ Sibbald, I.R., and P.M. Morse, 1982. Effects of a nitrogen correction and of feed input on true metabolizable energy (TME') values. Poultry Sci. $61: 1545$.

306 Storey, M.L., and N.K. Allen, 1982. The effect of fasting time of mature, non-laying female Embden geese on true metabolizable energy of corn. Poultry Sci. 61:101-106.

307 Storey, M.L., and N.K. Allen, 1982. Apparent and true metabolizable energy of feedstuffs for mature, non-laying female Embden geese. Poultry Sci. 61:739-745.

308 Tenesaca, G., 1982. Contenido de energia metabolizable verdadera en ingredientes utilizados en formulacion de dietas avicolas. vi cielo internacional de conferencias sobre avicultura. Sept., 1982, Unidad de Congresos del Centro Médico Nacional, Mexico, D.F. Pp. 92-98. 
309 *Thomas, V.M., R.J. Katz, D.A. Auld, C.F. Petersen and E.A. Sauter, 1982. Feeding value of expellor extracted rape and safflower oilseed meals for broilers. Poultry sci. 61:1555.

310 Vohra, P., D.B. Chami and E.O. Oyawoye, 1982. Determination of metabolizable energy by a fast method. Poultry Sci. 61:766-769.

311 Wehner, G.R., and R.L. Harrold, 1982. The effect of feeding techniques on the true metabolizable energy value of yellow corn. Poultry sci. $61: 595-597$.

312 Wehner, G.R., and R.L. Harrold, 1982. Crop volume of chickens as affected by body size, sex, and breed. Poultry sci. 61:598-600.

313 Yamazaki, M., and Z. Zi-Yi, 1982. A note on the effect of temperature on true and apparent metabolisable energy values of a layer diet. $\mathrm{Br}$. Poultry Sci. $23: 447-450$.

314 Yanaka, M., and J. Okumura, 1982. Effects of excess tyrosine and level of feed intake on nitrogen and energy utilization in chicks. Poultry Sci. $61: 2440-2446$. 


\subsection{Sibbald, I. R. \\ C759 La methode d'evaluation des \\ C 83-20 aliments par le calcul de l'energie \\ $\mathrm{fr}$ \\ OOAg \\ EX.3 \\ metabolisable vraie (E.M.V.)}

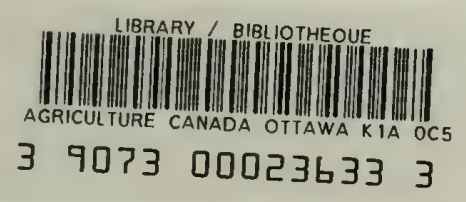


